ChipCflow - uma ferramenta para execução de algoritmos utilizando o modelo a fluxo de dados dinâmico em hardware reconfigurável

- operadores e grafos a fluxo de dados 

SERVIÇO DE PÓS-GRADUAÇÃO DO ICMC-USP

Data de Depósito: 22 de janeiro de 2009

Assinatura:

\title{
ChipCflow - uma ferramenta para execução de algoritmos utilizando o modelo a fluxo de dados dinâmico em hardware reconfigurável - operadores e grafos a fluxo de dados
}

\author{
Vasco Martins Correia
}

Orientador: Prof. Dr. Jorge Luiz e Silva

Dissertação apresentada ao Instituto de Ciências Matemáticas e de Computação - ICMC-USP, como parte dos requisitos para obtenção do título de Mestre em Ciências - Ciências de Computação e Matemática Computacional.

USP - São Carlos

Janeiro/2009 



\section{Agradecimentos}

À Deus, por ter me dado saúde, capacidade, persistência e sabedoria para realizar este trabalho. Ao meu orientador prof. Dr. Jorge Luiz e Silva, que por seus conselhos, incentivo e constante bom humor, se tornou mais do que um orientador, um amigo. Agradeço pelo apoio dado nesta conquista.

Aos amigos do LabES e LCR, pela amizade, compreensão e ajuda ao longo do mestrado.

À todos professores que contribuíram para minha formação acadêmica.

À minha família, pelo apoio incondicional dado em todas as etapas de minha vida.

À minha noiva, Alexandra, amiga e companheira incansável, fonte de carinho e força nos momentos mais difíceis. Pessoa fundamental na minha trajetória e na concretização deste trabalho.

Agradaço a todas as pessoas que diretamente ou indiretamente contribuíram para o desenvolvimento deste trabalho.

Ao CNPq pelo apoio financeiro. 

"Minha crença pessoal é que se a computação reconfigurável pretende ter sucesso ela deve criar uma metodologia para converter automaticamente um programa numa linguagem de programação padrão para o hardware do sistema. "Scott Hauck 

HipCflow é o projeto de uma ferramenta para execução de algoritmos escritos em linguagem $\mathrm{C}$ utilizando o modelo a fluxo de dados dinâmico em hardware com reconfiguração parcial. O objetivo principal do projeto ChipCflow é a aceleração da execução de programas por meio da execução direta em hardware, aproveitando ao máximo o paralelismo considerado natural do modelo a fluxo de dados. Em particular nesta parte do projeto, realizou-se a prova de conceito para a programação a fluxo da dados em hardware reconfigurável. O modelo de fluxo de dados utilizado foi o estático em plataforma sem reconfiguração parcial, dada a complexidade desse sistema, que faz parte de outro módulo em desenvolvimento no projeto ChipCflow. 

$\mathrm{N}$ order to convert $\mathrm{C}$ Language into hardware, a ChipCflow project, is a fundamental element to be used. In particular, dynamic dataflow architecture can be generated to produce a high level of parallelism to be executed into a partial reconfigurable hardware. Because of the complexity of the partial reconfigurable system, in this part of the project, a poof-of-concept was described as a program to be executed in a static reconfigurable hardware. The partial reconfiguration is a focus on another part of the ChipCflow project. 

Resumo

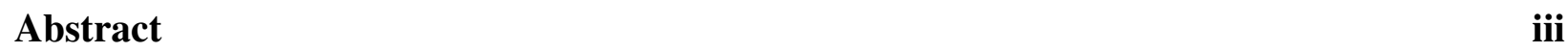

Lista de Siglas $\quad$ xi

1 Introdução $\quad 1$

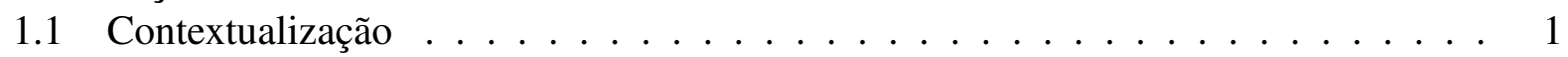

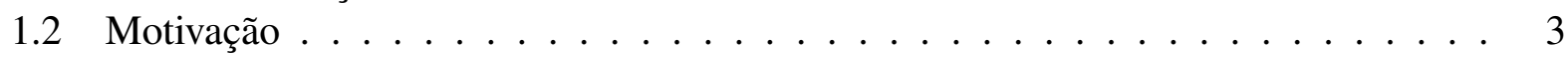

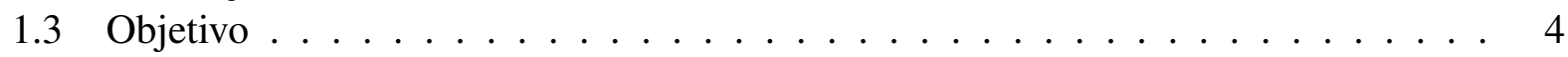

1.4 Organização . . . . . . . . . . . . . . . . . . . . 4

2 Computação Reconfigurável 5

2.1 Evolução dos FPGAs . . . . . . . . . . . . . . . . . . . 5

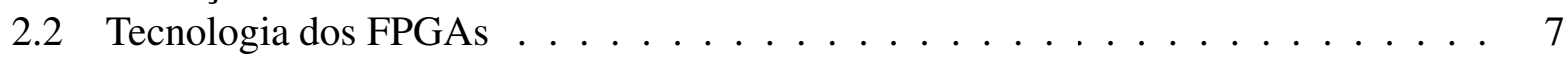

2.2.1 Arquitetura dos FPGAs . . . . . . . . . . . . . . . . . . 8

2.2.2 Tecnologias de Programação . . . . . . . . . . . . . . . . . 11

2.2 .3 Arquitetura dos blocos lógicos . . . . . . . . . . . . . . . . 12

2.2.4 FPGAs Dinâmicamente Reconfiguráveis . . . . . . . . . . . . . . . . . . 14

3 Máquinas a Fluxo de Dados $\quad 25$

3.1 Arquitetura das máquinas a Fluxo de Dados . . . . . . . . . . . . . . . . . . 30

3.2 Descrição de algumas arquiteturas existentes . . . . . . . . . . . . . . . . 32

3.2.1 Arquiteturas a fluxo de dados tradicionais . . . . . . . . . . . . . . . . 32

3.2.2 Arquiteturas a fluxo de dados contemporâneas . . . . . . . . . . . 35

4 Projeto ChipCflow $\quad 53$

4.1 Estrutura do Modelo a Fluxo de Dados . . . . . . . . . . . . . . . . . . 54

4.1.1 O Modelo de Instâncias . . . . . . . . . . . . . . . . . . . . 54

4.1.2 Operadores utilizados no Modelo . . . . . . . . . . . . . . . . . . . 57

4.1.3 Construções Iterativas no Modelo . . . . . . . . . . . . . . . . . 60

4.2 Estrutura "Matching"de Dados . . . . . . . . . . . . . . . . . . . . . 61

5 Implementação e Resultados $\quad 63$

5.1 Operadores do modelo a Fluxo de Dados . . . . . . . . . . . . . . . . . . 63

5.2 Implementação de Grafos a Fluxo de Dados . . . . . . . . . . . . . . . . 71 
5.2.1 Implementação da Sequência de Fibonacci . . . . . . . . . . . . . . . . . 81

6 Conclusão

A Implementação de grafos a fluxo de dados 


\section{Lista de Figuras}

2.1 Tecnologias para Projetos de Sistemas Digitais. . . . . . . . . . . . . . . 6

2.2 Arquitetura de um FPGA XILINX família 4000. . . . . . . . . . . . . 8

2.3 Bloco básico dos FPGAs Xilinx. . . . . . . . . . . . . . . . . . . . . 9

2.4 Conexões entre blocos lógicos. . . . . . . . . . . . . . . . . . . 10

2.5 Arquitetura de um sistema em um ambiente reconfigurável em tempo de execução. 15

2.6 Reconfiguração Parcial. . . . . . . . . . . . . . . . . . . . . . . 16

2.7 Arquitetura de Reconfiguração do Virtex-II. . . . . . . . . . . . . . . . . . . . 18

2.8 Arquitetura de Reconfiguração do Virtex-4. . . . . . . . . . . . . . . . . . . . . . 19

2.9 Geração do bitstream para reconfiguração parcial. . . . . . . . . . . . . . . . . . . . 19

2.10 Roteamento em dois caminhos diferentes. . . . . . . . . . . . . . . . . . 21

2.11 Esboço de um projeto básico com dois ou mais módulos reconfiguráveis. . . . . . . 22

3.1 Programa básico na linguagem a fluxo de dados. . . . . . . . . . . . . . 27

3.2 Links para a linguagem a fluxo de dados. (a) Link de dados. (b) Link de controle. . 27

3.3 Operadores para a linguagem a fluxo de dados. (a) operator (b) decider (c) T-gate

(d) F-gate (e) merge (f) boolean operator . . . . . . . . . . . . . . . 28

3.4 Gabarito da operação soma. . . . . . . . . . . . . . . . . . . . . 30

3.5 Diagrama funcional do elemento de processamento. . . . . . . . . . . . . . 31

3.6 Diagrama funcional do elemento de processamento. . . . . . . . . . . . . . . 32

3.7 (A) Fluxo da ferramenta ASH (B) Tradução do programa em hardware. . . . . . . . 36

3.8 Programa Fibonacci e sua implementação em ASH. . . . . . . . . . . . . . . . . . 38

3.9 Loops no WaveScalar: (a) um loop simples; (b) uma implementação a fluxo de dados; e (c) implementação WaveScalar. . . . . . . . . . . . . . . . . . . . . 41

3.10 Problema relacionado a falta de dependência em um grafo a fluxo de dados. . . . . 42

3.11 Organização hierárquica da micro-arquitetura do WaveCache. . . . . . . . . . . . . 43

3.12 Loop da Figura 3.9(c) mapeado sobre dois domains WaveCache. . . . . . . . . . . . 44

3.13 Diagrama de bloco de um PE. . . . . . . . . . . . . . . . . . . . . 45

3.14 Granularidade de elementos de processamento paralelos em um chip. . . . . . . . . 48

3.15 Arquitetura TRIPS . . . . . . . . . . . . . . . . . . . 49

4.1 Diagrama de Fluxo da Ferramenta ChipCflow. . . . . . . . . . . . . . . . . . 54

4.2 Instâncias diferentes para o operador "x". . . . . . . . . . . . . . . 55

4.3 Sub-grafo F a ser incluído no grafo original T. . . . . . . . . . . . . . . 55

4.4 Resultado da concatenação do sub-grafo $\mathrm{F}$ ao grafo $\mathrm{T}$. . . . . . . . . . . . . . . . . 56

4.5 Sub-grafo a ser removido do grafo original $\mathrm{T} \ldots \ldots \ldots$. . . . . . . . . . . 57 
4.6 Grafo Resultante da remoção de sub-grafo. . . . . . . . . . . . . . . . . . . 58

4.7 Operadores do Modelo ChipCflow. . . . . . . . . . . . . . . . . . . . 58

4.8 Tipos de enlace dos grafos a fluxo de dados. . . . . . . . . . . . . . . . . . 59

4.9 Grafo representando comandos em C . . . . . . . . . . . . . . . . . . . . . 59

4.10 Formato dos dados contendo Tags. . . . . . . . . . . . . . . . . 60

4.11 Exemplo de um programa com construtores iterativos. . . . . . . . . . . . . . 61

4.12 Instâncias com circuito de matching e variável comum. . . . . . . . . . . . . . . 62

5.1 Bloco esquemático do operador Branch e sua representação gráfica. . . . . . . . . . 64

5.2 ASM chart do operador Branch. . . . . . . . . . . . . . . . . . 65

5.3 Bloco esquemático do operador Copy e sua representação gráfica. . . . . . . . . . 65

5.4 ASM chart do operador Copy. . . . . . . . . . . . . . . . . . . . 66

5.5 Bloco esquemático do operador Decider e sua representação gráfica. . . . . . . . . . 67

5.6 ASM chart do operador Decider. . . . . . . . . . . . . . . . . . 68

5.7 Bloco esquemático do operador Non Deterministic Merge e sua representação gráfica. . . . . . . . . . . . . . . . . . . . 69

5.8 ASM chart do operador Non Deterministic Merge. . . . . . . . . . . . . . . 69

5.9 Bloco esquemático do operador Operator responsável pela operação soma e sua representação gráfica. . . . . . . . . . . . . . . . . . . 70

5.10 ASM chart do operador Operator responsável pela operação soma. . . . . . . . . . 70

5.11 Bloco esquemático do operador Deterministic Merge e sua representação gráfica. $\quad 71$

5.12 ASM chart do operador Deterministic Merge. . . . . . . . . . . . . . . . 72

5.13 Bloco esquemático do operador INDATA. . . . . . . . . . . . . 73

5.14 ASM chart do operador INDATA. . . . . . . . . . . . . . . . 73

5.15 Bloco esquemático do operador AOUT. . . . . . . . . . . . . . . . 74

5.16 ASM chart do operador AOUT. . . . . . . . . . . . . . . . . . 74

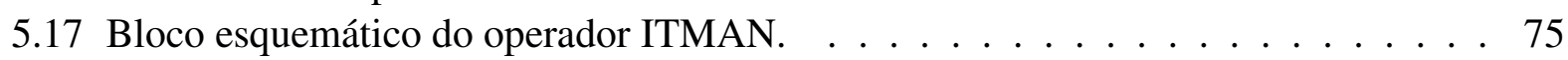

5.18 ASM chart do operador ITMAN. . . . . . . . . . . . . . . . . . 76

5.19 Grafo a fluxo de dados para o comando If-Else. . . . . . . . . . . . . . . 77

5.20 Implementação do grafo a fluxo de dados para o comando If-Else. . . . . . . . . . 77

5.21 Simulação do grafo a fluxo de dados implementado para o comando If-Else. . . . . 78

5.22 Grafo a fluxo de dados para o comando Switch. . . . . . . . . . . . . . . 79

5.23 Simulação do grafo a fluxo de dados implementado para o comando Switch. . . . . 80

5.24 Grafo a fluxo de dados para o comando While. . . . . . . . . . . . . . 81

5.25 Grafo a fluxo de dados para o comando For. . . . . . . . . . . . . . . . . . 82

5.26 Grafo a fluxo de dados para o comando Do-While. . . . . . . . . . . . . . 83

5.27 Simulação do grafo a fluxo de dados implementado para o comando While. . . . . 83

5.28 Simulação do grafo a fluxo de dados implementado para o comando For. . . . . . . 84

5.29 Simulação do grafo a fluxo de dados implementado para o comando Do-While. . . 84

5.30 Resultado da execução de programas em C dos comandos While, For e Do-While. . 84

5.31 Grafo a fluxo de dados para a Sequência de Fibonacci. . . . . . . . . . . . . . 85

5.32 Simulação do grafo a fluxo de dados implementado para a Sequência de Fibonacci. 86

5.33 Resultado da execução do programa em C para a Sequência de Fibonacci. . . . . . 86

A.1 Implementação do grafo a fluxo de dados para o comando Switch. . . . . . . . . 112

A.2 Implementação do grafo a fluxo de dados para o comando While. . . . . . . . . . . 113

A.3 Implementação do grafo a fluxo de dados do comando For. . . . . . . . . . . . . . 114

A.4 Implementação do grafo a fluxo de dados para o comando Do-While. . . . . . . . . 115

A.5 Implementação do grafo a fluxo de dados para a Sequência de Fibonacci. . . . . . 116 


\section{Lista de Tabelas}

5.1 Dados utilizados na simulação apresentada na Figura 5.21 . . . . . . . . . . . . 75

5.2 Dados utilizados na simulação apresentada na Figura 5.23 . . . . . . . . . . . . 78

5.3 Dados utilizados nas simulações apresentadas nas Figuras 5.27, 5.28 e 5.29. . . . 80

5.4 Dados utilizados na simulação apresentada na Figura 5.32 . . . . . . . . . . . . 82

5.5 Recursos gastos para implementação do grafo para a Sequência de Fibonacci. . . . 85 

ASH - Application Specific Hardware

ASIC - Application Specific Integrated Circuit

CASH - Compiler Application Specific Hardware

CLB - Configurable Logic Block

CI - Integrated Circuit

CPLD - Complex Programmable Logic Device

DDFG - Dynamic Dataflow Graph

DPR - Dynamic Partial Reconfiguration

FIFO - First in first out

EEPROM - Electrically-Erasable Programmable Read-Only Memory

EPROM - Erasable Programmable Read-Only Memory

FPGA - Field Programmable Gate Array

ICMC - Instituto de Ciências Matemáticas e de Computação

ISE - Integrated Software Environment

MPGA - Mask Programmable Gate Array

NIG - New Iteration Generation

NTD - New Tag Destructor

NTM - New Tag Manager

PAL - Programmable Array Logic

PE - Processor Elements

PLA - Programmable Logic Array

PLD - Programmable Logic Device

RTR - Run Time Reconfiguration

SPLD - Simple Programmable Logic Device

SRAM - Static Random Access Memory

ULA - Unidade Lógica e Aritmética

USP - Universidade de São Paulo

VHDL - Very high-speed integrated circuit Hardware Description Language

VLSI - Very Large Scale Integration 



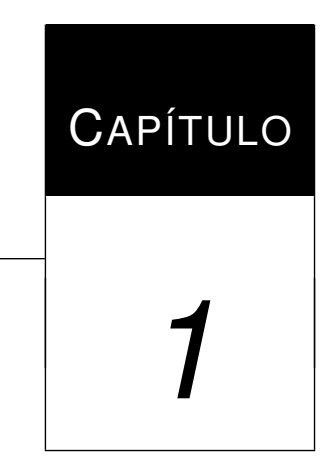

\section{Introdução}

\subsection{Contextualização}

Introduzido em 1985 pela empresa Xilinx, um FPGA (Field Programmable Gate Array) é um dispositivo reconfigurável que consiste em três partes principais: um conjunto de células lógicas programáveis, também chamados de blocos lógicos, uma rede de interconexões programáveis e um grupo de células de entrada/saída dispostos em volta do dispositivo (Bobda, 2007).

Todos os dispositivos FPGAs são por definição programáveis, ou seja, configurável pelo menos uma única vez. Os conceitos de reconfiguração estão relacionados com a possibilidade de reconfigurar o dispositivo muitas vezes ou constantemente se necessário.

Nos sistemas paralelos tradicionais um caminho para se obter maior desempenho é a exploração do paralelismo da aplicação por meio de múltiplos microprocessadores; nos sistemas computacionais reconfiguráveis o caminho é a implementação em hardware das partes do programa de aplicação computacionalmente mais intensas. Neles, a exploração do paralelismo existente em 
uma aplicação tem a característica de ser um modelo intrinsecamente concorrente (hardware) em vez dos modelos baseados na estrutura seqüencial de von-Neumann utilizados pela maioria dos sistemas de suporte ao processamento paralelo (Dehon, 1996).

Durante os anos 70 até meados dos anos 90 existiram algumas implementações buscando máquinas cujas organizações eram "naturalmente"paralelas, é o caso das máquinas com arquiteturas a fluxo de dados (Dennis e Misunas, 1974; Gurd et al., 1985; Shimada et al., 1986; Veen, 1986; Sato et al., 1992; Silva, 1992; Swanson et al., 2003; Arvind, 2005).

A diferença fundamental entre as arquiteturas tradicionais von Neumann e as arquiteturas a fluxo de dados está exatamente no controle do fluxo de informações que no caso das máquinas von Neumann é baseado no controle seqüencial, enquanto que nas máquinas a fluxo de dados o controle é executado pela presença dos dados (Cappelli et al., 2004; Swanson et al., 2003).

A arquitetura a fluxo de dados explora, de modo simples e natural, paralelismo de granularidade fina, uma vez que execução de cada instrução é dirigida somente pela disponibilidade de seus valores de entrada. Por este motivo, as máquinas a fluxo de dados têm execução assíncrona, que é uma característica desejável para o processamento paralelo.

Um grafo a fluxo de dados é um conjunto de operadores interligados por arcos. A presença dos dados em cada arco de um operador é que irá disparar a execução desse operador.

Existem dois modelos de arquiteturas a fluxo de dados: estático e dinâmico. No modelo estático apenas um dado pode estar presente em um arco esperando pelos seus dados parceiros. Um protocolo deve garantir o sincronismo entre os operadores para garantir que apenas um dado esteja presente em cada arco. Consequentemente o paralelismo fica limitado ao conjunto de operadores cujos arcos possuem apenas um dado.

No modelo dinâmico mais que um dado pode estar presente no arco. Consequentemente o paralelismo fica limitado ao conjunto de operadores cujos arcos possuem apenas um dado. No modelo dinâmico mais que um dado pode estar presente no arco. Um protocolo deve assegurar que os dados presentes nos arcos disparem as operações cujos dados parceiros também estejam presentes. O "Tagged-Token" é usado no protocolo para controlar os dados parceiros em cada arco (Arvind, 2005). Neste caso, o paralelismo acontece quando da execução de vários operadores cujos dados estejam todos disponíveis. 


\subsection{Motivação}

Segundo (Cardoso, 2000), acredita-se que a comunidade de software tem o predomínio no desenvolvimento de sistemas eletrônicos digitais. Enquanto não existir um suporte a implementação de sistemas reconfiguráveis a partir de algoritmos em alto nível, os programadores de software não se sentirão atraídos pelo desenvolvimento de aplicações neste modelo. Para tornar esse processo mais atrativo, seriam necessárias ferramentas que a partir de uma descrição de uma aplicação em uma linguagem de alto nível gerasse o código objeto para ser executado em um microprocessador embarcado e os arquivos de descrição de hardware necessários para programação em sistemas reconfiguráveis.

O ChipCflow é o projeto de uma ferramenta para execução de algoritmos utilizando o modelo a fluxo de dados dinâmico em hardware reconfigurável. Tem como principal objetivo utilizar o modelo de arquitetura a fluxo de dados, associado ao conceito de arquiteturas reconfiguráveis para acelerar a execução de algoritmos em alto nível, tais como programas escritos em linguagem Ansi-C. Essa aceleração vai acontecer por meio da execução direta em hardware, aproveitando ao máximo o paralelismo considerado natural do modelo a fluxo de dados.

A partir de algoritmos em alto nível escritos originalmente na linguagem $\mathrm{C}$, se extrai os grafos a fluxo de dados do programa de aplicação tendo como referência para os operadores, uma base de grafos a fluxo de dados a ser gerada especificamente para essa ferramenta. O grafo a fluxo de dados gerado já estará otimizado. O grafo então é convertido em VHDL (Very High Speed Integrated Circuit Hardware Description Language), tendo como base todo o conjunto de operadores propostos para o ChipCflow, previamente implementados em VHDL. O código VHDL é então sintetizado e simulado em ferramenta EDA comercial, em particular o trabalho será desenvolvido no ISE (Integrated Software Environment) da Xilinx, e o bitstream ${ }^{1}$ será então gerado para ser executado direto no hardware.

\footnotetext{
${ }^{1}$ Arquivo de configuração do $F P G A$, gerado pelo ISE da Xilinx.
} 


\subsection{Objetivo}

O ChipCflow é o projeto de uma ferramenta para execução de algoritmos utilizando o modelo a fluxo de dados dinâmico em hardware reconfigurável. Tem como principal objetivo utilizar o modelo de arquitetura a fluxo de dados associado ao conceito de arquiteturas reconfiguráveis, com a intenção de acelerar a execução de algoritmos em alto nível escritos em linguagem ansi-C.

Em particular, pretende-se validar conceitos no modelo de programação a fluxo de dados, sendo o principal objetivo deste trabalho o desenvolvimento dos operadores de máquinas a fluxo de dados propostos no projeto ChipCflow e sua execução em hardware através da implementação de grafos a fluxo de dados estáticos.

\subsection{Organização}

No capítulo 2 é apresentada a evolução dos circuitos digitais, tecnologias de fabricação de circuitos digitais, as características de reconfigurabilidade dos FPGAs, tecnologias de programação, a arquitetura interna dos blocos lógicos dos FPGAs e por fim será mostrada a tecnologia para reconfiguração parcial e dinâmica.

No capítulo 3 são apresentadas as máquinas a fluxo de dados e algumas arquiteturas existentes.

No capítulo 4 é apresentado o projeto ChipCflow, a estrutura do modelo a fluxo de dados, a estrutura matching de dados e a ferramenta de conversão C em grafos a fluxo de dados.

No capítulo 5 é descrito o desenvolvimento do trabalho, detalhando a implementação dos operadores utilizados no projeto ChipCflow e a construção de grafos a fluxo de dados.

No capítulo 6 são apresentadas as considerações finais e trabalhos futuros. 


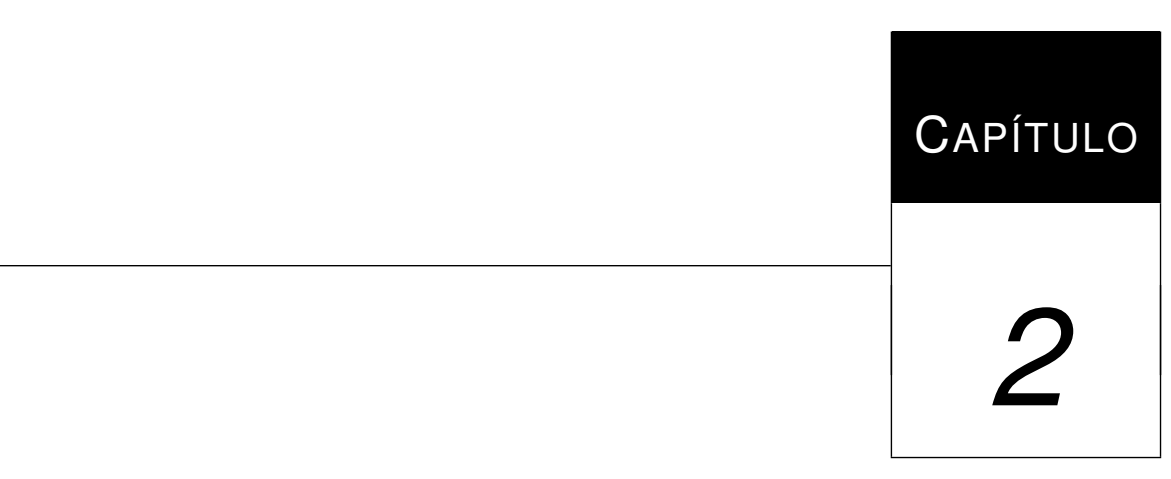

\section{Computação Reconfigurável}

\subsection{Evolução dos FPGAs}

A tecnologia de circuitos digitais vem se desenvolvendo rapidamente nas últimas décadas ocasionando uma ampla transformação em todo o processo de desenvolvimento de hardware. Os elementos empregados em projetos de sistemas evoluíram de transistores a circuitos integrados VLSI (Very Large Scale Integration) (Souza, 1998).

Os CIs (Integrated Circuit) digitais podem ser construídos utilizando-se de diversas tecnologias diferentes, a escolha da tecnologia adequada deve ser realizada com base no tipo de projeto que se pretente executar (Ribeiro, 2002). A Figura 2.1 apresenta as tecnologias para projetos de sistemas digitais.

As tecnologias de implementação de circuitos digitais, conforme a Figura 2.1 podem ser agrupadas em dois grandes grupos: circuitos customizados (ASICs) e circuitos semi-customizados. 


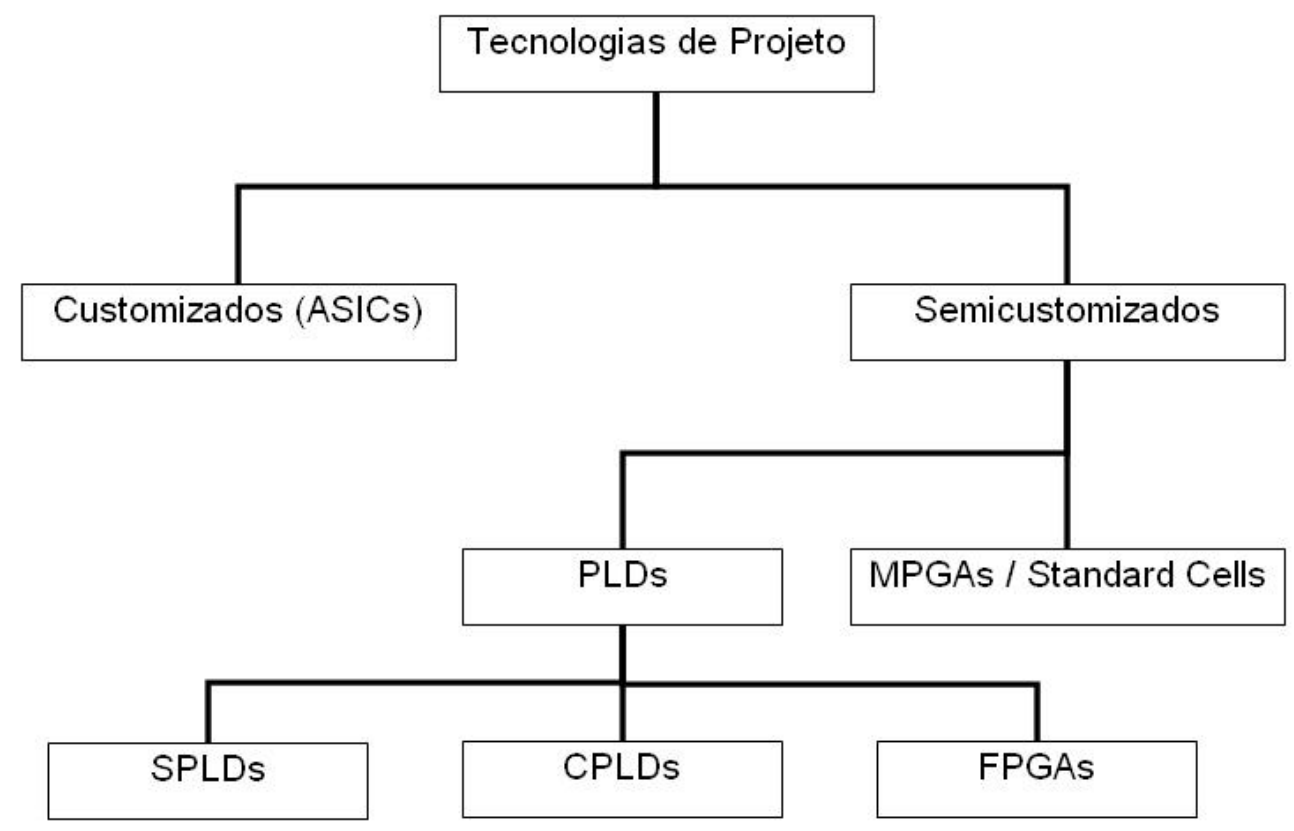

Figura 2.1: Tecnologias para Projetos de Sistemas Digitais.

Os circuitos customizados são indicados para aplicações e sistemas que necessitam de grande desempenho, baixo consumo de energia. As características desse tipo de implementação são os custos de projeto extremamente altos e o tempo de desenvolvimento longo. Em aplicações que requerem um grande volume de produção, o alto custo do projeto e dos testes é amortizado.

Os circuitos semi-customizados, se dividem ainda em outras duas categorias: PLDs (Programmable Logic Devices), MPGAs (Mask-programmable Gate Array)/Standard Cells.

Os MPGAs e Standard Cells foram agrupadas, devido suas semelhanças. Em comparação aos circuitos customizados, esses circuitos são menos eficientes em tamanho e desempenho, entretanto, seu custo de desenvolvimento é menor. Os $P L D s$ possuem como principal característica a capacidade de programação (configuração) pós-fabricação pelo usuário, facilitando assim as eventuais mudanças de projetos. Eles Possibilitam colocar muitas portas em um único circuito integrado e controlar eletronicamente a conexão entre elas. Em comparação com outras tecnologias, os PLDs apresentam ciclo de projeto muito curto com baixos custos de desenvolvimento. Os PLDs se dividem em três categorias: SPLDs (Simple Programmable Logic Device), CPLDs (Complex Programmable Logic Device) e FPGAs (Ribeiro, 2002; Souza, 1998).

Os SPLDs correspondem a categoria de todos os pequenos PLDs como PLAs (Programmable Logic Array), PALs (Programmable Array Logic). As características mais importantes dessa ca- 
tegoria é o baixo custo e alto desempenho. Esses dispositivos possuem apenas algumas centenas de portas lógicas. Os $C P L D s$, são constituídos de múltiplos SPLDs integrados em um único chip, apresentam interconexões programáveis para conectar os blocos SPLDs. Apesar de possuírem uma capacidade maior, comparados aos SPLDs, os CPLDs ainda são muito pequenos para serem utilizados em dispositivos de computação reconfigurável (Bobda, 2007)

Já os FPGAs são constituídos de um arranjo de elementos de circuitos não conectados: blocos lógicos e recursos de interconexão. A configuração é feita pelo usuário. A função a ser implementada no FPGA é dividida em módulos, cada qual pode ser implementada em um bloco lógico. Os blocos lógicos são então conectados juntos usando a interconexão programada (Bobda, 2007; Lopes, 2008).

\subsection{Tecnologia dos FPGAs}

No ano de 1985 foi introduzido pela Xilinx Inc. o FPGA, um dispositivo reconfigurável que consiste como os CPLDs, de três partes principais: um conjunto de células lógicas programáveis, também chamados de blocos lógicos, uma rede de interconexões programáveis e um grupo de células de entrada/saída dispostos em volta do dispositivo (Bobda, 2007; Lopes, 2008).

Os FPGAs são dispositivos reprogramáveis em campo, podendo ser reconfigurado muitas vezes ou constantemente se necessário. Muitas aplicações emergentes em multimídia e processamento de imagens necessitam que suas funcionalidades permaneçam flexíveis mesmo depois que o sistema tenha sido manufaturado. Tal flexibilidade é fundamental, uma vez que os requisitos das aplicações e as características dos sistemas podem mudar durante a vida do produto. Essa flexibilidade propicia novas abordagens de projeto voltadas para ganhos de desempenho, redução dos custos do sistema e/ou redução do consumo geral de energia.

Os FPGAs fornecem um chip pré-fabricado e totalmente reprogramado por milhares de vezes, essa capacidade é sua maior característica. Na realidade, um mesmo chip poderia assumir arquiteturas e funções completamente diferentes, sem a necessidade de mudanças do mesmo, em função apenas da necessidade do usuário, dessa forma facilita as mudanças em projetos, o que possibilita um curto ciclo de projeto e consequentemente baixo custo. Essas características garantem a atuali- 
zação constante do produto com um mesmo estoque de CIs. Como nos processadores, FPGAs são programados após a fabricação para solucionar virtualmente qualquer tarefa computacional, isto é, qualquer tarefa que caiba nos recursos finitos do dispositivo (Souza, 1998).

\subsubsection{Arquitetura dos FPGAs}

Segundo (Ribeiro, 2002), a arquitetura básica de um FPGA, apresentada na Figura 2.2, consiste de um arranjo 2-D de blocos lógicos. A comunicação entre blocos é feita por meio dos recursos de interconexão (interconexão programável). A borda externa do arranjo consiste de blocos especiais capazes de realizar operações de entrada e saída (blocos de I/O), esses blocos fazem a interface do FPGA com o mundo externo, em placas de prototipação, eles fazem a interface do FPGA com os demais recursos da placa, como por exemplo, memórias externas.

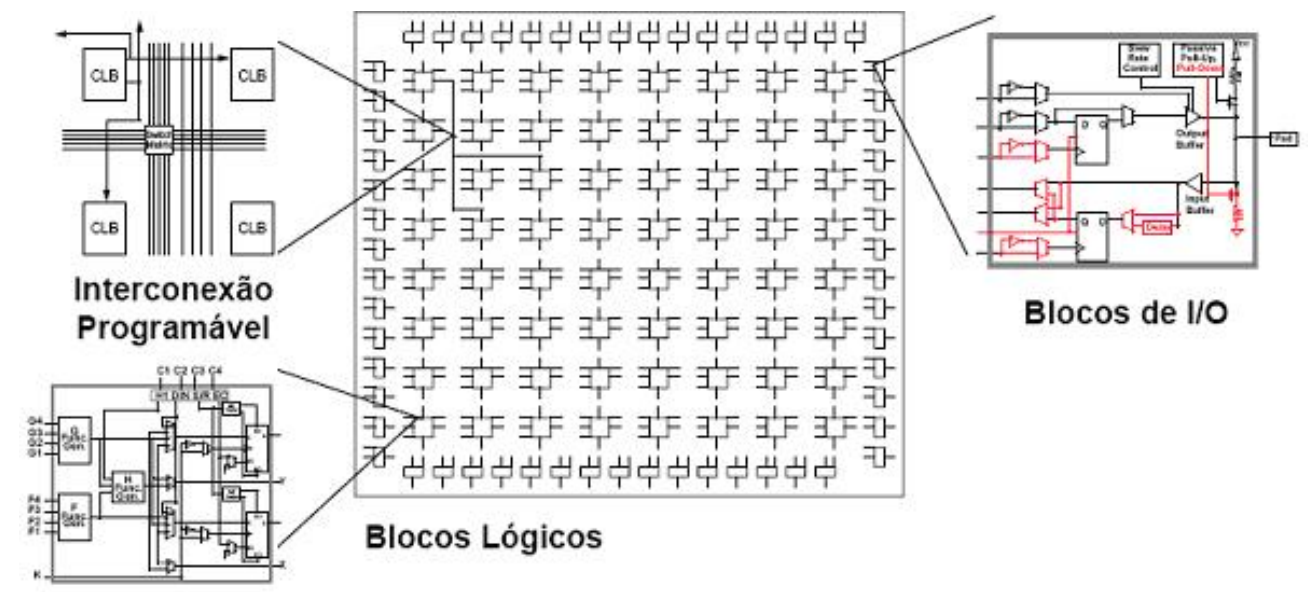

Figura 2.2: Arquitetura de um FPGA XILINX família 4000.

A arquitetura de um FPGA está, basicamente, composta de 3 partes. A primeira são Blocos Lógicos Configuráveis (Blocos lógicos). Um bloco lógico de um FPGA pode ser tão simples como um transistor ou tão complexo quanto um microprocessador. Ele é capaz de implementar várias funções lógicas combinacionais - tipicamente por meio de LUT (Lookup Tables) ou seqüenciais (por meio de flip-flops). As funções lógicas são implementadas no interior dos Blocos Lógicos. Em algumas arquiteturas os Blocos Lógicos possuem recursos seqüenciais tais como flipflop ou registradores. O fabricante Xilinx chama seu Bloco Lógico de CLB (Configurable Logic Block). 
Cada bloco lógico está conectado a um número determinado de matrizes de conexões programáveis, que, por sua vez, estão ligadas a um número de matrizes de chaveamento programáveis. Programando as conexões apropriadas, cada bloco pode fornecer uma variedade de funções lógicas combinacionais e/ou sequenciais, ou seja, qualquer função lógica desejada.

Como mostra a Figura 2.3, o bloco computacional básico nos FPGAs da Xilinx consistem de uma LUT com um variado número de entradas, um grupo de multiplexadores, lógica aritmética e elementos de armazenamento (Bobda, 2007).

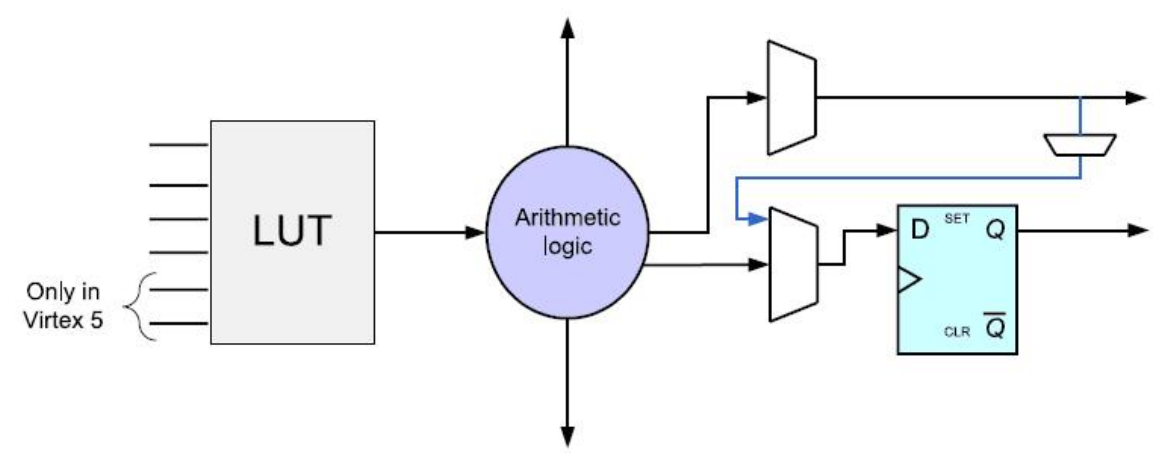

Figura 2.3: Bloco básico dos FPGAs Xilinx.

A LUT é um agrupamento de células de memória do tipo SRAM (Static RAM), que contém todos os resultados possíveis de uma dada função para um dado grupo de valores de entrada. Assim, uma LUT é capaz de implementar qualquer função booleana de até "n"variáveis, fazendo todas as possíveis combinações de valores entre elas. Os valores das funções são armazenados de tal modo que eles podem ser restaurados pelos correspondentes valores de entradas (Bobda, 2007).

Essa memória é carregada com os valores dados pelo arquivo de configurações bitstream. Esse arquivo é gerado pelas ferramentas de síntese de FPGAs e é composto pelas funcionalidades implementadas pelo usuário nessas ferramentas.

O número de blocos básicos em um $C L B$ varia de dispositivo para dispositivo. No FPGA Virtex-II Pro e Virtex-4, os CLBs são divididos em quatro slices ${ }^{1}$ cada qual contém dois blocos básicos. Os CLBs do Virtex-5 contêm apenas dois slices, cada qual contém quatro blocos básicos (Bobda, 2007; Lopes, 2008).

A segunda parte que compõem a arquitetura de um FPGA são as Interconexões Programáveis (Programmable Interconnect). As matrizes de conexões programáveis são usadas para estabelecer

\footnotetext{
${ }^{1}$ Na família Virtex da Xilinx, a menor unidade lógica configurável ou unidade lógica básica é denominada slice.
} 
ligações entre entradas e saídas dos blocos lógicos, enquanto as matrizes de chaveamento programáveis são empregadas para rotear os sinais entre as várias matrizes de conexões, conforme a Figura 2.4. Nos dispositivos Xilinx, os CLBs são embutidos em estruturas de roteamento que consiste de linhas verticais e horizontais. Cada CLB está amarrado a uma matriz de conexão para acessar a estrutura de roteamento geral. A matriz de conexão provê multiplexadores programáveis, os quais são utilizados para selecionar os sinais de um dado canal de roteamento que deveria ser conectado aos terminais dos CLBs. A matriz de conexão pode também conectar linhas horizontais e verticais, assim permitindo o roteamento completo no FPGA (Bobda, 2007).

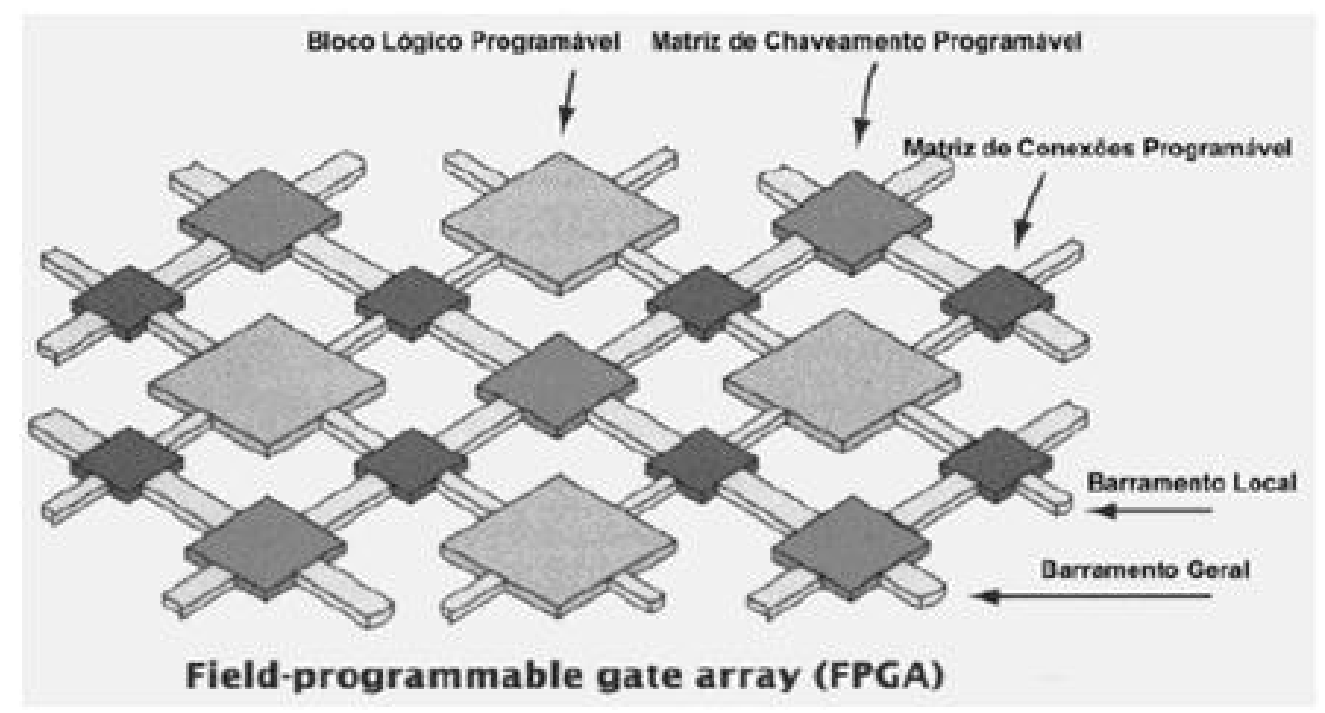

Figura 2.4: Conexões entre blocos lógicos.

A terceira parte da arquitetura do FPGA são os Blocos de Entrada/Saída Configuráveis (I/O Blocks). Os FPGAs possuem componentes de entrada/saída chamados de IOB (I/O Block), formados por estruturas bidirecionais que incluem buffer, flip-flop de entrada, buffer tri-state ${ }^{2}$ e flip-flop de saída. Ou seja, assim como os $C L B s$, cada pino de $E / S$ do componente pode ser programado pelo usuário. Um FPGA pode dispor de dezenas a centenas de pinos programáveis.

Estes aspectos influenciam diretamente no desempenho e na densidade das diferentes arquiteturas de FPGAs, entretanto não se pode afirmar que há uma melhor arquitetura, e sim a mais adequada para uma determinada aplicação (Ribeiro, 2002; Lopes, 2008). Os componentes de en-

\footnotetext{
${ }^{2}$ Em um barramentos de dados somente um dispositivo pode operar por vez. Os buffers tri-state são utilizados para isolar os dispositivos que não estão em uso do acesso ao barramento.
} 
trada/saída são localizados em volta, na periferia do dispositivo e permitem a comunicação do dispositivo com os dispositivos localizados fora do chip.

Os IOBs (input/output block) podem ser utilizados de forma independente um dos outros como entradas e/ou saídas ou eles podem ser combinados em grupos de dois para ser utilizados como pares diferenciais diretamente conectados na matriz de conexão (Bobda, 2007).

As famílias de FPGAs diferem principalmente nas formas de realizar a programação, nas formas de organização dos condutores de interconexão e no funcionamento dos blocos lógicos.

\subsubsection{Tecnologias de Programação}

Um FPGA é programado usando comutadores programáveis eletricamente. As propriedades desses comutadores, tais como tamanho, resistência, capacitância, tecnologia, afetam principalmente o desempenho e definem características como volatilidade e capacidade de reprogramação, que devem ser avaliadas na fase inicial do projeto para a escolha do dispositivo (Souza, 1998; Ribeiro, 2002). Em todos os tipos de FPGAs os comutadores programáveis ocupam uma grande área. Existem basicamente dois tipos de tecnologias de programação principais: Antifuse e SRAM (Bobda, 2007).

O antifuse é um dispositivo de dois terminais, que no estado não programado apresenta uma alta impedância entre seus terminais. Quando aplicado uma tensão entre 11 e 20 Volts o antifuse "queima", criando uma conexão de baixa impedância, não permitindo reprogramações posteriores.

Enquanto a tecnologia antifuse está limitada a realização das interconexões, a tecnologia SRAM é usada para a computação, bem como para interconexão (Bobda, 2007; Lopes, 2008).

Entre as vantagens do antifuse está o seu tamanho reduzido (Bobda, 2007). A desvantagem está no espaço extra gasto para conseguir isolar os transistores no circuito de programação, já que eles trabalham com tensão de até $20 \mathrm{~V}$.

A tecnologia de programação $S R A M$, utiliza células memória $S R A M$ para controlar transistores de passagem ou multiplexadores. A maior vantagem, segundo (Bobda, 2007) é que os FPGAs com essa tecnologia podem ser reprogramados indefinidamente, pois é necessário apenas modificar os valores nas células $S R A M$ para realizar uma nova conexão ou uma nova função. 
Como desvantagem, a tecnologia SRAM, ao contrário da tecnologia antifuse, é uma memória volátil, portanto perde sua configuração na ausência de eletricidade, necessitando de uma memória externa, como uma EPROM ou EEPROM ou um dispositivo não volátil de armazenamento, tal como o $C P L D$ para guardar suas configurações na ausência de eletricidade. Outra desvantagem é que essa tecn'ologia ocupa muito espaço no chip, pois para cada comutador estão associados pelo menos 6 transistores.

Os recentes FPGAs e dispositivos reconfiguráveis utilizam a tecnologia de programação SRAM. Porém, Segundo (Compton e Hauck, 2002; Lopes, 2008), o termo SRAM é tecnicamente incorreto para muitas arquiteturas de FPGAs, isto porque, a memória de configuração nem sempre suporta acesso randômico. Segundo (Bobda, 2007), um FPGA pode ser programado uma ou várias vezes, dependendo da tecnologia utilizada.

\subsubsection{Arquitetura dos blocos lógicos}

Os FPGAs possuem uma grande variedade de tamanhos e com muitas combinações diferentes de características internas e externas. O que eles têm em comum é o fato de serem compostos por blocos lógicos configuráveis. Em um FPGA, a estrutura interna dos blocos lógicos, como por exemplo, LUTs, registradores, multiplexadores, podem ser replicadas milhares de vezes para construir um grande dispositivo reconfigurável (Compton e Hauck, 2002; David e Scott, 2005).

Em FPGAs mais complexos, esses blocos lógicos são combinados com lógicas digitais maiores, como lógicas aritméticas, estruturas de controles, tais como multiplicadores e contadores.

Com a finalidade de classificar os FPGAs quanto à capacidade lógica dos blocos lógicos, podese dividi-los em três categorias de granularidade: fina, media e grossa (Ribeiro, 2002; Compton e Hauck, 2002).

Cada bloco lógico pode ser simples como um LUT de três entradas ou complexo como uma ULA (Unidade Lógica Aritmética) de 4 bits. Essas diferenças entre os blocos podem ser referenciadas como granularidade do bloco lógico, no qual uma LUT de três entradas é um exemplo de um bloco lógico de granularidade fina e uma ULA de 4 bits é um exemplo de bloco lógico de granularidade grossa (Compton e Hauck, 2002). 
Os blocos de granularidade fina são úteis para manipulações em nível de bits. Eles manipulam apenas 2 ou 3 valores de 1 bit.

O melhor exemplo para um bloco de granularidade fina seria um bloco contendo alguns transistores interconectáveis ou portas lógicas básicas. Para se implementar um somador, deve-se utilizar várias dessas células (Cardoso, 2000). Como vantagem, esse tipo de bloco é quase totalmente utilizado, fornecendo um alto grau de funcionalidade com um número relativamente pequeno de transistores. A desvantagem principal é que por serem muito pequenos, eles tem baixa capacidade lógica, assim, podem ser requeridos muitos blocos lógicos em uma determinada aplicação, elevando a quantidade de trilhas de conexões e comutadores programáveis o que sobrecarrega o roteador. Um roteador desse tipo de FPGA se torna lento e ocupa grande área do chip. Assim, a tecnologia antifuse é a mais adequada para a fabricação desse tipo de FPGA devido o seu tamanho reduzido. Um exemplo de um FPGA fabricado com essa granularidade é o FPGA XC6200 da Xilinx (Ribeiro, 2002).

Os blocos de granularidade media operam com 2 ou mais dados com 4 bits de tamanho. Isso aumenta o número total de linhas de entrada do circuito e prove estruturas computacionais mais eficientes para problemas computacionais mais complexos. Similares aos blocos lógicos com granularidade fina, porém, esses podem executar operações mais complexas com um grande número de entradas. Esses blocos podem implementar operações lógico-aritméticas (Cardoso, 2000). Esse tipo de estrutura também pode ser usada para implementar operações mais complexas, tais como máquinas de estado finito (Compton e Hauck, 2002).

Os FPGAs da família Virtex da Xilinx são exemplos de dispositivos de granularidade média (Ribeiro, 2002).

Os blocos de granularidade grossa são úteis para aplicações que manipulam grandes quantidades de bits, porque o bloco lógico é otimizado para aplicações computacionais grandes, por isso eles executam as operações dessas aplicações muito rapidamente, consumindo menos área. Porém, devido a sua composição ser estática, eles são incapazes de ser otimizados para se adequar aos tamanhos dos operandos. Se, por exemplo, somadores, multiplicadores forem compostos por 16 bits e apenas valores de 1 bit forem processados, então o uso dessa arquitetura não oferece 
vantagens, devido ao fato de todos os 16 bits serem computados e o gasto desnecessário de área e overhead (Compton e Hauck, 2002).

Segundo (Cardoso, 2000), esses blocos são verdadeiros núcleos de processamento, que muitas vezes incorporam processadores e memórias acoplados a uma matriz de lógica reconfigurável com arquiteturas que podem ser blocos de granularidades finas e medias.

Os blocos de granularidade grossa requerem menos overhead de comunicação entre os processos no FPGA. Se cada processo mantiver sua memória local e tiver delineado uma tarefa para ser executada, então, a aplicação poderá ser facilmente dividida entre diferentes áreas do FPGA.

\subsubsection{FPGAs Dinâmicamente Reconfiguráveis}

Atualmente, alguns FPGAs suportam a reconfiguração parcial, onde um bitstream menor pode ser utilizado para reconfigurar uma área do FPGA. Reconfiguração parcial dinâmica, em inglês DPR (Dynamic Partial Reconfiguration) é feito enquanto o dispositivo está ativo: certas áreas do dispositivo podem ser reconfiguradas enquanto que outras áreas continuam em operação e não são afetadas pela reconfiguração (Tadigotla et al., 2006).

Em (Bobda, 2007), o termo run-time reconfiguration é utilizado para especificar reconfiguração parcial e dinâmica. A implementação de um sistema no modo run-time reconfiguration, a computação e a seqüência de configuração do projeto não são conhecidas em tempo de compilação, assim, os requisitos para implementar uma dada tarefa é conhecida no tempo de execução. Run-time reconfiguration é um procedimento difícil, pois deve-se lidar com fatores de efeitos colaterais, tais como desfragmentação do dispositivo e comunicação entre os módulos recentemente colocados nele (Bobda, 2007).

A reconfiguração parcial e dinâmica de FPGAs exige dois tipos de particionamento:

1. Particionamento espacial: forma espacial com que os módulos de hardware serão distribuídos nos recursos de lógica reconfigurável;

2. Particionamento temporal: definição dos intervalos de tempo em que cada módulo de hardware deverá está presente no FPGA, já que algum módulo reconfigurável pode ocupar recursos no dispositivo, já ocupado por outro (Bobda, 2007). 
Conforme ilustra a Figura 2.5, a administração do dispositivo reconfigurável é usualmente feitas por um escalonador e um placer $^{3}$ que podem ser implementados como parte de um sistema operacional executando em um processador, que pode residir dentro ou fora do chip (Bobda, 2007).

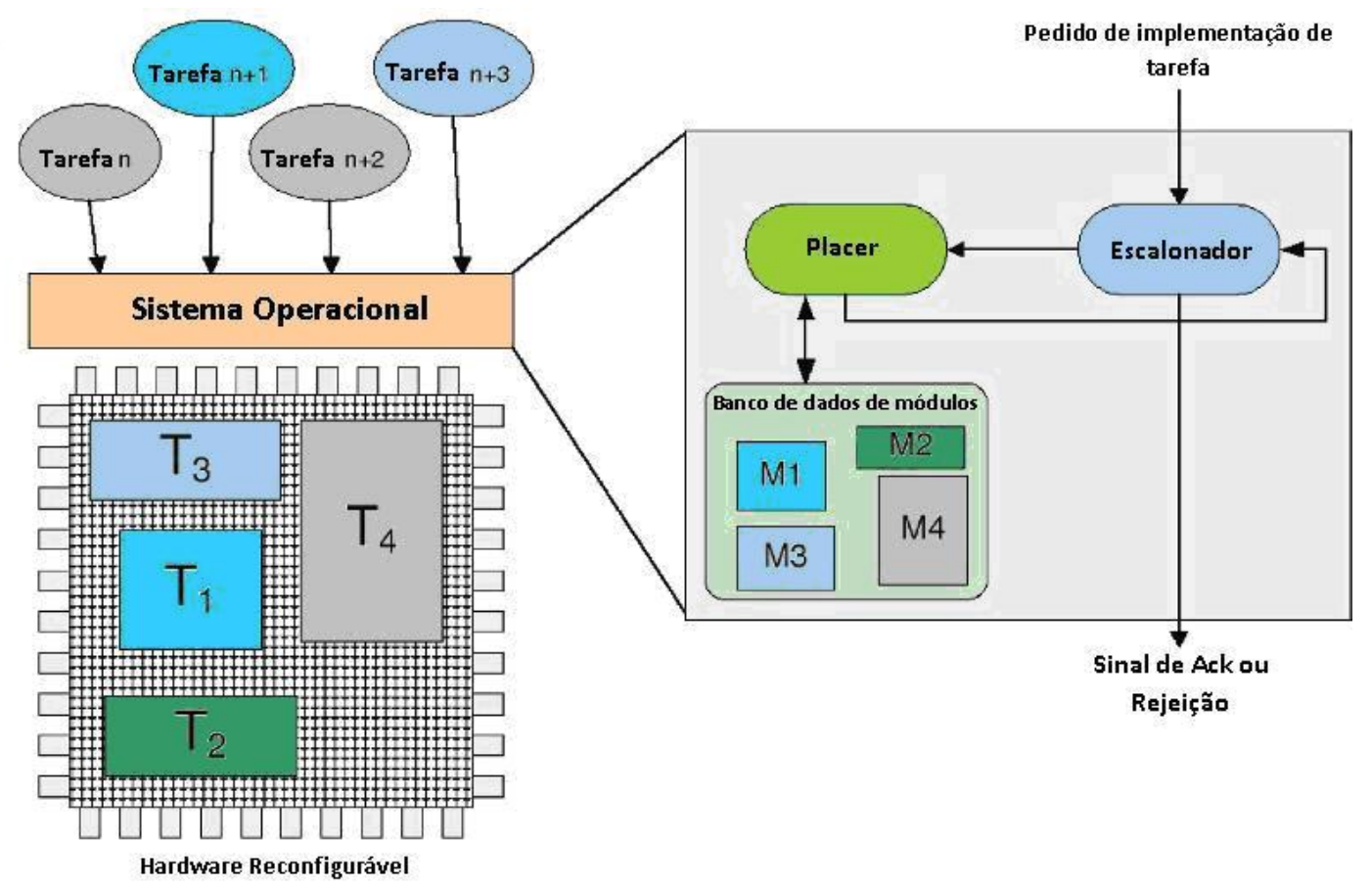

Figura 2.5: Arquitetura de um sistema em um ambiente reconfigurável em tempo de execução.

Em sistemas embutidos, que fazem uso de sistemas reconfiguráveis, os processadores são geralmente integrados no dispositivo reconfigurável e são utilizados mais para o propósito de administração do que para computação. Os FPGAs atuam como co-processadores com uma variedade de grupos de instruções que são acessadas pelo processador em uma chamada de função. No inicio da computação, o host processador configura o dispositivo reconfigurável e então envia os segmentos de dados para serem processados pelo FPGA. O host processador e o FPGA podem então processar em paralelo seus segmentos de dados. No final da computação, o host processador coleta os resultados do processamento na memória do FPGA.

O escalonador administra as tarefas e decide quando uma delas deveria ser executada. As tarefas estão disponíveis como dados de configuração em uma base de dados e são caracterizadas pelo tamanho da área que ela ocupará no FPGA e seu tempo de execução ${ }^{4}$ (Bobda, 2007).

\footnotetext{
${ }^{3}$ Placer determina a posição que cada módulo reconfigurável deve ocupar no FPGA

${ }^{4}$ Tempo em que ele deverá substituir outro módulo reconfigurável no FPGA
} 
Conforme a Figura 2.5, o escalonador determina qual tarefa deveria ser executada no FPGA e então, a entrega para o placer que irá tentar alocá-la no dispositivo. Se o placer não for capaz de encontrar uma localização para a execução da nova tarefa no hardware, ele irá devolvê-la ao escalonador que poderá decidir reenviá-la mais tarde e assim irá enviar uma nova tarefa para o placer. Nesse caso, diz-se que a tarefa foi rejeitada (Bobda, 2007).

Segundo (Bobda, 2007), existem três abordagens de projetos utilizadas para a reconfiguração parcial nos FPGAs da família Virtex da Xilinx. A abordagem JBits, a abordagem Modular Design Flow e a abordagem Early Access Design Flow, conhecida como EAPR Design Flow (Tadigotla et al., 2006).

Como mostra a Figura 2.6, a reconfiguração parcial é útil quando um projeto muito grande não precisa ocupar todo o FPGA, em um dado tempo ou quando apenas uma parte do projeto necessita ser modificada. Em uma configuração parcial, os bits de programação que necessitam ser modificados no FPGA funcionam como um código em uma memória RAM. Um endereço é utilizado para especificar a exata localização desses bits no dispositivo reconfigurável. Quando um sistema não necessita de todo o espaço físico de configuração de um FPGA, um número de diferentes configurações podem ser alocadas nas áreas não utilizadas do hardware em diferentes tempos. Em (Compton e Hauck, 2002) é mostrado alguns fabricantes de FPGAs que suportam a reconfiguração parcial e dinâmica.

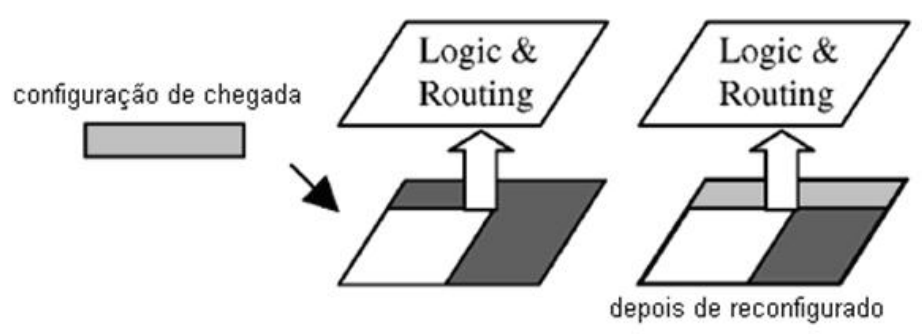

Figura 2.6: Reconfiguração Parcial.

O Jbits é utilizado apenas para algumas famílias Virtex antigas; as abordagens mais utilizadas para os FPGAs Virtex atualmente são EAPR Design Flow e a Modular Design Flow (Bobda, 2007).

FPGAs Virtex como outros FPGAs da Xilinx são organizados com arranjos bidimensionais de $C L B s$ contendo certa quantidade de lógica. Esses FPGAs são configurados com dados de configu- 
ração chamados de bitstream, os quais podem ser descarregados no dispositivo por uma porta de configuração.

A idéia por trás da reconfiguração parcial é realizar a reconfiguração apenas mudando algumas partes da configuração sendo executadas no FPGA. Fragmentos do bitstream chamados de pacotes (packets) são enviados para o dispositivo para reconfigurar as partes necessárias dele. Uma cópia da configuração existente no FPGA é mantida em uma parte dedicada da memória do processador, chamada de memória de configuração (configuration memory). A reconfiguração parcial é feita pela sincronização entre a memória de configuração e o dispositivo reconfigurável. As mudanças feitas entre a última configuração e a presente são marcadas e então enviadas para o dispositivo para a reconfiguração parcial.

A arquitetura dos FPGAs Virtex da Xilinx é organizada em frames ou colunas de slices. Os frames são pequenas unidades de reconfiguração. A Figura 2.7 mostra a arquitetura de configuração utilizada nos dispositivos Virtex-II e Virtex-II Pro. Os dados de configuração são carregados nos frames do FPGA Virtex.

As últimas gerações de FPGAs Virtex, tais como os da família Virtex-4, marcam uma significativa mudança na arquitetura, com relação às famílias anteriores. Como mostra a Figura 2.8, a arquitetura de configuração é baseada em frames, como nas famílias anteriores, porém, nessas famílias de FPGAs, as colunas são constituídas de múltiplos frames independentes, ou seja, um frame transpõe apenas 16 linhas de blocos lógicos, ao invés de uma coluna inteira (Craven, 2008). Isso significa que a reconfiguração de um componente presente em um bloco afeta apenas os componentes dele, os quais compartilham uma coluna comum com o módulo reconfigurável (Bobda, 2007).

O maior problema da reconfiguração parcial é justamente produzir o bitstream parcial. Há duas formas principais para fazer a extração do bitstream parcial, representando um dado módulo: a abordagem construtiva, representada na Figura 2.9-a, permite fazer a implementação de um dado módulo separadamente usando ferramentas comuns de desenvolvimento, tal como o ISE da Xilinx e então, juntar esse módulo no bitstream completo ou construí-lo como somas de módulos parciais. Essa é a abordagem seguida pelos EAPR Design Flow e o Modular Design Flow. A segunda possibilidade, representada na Figura 2.9-b consiste primeiramente implementar o bitstream com- 


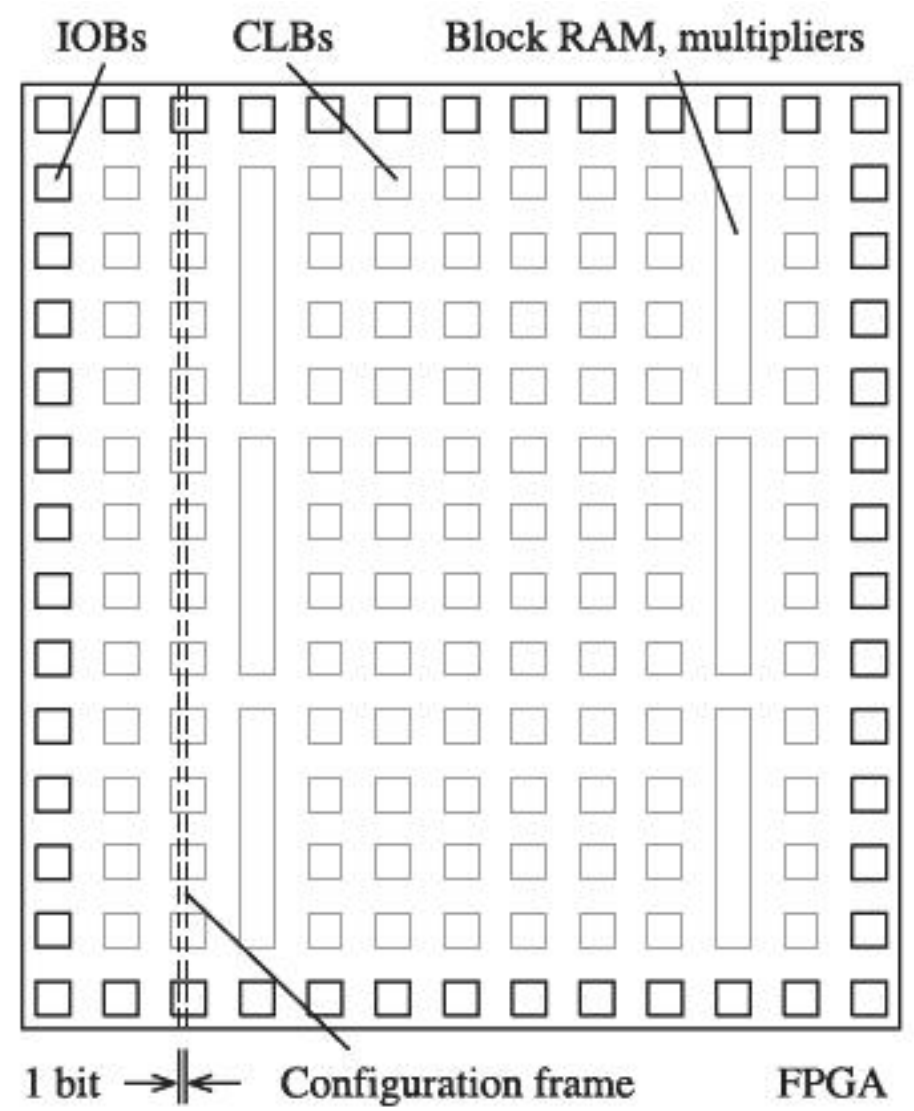

Figura 2.7: Arquitetura de Reconfiguração do Virtex-II.

pleto separadamente. As partes fixas bem como as partes reconfiguráveis são implementadas como componentes e juntadas em outro bitstream. As diferenças dos dois bitstream estão nas partes reconfiguráveis e, então, os dois bistreams são computadas para se obter o bitstream parcial (Bobda, 2007).

Segundo (Zheng et al., 2005), Jbits é uma API (Application Programming Interface) desenvolvida pela Xilinx. Jbits é formado por um grupo de classes Java, métodos e ferramentas que podem ser utilizadas para modificar o conteúdo de uma LUT bem como interconexões dentro do FPGA, sem a necessidade de outra ferramenta de configuração. Segundo (Bobda, 2007), isso é tudo o que é exigido para implementar funções em um FPGA.

JBits possui centenas de cores $^{5}$ pré-definidos, tais como somadores, subtratores, multiplicadores, entre outros. Eles também podem ser combinados para gerar cores mais complexos (Bobda, 2007; Lopes, 2008).

\footnotetext{
${ }^{5}$ Núcleos de propriedade intelectual, núcleos IP (Intellectual Property), ou simplesmente cores
} 


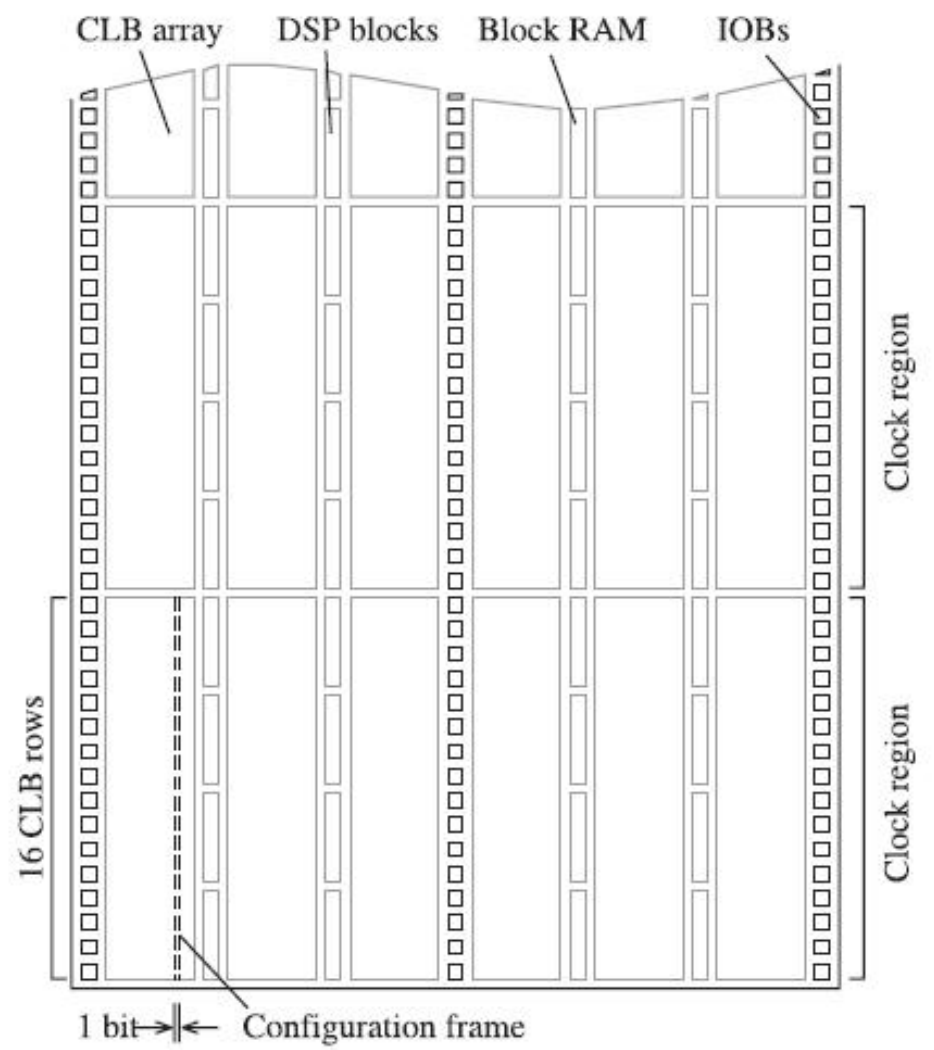

Figura 2.8: Arquitetura de Reconfiguração do Virtex-4.
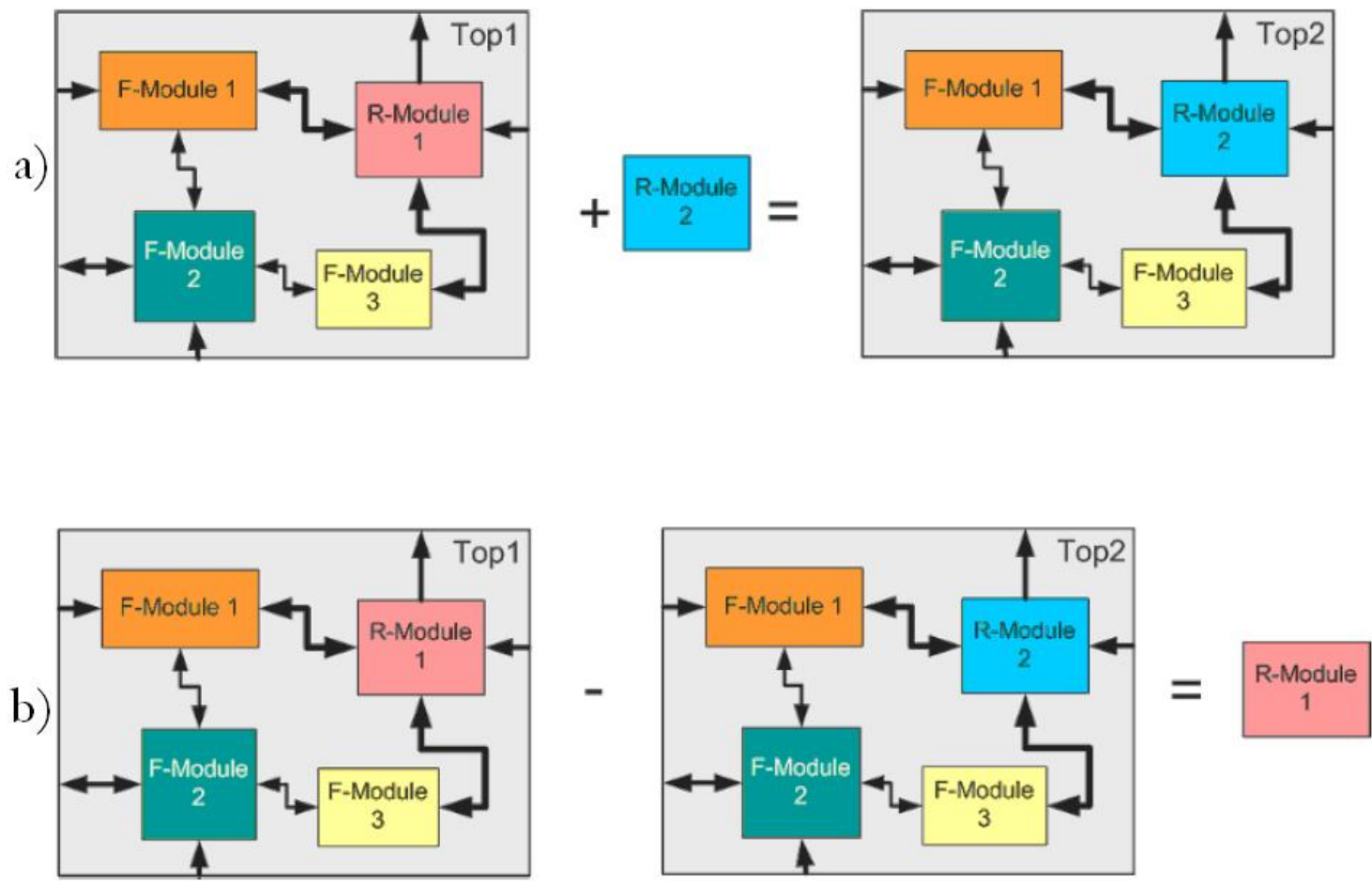

Figura 2.9: Geração do bitstream para reconfiguração parcial. 
Embora qualquer função possa ser implementada inteiramente com o JBits, ele não é a melhor abordagem utilizada para reconfiguração parcial e dinâmica porque ele torna muito complexo a construção de componentes a nível de portas lógicas e interconexões. Segundo (Zheng et al., 2005) o JBits possui uma baixa abstração, comparando-se com a abstração utilizada na síntese lógica de alto nível, encontrada nas ferramentas de descrição de hardware. Além disso, o suporte para dispositivos Virtex, relacionado ao JBits, está limitado a família Virtex-II, até o presente momento.

No método Difference-based flow, a reconfiguração parcial é realizada fazendo-se pequenas mudanças em um projeto e então, é gerado um bitstream baseado apenas na diferença desse projeto com o original. A troca de configuração de um módulo de uma implementação para outra é muito rápido, devido às pequenas modificações feitas no projeto (Montminy et al., 2007).

Segundo (Upegui e Sanchez, 2005), nesse método o projetista deve fazer manualmente as mudanças no projeto, ao nível das interconexões internas do FPGA, utilizando, por exemplo, o FPGA Editor, uma ferramenta de edição nesse nível. Essa ferramenta vem com o ISE da Xilinx. Nessa ferramenta, o projetista pode mudar as configurações dos componentes tais como: equações nas LUTs, conteúdos na RAM interna, multiplexadores, inicialização de flip-flops, roteamentos, entre outros. Depois de editado as mudanças, um bitstream parcial é gerado, contendo apenas as diferenças entre o projeto original e as modificações. Para projetos complexos, esse método seria impraticável devido a edição no nível de interconexões no arquivo bistream.

Segundo (Bobda, 2007), uma das principais desvantagens de JBits é a dificuldade de prover canais de roteamento fixos para uma conexão direta entre dois módulos. Segundo (Tadigotla et al., 2006) a abordagem Modular Design Flow é mais dinâmica e flexível do que a abordagem usando o Difference-base flow. Por isso, ela é mais utilizada nos processos de reconfiguração parcial.

Isso é importante porque deve-se garantir que sinais não serão roteados por caminhos errados depois da reconfiguração. A Figura 2.10 ilustra um exemplo de roteamento em caminhos diferentes. Na reconfiguração, o projeto provavelmente não irá funcionar corretamente, porque foi criada uma situação não prevista no projeto.

Na Figura 2.10 são mostrados dois projetos: Top1 e Top2. Após a reconfiguração dinâmica, o módulo R-Module 1 em Topl foi substituído pelo módulo R-Module 2, gerando assim o projeto Top2. Tantos os módulos fixos quanto os reconfiguráveis foram colocados nas mesmas posições 


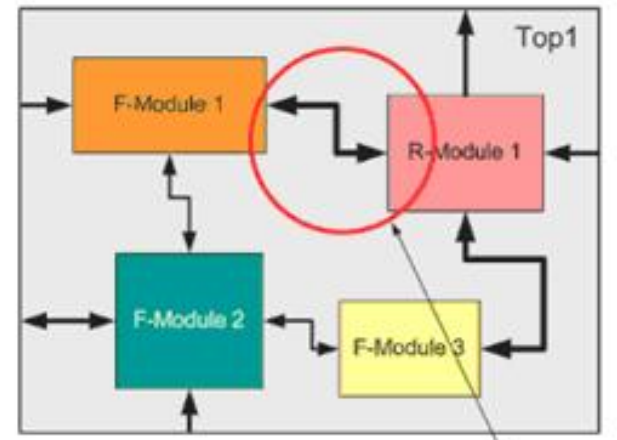

(a)

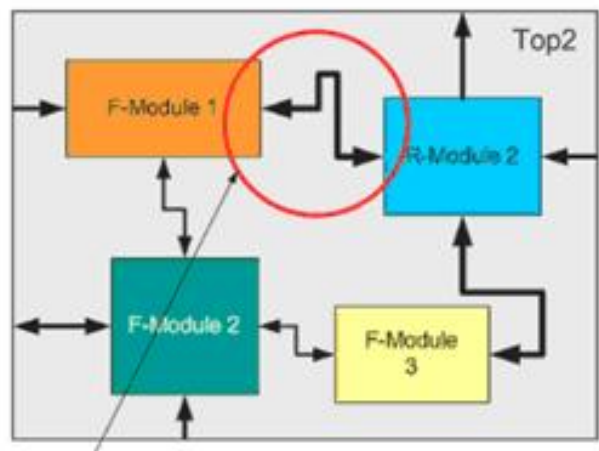

(b)

Diferentes possibilidades de roteamento

Figura 2.10: Roteamento em dois caminhos diferentes.

originais, como em Top1. A conexão F-Module 1 <-> R-Module 1 está roteada em um caminho diferente em relação a conexão $F$-Module $1<->R$-Module 2.

Uma das principais contribuições da abordagem modular é o uso da primitiva Bus Macro que garante canais de comunicação fixos entre componentes que serão reconfigurados em tempo de execução e os componentes fixos do projeto (Bobda, 2007).

Ainda segundo (Bobda, 2007), a abordagem modular não foi desenvolvida inicialmente para dar suporte à reconfiguração parcial. Ela foi desenvolvida para permitir a cooperação de engenheiros que trabalham no mesmo projeto, ou seja, ela permite que o projeto completo seja dividido em módulos, os quais podem ser estáticos e/ou dinâmicos. Por exemplo, em um grupo de projetistas, o responsável pelo projeto identifica todos os componentes que farão parte do projeto, estima a quantidade de recursos que será consumido por cada componente, define a localização física do componente no dispositivo e, então, distribui cada componente para um engenheiro projetar. Depois, esses componentes são integrados no projeto final e gerado um arquivo de configuração final.

Baseado em áreas especificas, módulos fixos e reconfiguráveis serão alocados em regiões no FPGA. Quando um módulo reconfigurável necessitar comunicar-se com um módulo estático ou dinâmico, isto deve ser feito por meio do Bus Macro. O Bus Macro mantém de forma correta as conexões entre os dois módulos durante a reconfiguração parcial. Um projeto com módulos fixos 
e reconfiguráveis é mostrado na Figura 2.11, onde o Bus Macro fornece a comunicação necessária entre os módulos (Tadigotla et al., 2006).

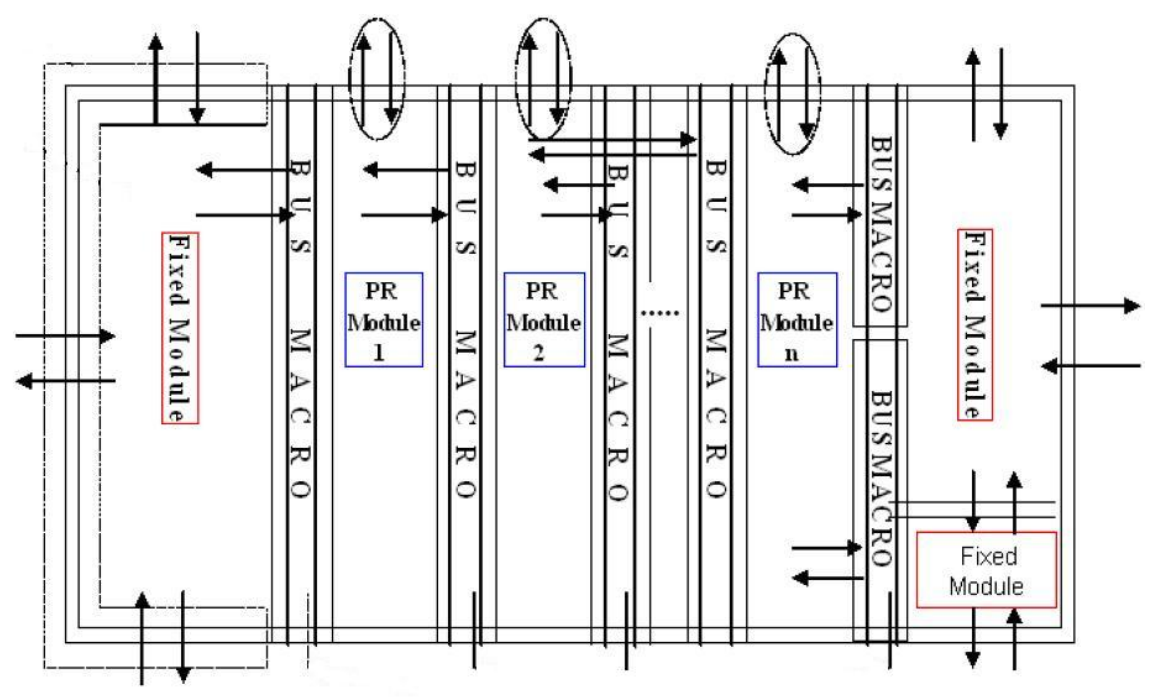

Figura 2.11: Esboço de um projeto básico com dois ou mais módulos reconfiguráveis.

Segundo (Tadigotla et al., 2006; Bobda, 2007) o EAPR Design Flow é um upgrade da abordagem projeto modular e as principais mudanças estão relacionadas com a usabilidade e atenuação de algumas restrições rígidas da abordagem anterior, o que reduz significativamente a complexidade de reconfiguração parcial.

Um dos principais benefícios dessa abordagem é que ela permite ao projetista realizar a reconfiguração parcial em regiões de qualquer tamanho regular, removendo assim um dos requisitos de reconfiguração parcial das abordagens anteriores (Tadigotla et al., 2006). Isto prove a possibilidade para dispositivos Virtex-4 e superiores.

Quando uma pequena região é configurada, a coluna inteira é escrita, mas o controlador de configuração no FPGA verifica se a reconfiguração deveria modificar o conteúdo dos CLBs. Assim a execução da reconfiguração é feita apenas onde as mudanças são necessárias, conseqüentemente, a reconfiguração não irá afetar os blocos que deveriam manter-se inalterados (Bobda, 2007).

A mais importante característica do EAPR Desing é que ela permite a comunicação entre diferentes regiões do FPGA. Na abordagem modular, quando um sinal de um módulo estático necessitasse passar por meio de um módulo reconfigurável, era necessário fazê-lo por meio do bus macro e sempre quando esse módulo era configurado, os sinais de roteamento interno também eram o 
que provocava quebra de comunicação entre alguns módulos estáticos no sistema. Na abordagem $E A P R$, os sinais que apenas atravessam módulos reconfiguráveis, sem interagir com eles, não terão que passar mais por meio do bus macro. O algoritmo de roteamento é capaz agora de determinar esses sinais e usar longos sinais de comunicação que não serão afetados pela reconfiguração parcial (Bobda, 2007), o que possibilita aumento do desempenho de tempo e simplifica o processo de construção de um projeto parcialmente reconfigurável. 



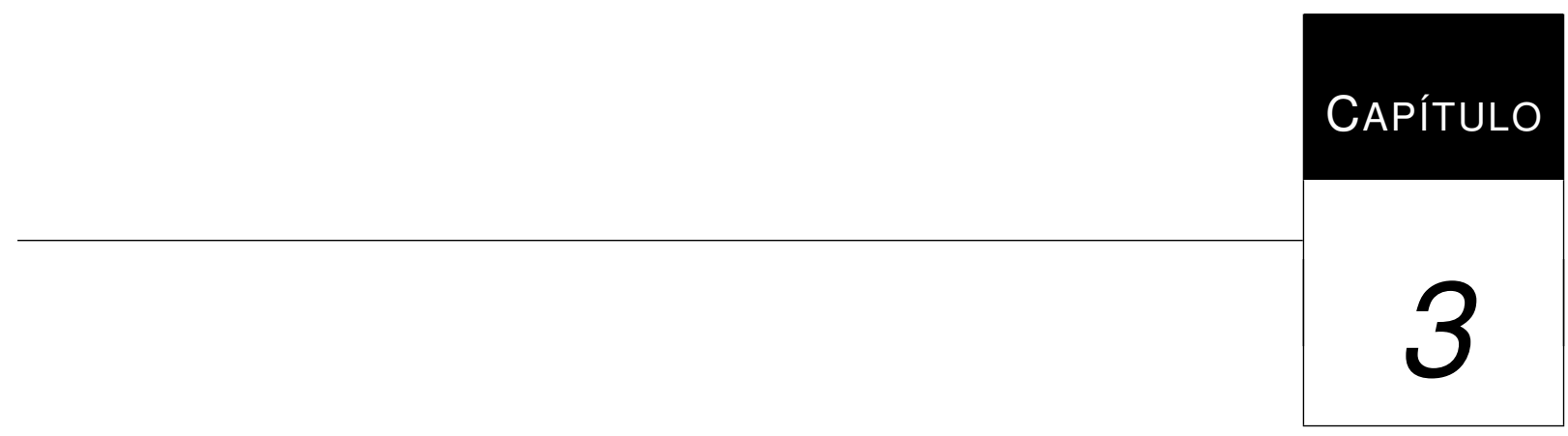

\section{Máquinas a Fluxo de Dados}

Arquiteturas de alto desempenho em geral estão centradas em conceitos de processamento paralelo. Segundo (Silva, 1992), máquinas a fluxo de dados foi uma dessas frentes de pesquisa, devido a natureza do paralelismo encontrado nesses sistemas, uma vez que o processo de execução de programas nestas maquinas é determinado pela disponibilidade dos dados, contrário às estruturas tradicionais onde o fluxo de dados é determinado por um controle explicito. Considerando que diversas operações poderão estar processando em paralelo, dependendo da aplicação, teremos um paralelismo natural conforme os dados vão sendo gerados e processados (Dennis e Misunas, 1974; Veen, 1986).

Segundo (Arvind e Culler, 1986), o modelo de computação a fluxo de dados oferece um simples, porém, poderoso formalismo para descrever computação paralela. Existiram um número considerável de arquiteturas a fluxo de dados diferentes.

Segundo (Veen, 1986), máquinas a fluxo de dados são computadores programáveis de granularidade fina, nos quais o hardware é otimizado para computação paralela dirigida pelos dados. 
Em 1969, Dennis desenvolveu o esquema do modelo a fluxo de dados. Eles chamaram esse esquema de grafo a fluxo de dados. O primeiro projeto de uma máquina a fluxo de dados é encontrado em (Dennis e Misunas, 1974).

Segundo (Veen, 1986), não há uma definição exata para se distinguir máquinas a fluxo de dados de todos os outros computadores. Considera-se que máquinas a fluxo de dados são todos os computadores programáveis dos quais o hardware é otimizado para computação paralela de granularidade fina e computação dirigida por dados.

Em arquiteturas a fluxo de dados não existe o conceito de memória como nas arquiteturas von Neumann. O conceito de memória em arquiteturas von Neumann torna esse modelo seqüêncial, pois a passagem de dados entre as instruções é feita através de atualizações em áreas de memória e um ponteiro de instruções é responsável por estabelecer o fluxo de controle de uma instrução para outra. Devido a esse fato, o modelo von Neumann também é conhecido como modelo de fluxo de controle ou control flow (Treleaven et al., 1982).

Conforme já mostrado, nas máquinas a fluxo de dados não existe o conceito de armazenamento de dados em memória, eles simplesmente são produzidos por uma instrução e consumido por outra (Veen, 1986). A chegada dos dados serve como sinal para habilitar a execução de uma instrução, eliminando a necessidade de controle de fluxo.

Em máquinas datafow cada instrução é considerada como um processo separado (Veen, 1986). Para facilitar a execução, cada instrução que produz dados como resultado contém ponteiros para todos os seus consumidores. Visto que uma instrução em um programa a fluxo de dados somente contém referências para outras instruções, ele pode ser visto como um grafo (Veen, 1986).

Essa notação de grafo refere-se como um grafo a fluxo de dados dirigidos, no qual cada nó representa uma operação (instrução) e os arcos que interligam esses nós representam a dependência entre as operações (Dennis e Misunas, 1974; Veen, 1986).

Nas arquiteturas a fluxo de dados, as instruções são conhecidas como nós e os dados como tokens. Um nó produtor é conectado a um nó consumidor por um arco e o "ponto"no qual o arco entra no nó é chamado porta de entrada. A execução de uma instrução é chamada de disparo do nó. O disparo de um nó apenas pode acontecer se o nó estiver habilitado, o que acontece por sua vez por meio de uma regra de habilitação, que geralmente é a disponibilidade de todos os tokens 
nas entradas de um nó (Veen, 1986). O termino de execução de uma operação liberam valores ou decisões para os nós do grafo, cuja execução depende deles.

Um exemplo de um programa na linguagem a fluxo de dados pode ser visto na Figura 3.1.

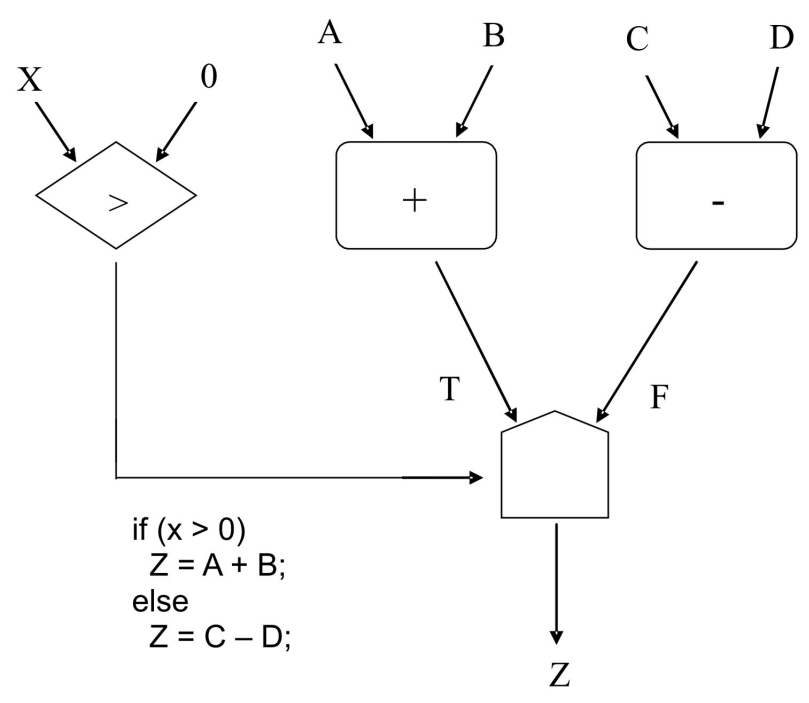

Figura 3.1: Programa básico na linguagem a fluxo de dados.

A Figura 3.1 ilustra um grafo a fluxo de dados, composto por quatro nós. Quando há tokens nas entradas dos nós eles podem ser processados e geram um token de saída. Os nós habilitados podem ser disparados em tempos não especificados, em qualquer ordem ou concorrência. O disparo envolve a remoção dos tokens de entrada e a computação do resultado.

Para representar programas na linguagem a fluxo de dados os enlaces e operadores são descritos nas Figuras 3.2 e 3.3 (Dennis e Misunas, 1974).

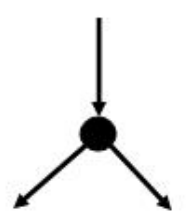

(a)

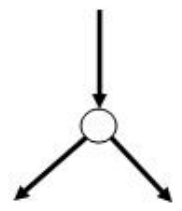

(b)

Figura 3.2: Links para a linguagem a fluxo de dados. (a) Link de dados. (b) Link de controle.

O Link de Dados é responsável em transmitir números inteiros, reais ou complexos e o Link de Controle de transmitir valores booleanos (true ou false). Os dados de controle são gerados por um operador decider, que ao receber dados de seus arcos de entrada, é aplicado um "predicado"que gera um dado de controle com um valor true ou false. 


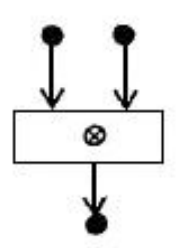

(a)

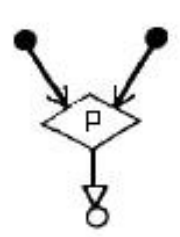

(b)

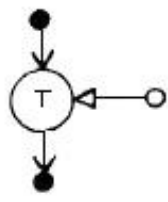

(c)

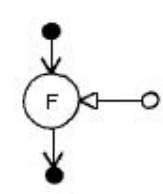

(d)

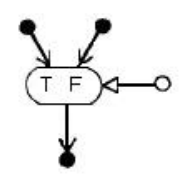

(e)

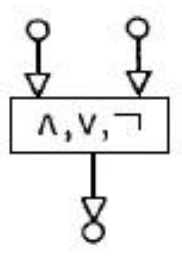

(f)

Figura 3.3: Operadores para a linguagem a fluxo de dados. (a) operator (b) decider (c) T-gate (d) F-gate (e) merge (f) boolean operator

Para representar computação interativa ou condicional em grafos a fluxo de dados, são utilizados os operadores decider, T-gate, F-gate e merge. O operador decider é utitilzado para a aplicação de uma operação lógica sobre os seus arcos de entrada e gera um valor resultante contendo true ou false. O operator do grafo a fluxo de dados requer também um dado para cada arco de entrada e produz um dado como resultado da aplicação de uma operação aritmética ou lógica sobre os dados recebidos.

Dados de controle representam valores booleanos (true e false) que controlam o fluxo de dados através dos operadores T-gate, F-gate e merge. O operador T-gate transmite um dado de seu arco de entrada para o seu arco de saída somente quando ele recebe um valor true no seu arco de entrada, caso o valor recebido em seu arco de entrada seja false, ele nao transmitirá o dado para o arco de saída. O operador F-gate possui um comportamento similar, exceto que o valor do controle é reverso. Um operador merge possui arcos de entrada de dados true e false e um arco de controle. Quando um dado true é recebido no arco de controle, o operador merge posiciona o dado do arco de entrada T no seu arco de saída e o dado no arco de entrada não usado é descartado. O mesmo acontece se o dado false for recebido no arco de controle, o operador merge inverte o processo e o dado de entrada presente na entrada F é passado para o arco de saída.

Uma situação que pode ocorrer nos grafos a fluxo de dados é a reentrância, ou seja, um nó pode disparar repetidamente. O modo que a reentrância é manipulada define uma classificação das maquinas a fluxo de dados (Veen, 1986; Arvind e Culler, 1986).

Há quatro maneiras distintas de se tratar o problema da reentrância em um sub-grafo: lock, acknowledge, code copying, e tagged tokens. Máquinas a fluxo de dados que manipulam a reentrância por lock ou acknowledge são chamadas de estáticas e aquelas que manipulam a reentrância por code copying ou tagged tokens são chamadas de dinâmicas (Veen, 1986). 
Um grafo a fluxo de dados é uma linguagem atrativa para uma maquina paralela, desde que todos os nós que não tem dependência de dados podem disparar concorrentemente (Veen, 1986).

Há duas implementações de arquitetura do modelo abstrato a fluxo de dados: a arquitetura estática e a dinâmica.

No modelo estático (Dennis e Misunas, 1974; Davis, 1978), permite apenas um token por arco no grafo a fluxo de dados. Um modelo de sincronismo para garantir a presença de um único dado no arco pode ser implementado por um protocolo específico que implementa a comunicação entre os operadores. Conseqüentemente o paralelismo neste caso é limitado pela seqüência de dados que vão sendo colocados nos diversos arcos, além do paralelismo existente entre os operadores.

As máquinas dinâmicas (Shimada et al., 1986; Gurd et al., 1985; Kishi et al., 1983; Grafe et al., 1989; Papadopoulos e Culler, 1990) são uma evolução das máquinas estáticas, por nelas permitirem que mais de um token esteja presente em um arco, o que significa utilizar toda a potencialidade da programação a fluxo de dados, exigindo, no entanto um tratamento mais complexo na implementação do sistema, pois é preciso além de armazenar os dados, identificar os parceiros dos dados que disparam uma operação.

Um alto nível de paralelismo é obtido quando cada iteração do grafo a fluxo de dados é executada em uma instância (ou cópia) separada de um sub-grafo reentrante. Para que isso aconteça é necessário existir na máquina algumas facilidades para criar uma nova instância de um sub-grafo e direcionar os tokens para as novas instâncias. Um modo eficiente de se implementar essas facilidades seria compartilhar a descrição dos nós entre diferentes instâncias de um grafo, sem que haja confusão nos tokens que pertencem a instâncias separadas. Isso é feito adicionando-se um rótulo (tag) para cada token, para identificar a instância do nó que ele será direcionado. Estas máquinas são chamadas de arquitetura tagged-token e possuem uma regra de habilitação que determina que um nó está habilitado se cada arco de entrada do nó possuir um token com um rótulo idêntico. Nessa máquina, não há mais do que um token com o mesmo rótulo. 


\subsection{Arquitetura das máquinas a Fluxo de Dados}

Uma máquina a fluxo de dados típica consiste de um número de elementos de processamento, os quais podem comunicar-se uns com os outros. Os nós de um programa a fluxo de dados são freqüentemente armazenados na forma de um gabarito contendo a descrição do nó e espaço para os tokens de entrada (Veen, 1986). A Figura 3.4 mostra um gabarito correspondendo ao operador "soma"(Silva, 1992).

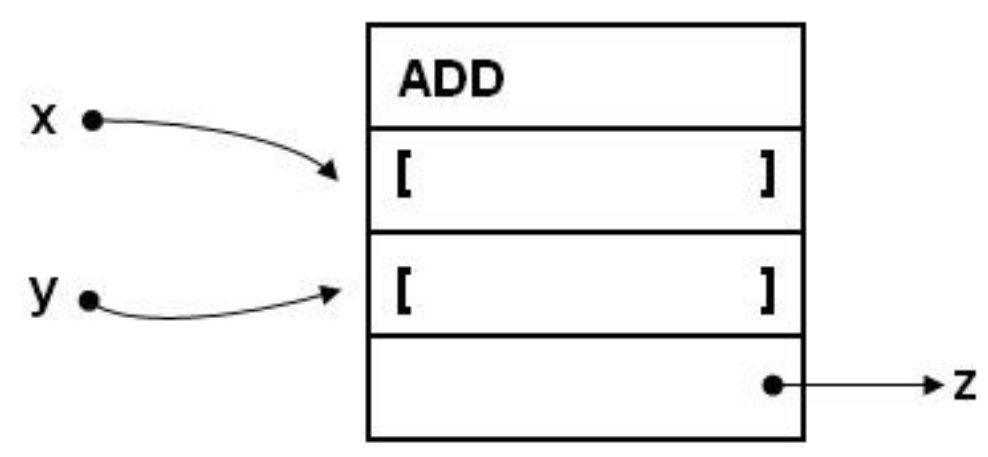

Figura 3.4: Gabarito da operação soma.

Existem quatro campos no gabarito da Figura 3.4: um para o código de operação especificando a operação a ser executada; dois receptores, que esperam para ser preenchidos com valores de operandos; e campo destino, que especifica o que fazer com o resultado da operação sobre os operandos.

Pode-se pensar na movimentação de um token entre dois nós como uma atividade local de um processo. Nas máquinas a fluxo de dados a coordenação dos tokens consumidos nos nós resume-se a administração da regra de habilitação desses nós que requerem mais que uma entrada (Veen, 1986).

A Figura 3.5 ilustra um diagrama funcional de um elemento de processamento. Alguns autores chamam a unidade que administra o armazenamento dos tokens de unidade de habilitação (enabling unit). Ela seqüencialmente aceita um token e o armazena no endereço do nó na memória. Se isso fizer o nó, o qual o token está endereçado, se tornar habilitado (ex: cada porta de entrada contém um token), esses tokens de entrada são extraídos da memória e juntos com uma cópia do nó, formam um pacote executável e são enviados a unidade funcional (functional unit), onde eles 
são processados. Esse pacote consiste de valores dos tokens de entrada, código do operando e uma dista de destino. A unidade funcional processa os valores de saída e os combinam com os endereços de destino dentro dos tokens. Os tokens são enviados de volta a unidade de habilitação, onde eles podem habilitar outros nós. Desde que a unidade de habilitação e a unidade funcional trabalhem concorrentemente, elas são freqüentemente referenciadas como pipeline circular. Os módulos dedicados a buffering ou comunicação foram deixados de fora do diagrama exposto na Figura 3.5 (Veen, 1986).

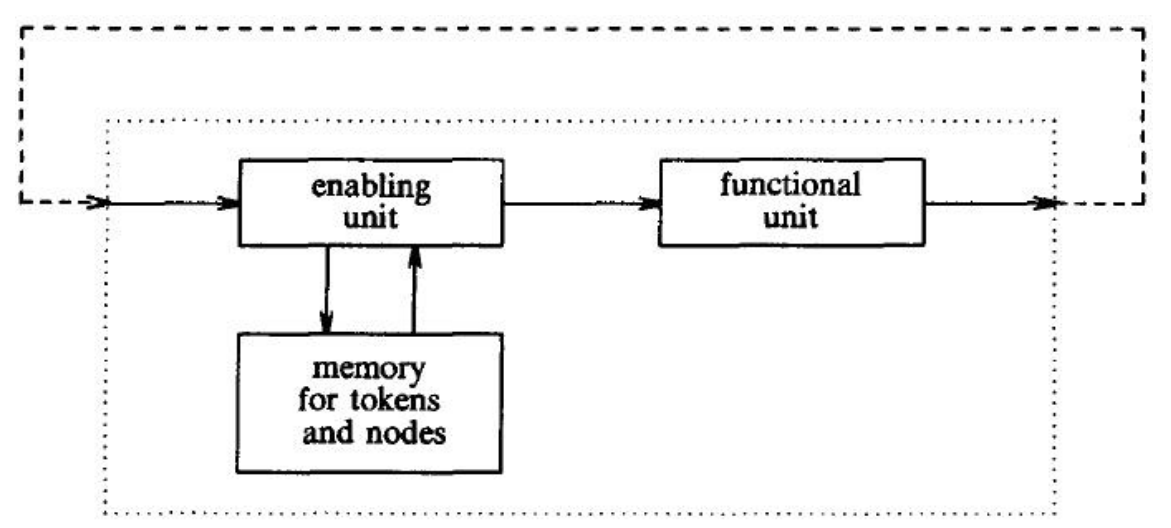

Figura 3.5: Diagrama funcional do elemento de processamento.

Em algumas máquinas a fluxo de dados, o elemento de processamento não tem que ser tão potente e ele consiste de uma memória conectada a uma unidade que liga o armazenamento de tokens e a execução dos nós (Veen, 1986).

Como discutido no início desse capítulo, as máquinas a fluxo de dados podem diferenciar nas suas arquiteturas. Segundo (Veen, 1986), em outras máquinas, o pipeline circular consiste de mais unidades concorrentes.

Em algumas máquinas a unidade de habilitação é separada em duas unidades: a unidade de matching store e a unidade de fetching, usualmente organizadas como mostra a Figura 3.6 (Veen, 1986).

A matching unit armazena tokens em suas memórias e verifica se uma instância do nó destino está habilitada. Esta operação requer uma compatibilidade de endereço de destino e rótulo. Os tokens são armazenados na memória conectada a matching unit. Para cada token que a matching unit aceita, ela tem que verificar se o endereço do nó está habilitado. Na maioria das máquinas tagged-token isto é facilitado limitando-se o número de arcos de entrada para dois e disponibi- 


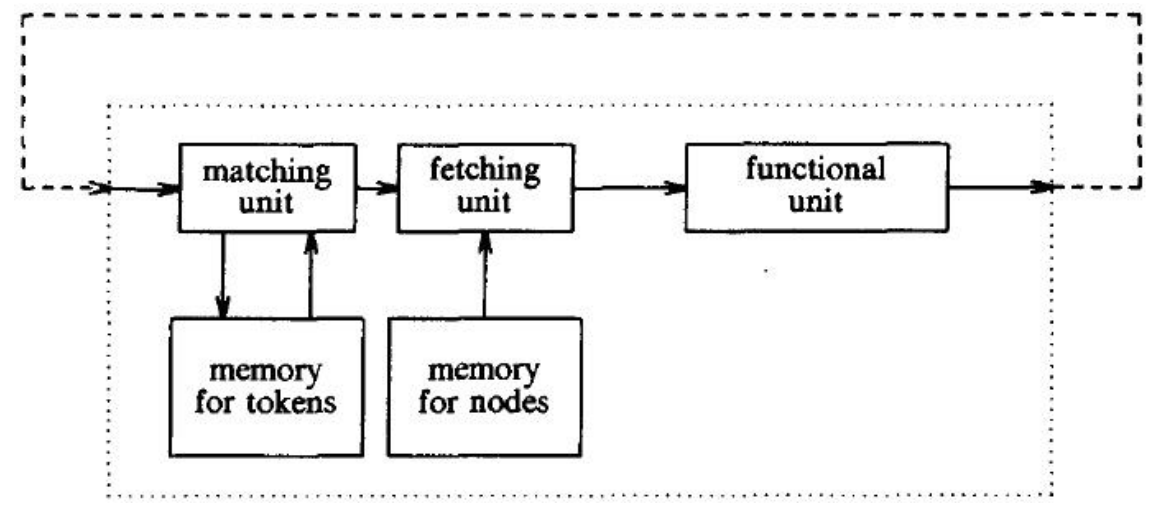

Figura 3.6: Diagrama funcional do elemento de processamento.

lizando para cada token um bit extra que indica se o nó endereçado possui uma entrada ou duas. Apenas para nós com duas entradas, o matching unit tem que verificar se a memória já contém um token parceiro, que é um token com o mesmo destino e um rótulo (tag), que indicam suas posições locais nos arcos (Arvind e Culler, 1986). Quando todos os tokens para uma instância de um nó em particular chegam, eles são enviados a fetching unit, a qual os combina com uma cópia da descrição do nó dentro de um pacote executável a ser enviado para a unidade funcional.

Conceitualmente, segundo (Veen, 1986), uma matching unit simplesmente combina endereço e rótulo em um endereço e verifica se o local denotado pelo endereço contém um token.

O grupo de localizações endereçáveis pelo rótulo e o endereço de destino formam um espaço chamado de matching space. Administrar esse espaço e representá-lo em uma memória física é um dos problemas chaves na arquitetura a fluxo de dados tagged-token (Veen, 1986).

\subsection{Descrição de algumas arquiteturas existentes}

A seguir são descritas arquiteturas a fluxo de dados tradicionais e em seguida são descritas com maiores detalhes aquiteturas a fluxo de dados contemporâneas.

\subsubsection{Arquiteturas a fluxo de dados tradicionais}

Como citado anteriormente, (Dennis e Misunas, 1974) foram os pioneiros nas pesquisas de computadores a fluxo de dados. A idéia era a construção de um sistema de computador altamente 
paralelo, que executasse simultaneamente vários fragmentos de um programa, porém esse alto grau de atividades concorrentes deveria ser encontrado sem nenhum sacrifício.

Com as características acima, um grande números de projetos de arquiteturas a fluxo de dados foram desenvolvidos e construídos ao longo dos anos. Um desses projetos de máquina a fluxo de dados começou com o Massachusetts Institute of Technology - MIT (Arvind e Kathail, 1981).

Na máquina a fluxo de dados do MIT somente um token pode ocupar um arco a cada instante. Isto implica que a regra de disparo é tal que uma instrução é habilitada se um token está presente sobre cada um de seus arcos de entrada e nenhum token está presente sobre qualquer um de seus arcos de saída. Na organização de programas da MIT existem tokens de controle e de dados, que contribuem para a habilitação de uma instrução. Tokens de controle atuam como sinal de reconhecimento quando os tokens de dados são removidos dos arcos de saída. Sua arquitetura consiste de cinco partes conectadas por canais através dos quais são enviados tokens usando um protocolo de comunição assíncrono, sendo uma Seção de Memória que contém instruções e seus operandos; uma Seção de Processamento que realiza operações sobre os tokens de dados; uma Rede de Arbitragem que distribui as instruções da seção de memória para a seção de processamento; uma Rede de Controle que distribui tokens de controle da seção de processamento para a seção de memória e por último uma Rede de Distribuição que distribui tokens de dados da seção de processamento para a seção de memória.

Um outro projeto de uma máquina a fluxo de dados dinâmico foi desenvolvido na Universidade de Manchester denominada MMDM (Manchester Multi-Ring Dataflow Machine) (Gurd et al., 1985). Ela consiste de cinco unidades principais:

- Comutador: responsável em providenciar as entradas e saídas para o sistema;

- Pilha de Token de dados: responsável em realizar o armazenamento temporário de um token de dados;

- Unidade de Disparo: responsável em igualar par de token de dados;

- Memória de Instruções: memória que mantém os programas a fluxo de dados;

- Unidade de Processamento: consite de um número de Elementos de Processamento idênticos, que executam as instruções. 
O comutador é usado para passar tokens de dados para dentro ou fora do sistema. Para iniciar a execução de um programa, os tokens de iniciação são inseridos através de comutadores e dirigidos por suas tags para as instruções de início da computação. No final do programa são inseridos intruções especiais que geram pacotes de dados de saída.

Em (Sato et al., 1992) é apresentada uma máquina a fluxo de dados híbrida denominada $E M-4$, onde sua arquitetura multithread ${ }^{1}$ pode explorar tanto programas von Neumann como programas a fluxo de dados.

Do ponto de vista de uma execução sequencial de threads, EM-4 pode ser visto como multiprocessador com memória distribuída. Cada elemento de processamento possui sua própria memória local e as threads dentro de um elemento de processamento operam somente sobre a memória local.

No modelo a fluxo de dados utilizado na $E M-4$, os grafos a fluxo de dados são classificados dentro de duas categorias: arcos normais e arcos fortemente conectados. Um conjunto de nós interligados por arcos fortemente conectados é chamado de SCB (strongly connected block). Arcos fortemente conectados possuem regras de disparo dentro de um $S C B$.

Um $S C B$ é implementado como uma sequencia de instruções e executado dentro de um elemento de processamento, controlado por um contador de programa. Do ponto de vista do modelo a fluxo de dados $S C B$ são armazenados em registradores em vez de serem transferidos como tokens, reduzindo o custo de comunicação.

A unidade de toda a comunicação no EM-4 é o pacote. O token de uma computação a fluxo de dados é entregue como um pacote. Uma parte do endereço do pacote especifica o $S C B$ que será invocado para aquele pacote.

Cada instrução possui um bit para indicar se a execução de um $S C B$ deve continuar ou não. Este bit corresponde aos arcos fortemente conectados. Uma vez que um $S C B$ é executado, sua execução continua até que uma instrução possua este bit configurado para encerrar a execução do $S C B$.

Um outro projeto de uma máquina a fluxo de dados é o DDMI (Davis, 1978), implementada na Universidade de Utah. Tanto o programa como a arquitetura da máquina são organizados

\footnotetext{
${ }^{1}$ Em um ambiente de múltiplos threads
} 
utilizando os conceitos de recursão. O computador é composto de elementos computacionais estruturados de forma hierárquica (pares processador-memória) onde cada elemento é logicamente recursivo. Fisicamente a arquitetura do computador é estruturada em árvore, onde cada elemento computacional é conectado a um elemento superior e a oito elementos inferiores.

Na máquina a fluxo de dados de Utah não existem tokens de controle, os tokens de dados providenciam toda comunicação entre as instruções. Nesta organização, os arcos do grafo a fluxo de dados, são vistos como uma fila FIFO (First-in First-out), onde os tokens de dados são armazenados à medida que vão chegando mas não são imediatamente consumidos pelas instruções. Para isso cada instrução consiste de um código de operação e uma lista de endereços distintos para os resultados, junto com um número variável de conjuntos de tokens de dados esperando para ser consumidos pela instrução.

Na Universidade de Newcastle foi desenvolvido um projeto de uma máquina a fluxo de dados denominada Jumbo (Treleaven et al., 1982). O objetivo era estudar a integração entre a computação a fluxo de dados e a fluxo de controle. Ela consiste em três componentes principais interconectadas por buffers FIFO. O primeiro componente é a Unidade de Disparo, que controla a habilitação de instruções igualando um conjunto de tokens de dados, que são enviados para a Unidade de Memória quando executadas; o segundo componente é a Unidade de Memória responsável em armazenar dados e instruções; o último componente é a Unidade de Processamento, que oferece suporte para execução de instruções e a distribuição de resultados.

\subsubsection{Arquiteturas a fluxo de dados contemporâneas}

Um modelo a fluxo de dados foi apresentado por (Budiu e Goldstein, 2002) denominado ASH (Application-Specific Hardware). ASH é uma estrutura arquitetural para implementar aplicação específica em hardware. ASH é baseado na síntese automática de linguagens de alto nível.

O ASH utiliza o compilador $C A S H$, um compilador escalonado, que gera hardware a partir de programas escritos em C. O compilador explora paralelismo ao nível de instruções usando técnicas como aggressive speculation e dynamic scheduling.

Os circuitos que o ASH gera podem ser usados de forma autônoma, com a implementação da aplicação inteira nele ou com um processador de propósito geral (Budiu et al., 2005). 
O principal componente do sistema $A S H$ é o compilador CASH.

A estrutura do $A S H$ é ilustrada na Figura 3.7. Na Figura 3.7(a) é descrito o fluxo de execução da estrutura, onde programas escritos em linguagens de alto nível são as entradas para o compilador $C A S H$, que depois são convertidos para hardware. Na Figura 3.7(b) são descritos os três tipos de objetos que o compilador constrói para cada procedimento do programa (circuito, memória local e rede de interconexões) (Budiu e Goldstein, 2002).

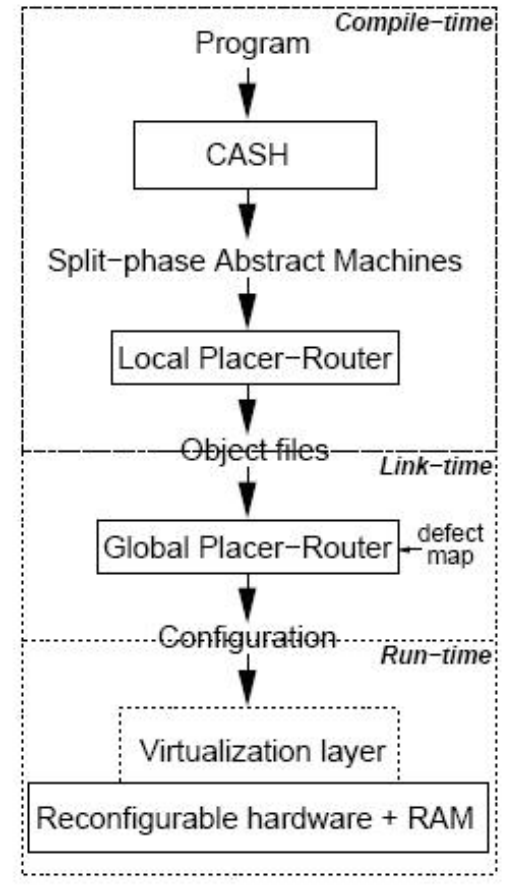

(A)

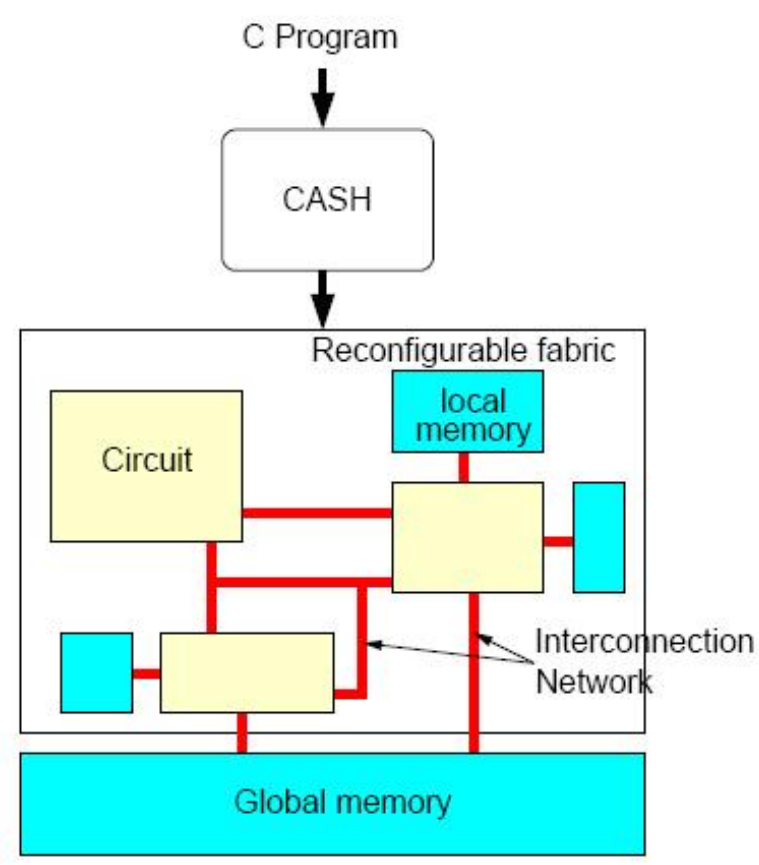

(B)

Figura 3.7: (A) Fluxo da ferramenta $A S H$ (B) Tradução do programa em hardware.

A partir do compilador $C A S H$ na Figura 3.7(a), para cada procedimento do programa o compilador cria três diferentes tipos de objetos: estruturas de computação, interconexões e memória local. O resultado é uma arquitetura para hardware reconfigurável, Figura 3.7(b). Cada procedimento é independentemente otimizado, sintetizado, alocado e roteado. Os procedimento comunicam-se uns com os outros de forma assíncrona. Todos os sinais de um procedimento tem latência previsível, incluindo o acesso a memória local. Todavia, os procedimentos podem invocar operações remotas, as quais têm latência imprevisível.

Sempre que um procedimento necessita executar uma operação que tem latência imprevisível, ele usa a rede de interconexões: acesso de memória remoto e transferências de controle de fluxo 
são conceitualmente transformados em mensagens, as quais podem ser roteadas dinamicamente em uma rede (Budiu e Goldstein, 2002).

O compilador $C A S H$ divide cada procedimento em uma coleção de hyperblocks, transformando cada hyperblock em linhas de código direta (sem laços), usando uma técnica em compiladores chamada speculation ${ }^{2}$, em seguida traduz cada hyperblocks em circuitos a fluxo de dados.

Uma vez que um hyperblock começa a executar, cada uma de suas operações são executadas exatamente uma vez.

O circuito produzido pelo sistema $A S H$ funciona da mesma forma que um sistema produtor/consumidor. Uma vez que o dado é consumido ele não estará mais disponível.

Em geral um operador é rígido, pois não computa a menos que todos os dados estejam presentes em suas entradas.

Segundo (Budiu e Goldstein, 2002), circuitos a fluxo de dados podem ser facilmente utilizados para expressar códigos diretos. Para permitir a implementação de construções a fluxo de controle (ramificações e chamadas a procedimentos), ASH aumenta o grupo de operações a fluxo de dados com duas construções especiais: nós merge e eta.

Esses nós são usados entre os hyperblocks e são suficientes para sintetizar circuitos correspondentes a um fluxo de controle arbitrário, incluindo grafos irregulares. Os nós merge são denotados por um triangulo que aponta para cima, enquanto eta é denotado por um triangulo que aponta para baixo.

O operador eta possui duas entradas, uma para o dado e outra para um predicado e uma saída de dados. Se o predicado é verdadeiro true o dado da entrada é copiado para a saída, porém, se o predicado for falso, o dado de entrada é apenas consumido e nenhuma saída é gerada. O operador merge possui "n"entradas e uma saída. Para que ele possa executar não é necessário que todas as suas entradas estejam disponíveis, ele simplesmente copia uma entrada disponível para a saída. O operador merge recebe dados de múltiplos operadores, mas somente um deles pode ativá-lo.

\footnotetext{
${ }^{2}$ Existem dois tipos de especulação: a de dados e a de controle. Com a especulação, o compilador antecipa uma operação de forma que sua latência, ou seja, tempo gasto seja retirada do caminho crítico. A especulação é uma forma de permitir ao compilador evitar que operações lentas atrapalhem o paralelismo das instruções. A especulação de controle é a execução de uma operação antes do desvio que a precede. Por sua vez, a especulação de dados é a execução de uma carga da memória (load) antes de uma operação de armazenagem (store) que a precede e com a qual pode estar relacionada.
} 
A maior abstração utilizada ao nível de programa é o hyperblock. Um hyperblock é parte de um grafo de fluxo de controle $C F G$, com um único ponto de entrada, mas múltiplas saídas possíveis.

Na Figura 3.8 é visto que compilador gera três hyperblocks para a sequiência de Fibonacci, marcados do lado direito da figura por linhas pontilhadas. O conjunto de hyperblocks são convertidos e executados diretamente no hardware.

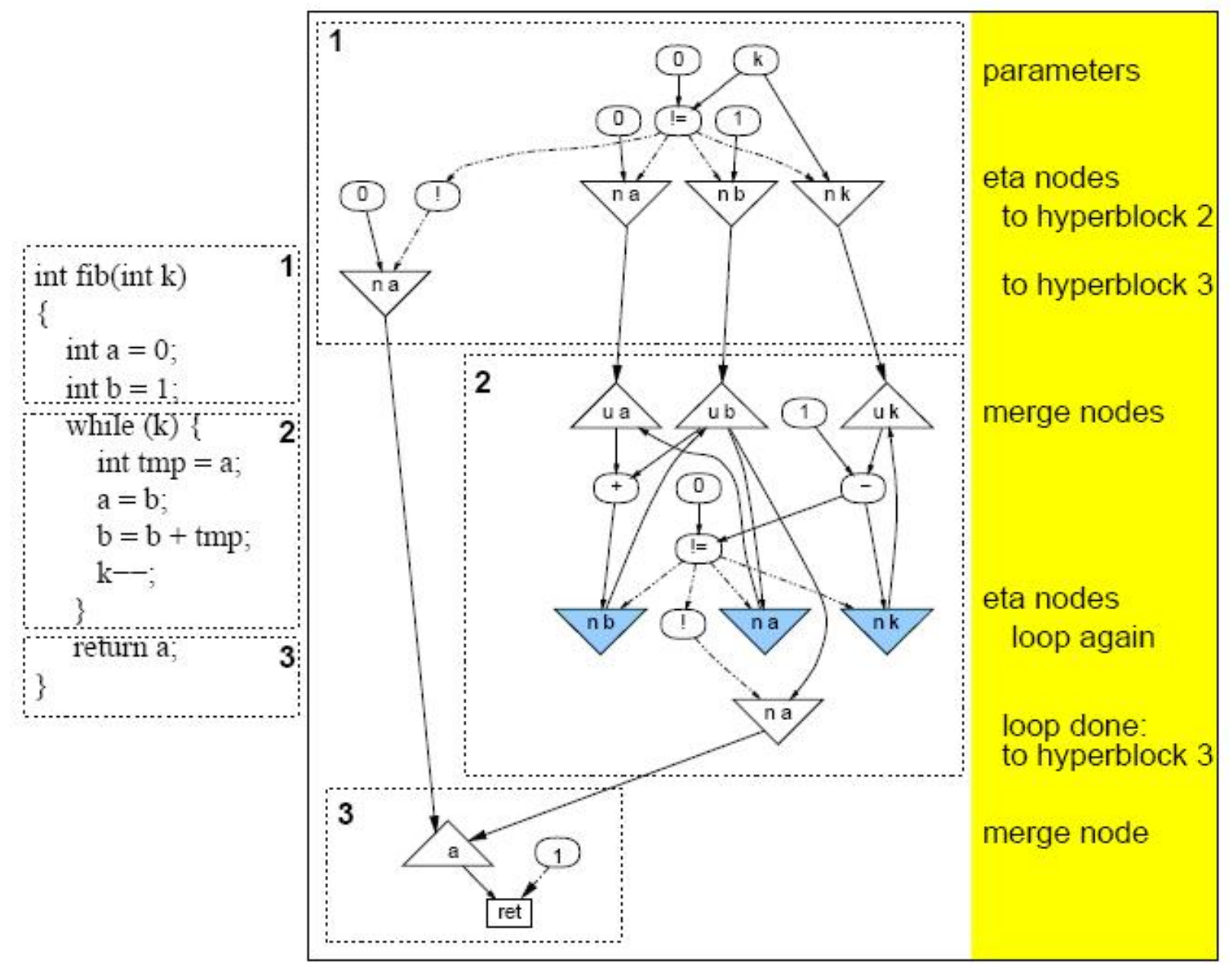

Fibonacci program

ASH implementation

Figura 3.8: Programa Fibonacci e sua implementação em $A S H$.

Como mostra a Figura 3.8, há nós merge nos hyperblocks 2 e 3. Os nós merge no hyperblock 2 aceitam dados do hyperblock 1 e do próprio hyperblock 2, controlando o laço while. Os nós merge no hyperblock 3 podem aceitar dados de controle dos hyperblock 1 ou do hyperblock 2.

Os circuitos gerados para os hyperblocks são ligados juntos usando os nós merge e eta. Para cada variável ativa na entrada de um hyperblock é criado um operador merge; para cada variável 
ativa na saída do hyperblock é criado um operador eta. A saída do operador eta é conectado a entrada do operador merge correspondente no hyperblock que sucede (Budiu et al., 2005).

A principal desvantagem do $A S H$ é a exigência para recursos de hardware. Porém, isso pode ser suavizado pelo particionamento hardware/software (Budiu e Goldstein, 2002).

O circuito gerado pelo $A S H$ está relacionado a máquinas a fluxo de dados, mas são destinados a ser implementado diretamente em hardware e não interpretado nas máquinas a fluxo de dados usando passagem de tokens (Budiu e Goldstein, 2002).

Em (Swanson et al., 2003, 2007) é descrito a arquitetura a fluxo de dados, chamada de arquitetura WaveScalar. Essa arquitetura possui um grupo de instruções a fluxo de dados e modelo de execução projetado para ser escalonado, ter baixa complexidade e alto desempenho de processamento.

Diferente das máquinas a fluxo de dados existentes, WaveScalar pode fornecer de forma eficiente as semânticas de memória seqüencial que as linguagens imperativas exigem. Para permitir aos programadores expressar facilmente o paralelismo, WaveScalar suporta estilos de programação pthread $^{3}$, multithread e a fluxo de dados. No WaveScalar, como em toda arquitetura a fluxo de dados, o programa é representado para o processador como grafos a fluxo de dados. Cada nó no grafo é uma instrução e os arcos entre os nós codificam estaticamente a dependência de dados entre instruções.

Além disso, WaveScalar permite combinar os dois estilos de programação em uma aplicação ou até em uma simples função (Swanson et al., 2007).

Para executar programas WaveScalar, foi projetado uma arquitetura de processador baseada em tile $^{4}$, chamada WaveCache. Esse processador possui uma arquitetura escalonada e descentralizada. A medida que um programa executa, o WaveCache organiza as instruções de programa sobre seus arranjos de elementos de processamentos PEs (Processor Elements).

As instruções continuam em seus elementos de processamento para muitas invocações futuras e conforme ocorre o processamento de um programa o grupo de instruções muda. Então

\footnotetext{
${ }^{3}$ Interface de manipulação de threads padronizada em 1995 pelo IEEE (IEEE POSIX 1003.1c)

${ }^{4} \mathrm{Na}$ indústria de processadores, muitos projetistas estão abandonando o conceito de processadores monolíticos, complexos e de alto desempenho em favor de elementos de processamento (PE), mais simples, replicados dentro do chip. Estas arquiteturas são denominadas tiled architectures.
} 
o WaveCache remove as instruções ociosas e organiza novas instruções em seus lugares. As instruções comunicam-se diretamente com as outras por meio de uma rede hierárquica de interconexão escalonada on-chip, evitando assim longos fios.

O projeto WaveScalar foi construído no modelo de execução a fluxo de dados e explora as propriedades desse modelo, tais como descentralização e escalonamento (Swanson et al., 2007).

Além disso, como já mostrado nos capítulos anteriores, o modelo de execução a fluxo de dados permite aos programadores e compiladores expressar explicitamente o paralelismo, em vez de depender de um hardware para extraí-lo (Swanson et al., 2007).

Os sistemas a fluxo de dados antigos não podiam executar de forma eficiente a semântica seqüencial de memória que as linguagens imperativas, tais como $C, C++$ e Java exigem. A execução nessa ordem é necessária para preservar as dependências entre as instruções de leitura e escrita, por exemplo. Segundo (Swanson et al., 2007), linguagens imperativas modernas basicamente fornecem semântica de memória idêntica, sendo que os sistemas a fluxo de dados antigos usavam linguagens a fluxo de dados especiais que limitavam a sua utilidade (Swanson et al., 2007).

WaveScalar explora as propriedades do modelo a fluxo de dados e supera essas limitações por meio de um esquema de ordenação de memória, chamado de wave-ordered memory, necessário para linguagens imperativas. Usando esse esquema de ordenação de memória, WaveScalar suporta estilos de programação pthread, multi-thread. Os programadores podem combinar esses diferentes modelos de threads no mesmo programa ou na mesma função.

Segundo (Swanson et al., 2007), aplicar diversos estilos de threads em um único programa pode expor de forma significante o paralelismo no código, que de outra forma seria difícil de ser completamente paralelizável. Expor o paralelismo é apenas o primeiro passo. O processador deve então traduzir esse paralelismo em desempenho.

O Wave Cache é baseado no modelo descentralizado da execução a fluxo de dados, assim, ele não tem nenhuma unidade de processamento central. Ao invés disso, o WaveCache consiste de nós de processamento, que substituem o processador central e o cachê de instruções de um sistema convencional. A utilização de técnicas de threads em programas WaveScalar, necessita de um compilador próprio para a arquitetura. WaveScalar é uma arquitetura a fluxo de dados dinâmica. Nele, os tags são chamados de waves numbers. Os tokens são simbolizados com waves numbers 
"w"e valor "v"como "w.v"(Swanson et al., 2007). Ao invés de atribuir diferentes wave numbers para diferentes instâncias de uma instrução específica (como faz a maioria das máquinas a fluxo de dados dinâmicas), o WaveScalar os atribui na porção delimitada do compilador do grafo a fluxo de dados, chamada waves. Os waves são similares a hyperblocks ${ }^{5}$, mas são mais gerais, visto que eles podem conter fluxo de controle juntos e ter mais que uma entrada. Eles não contém loops, pois eles são divididos em waves, como mostra a Figura 3.9.

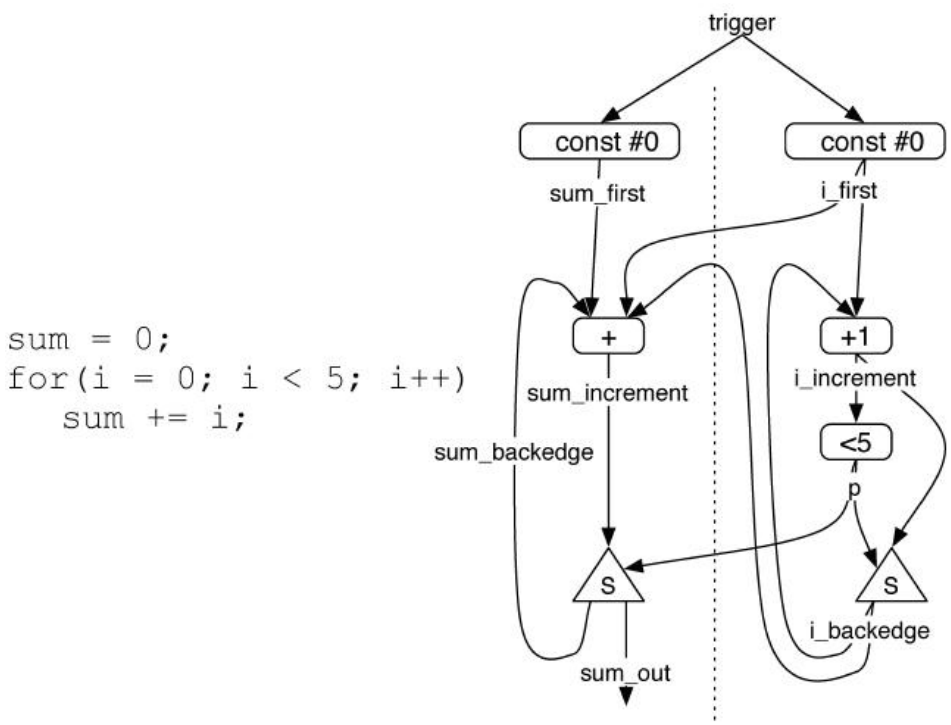

(a) (b)

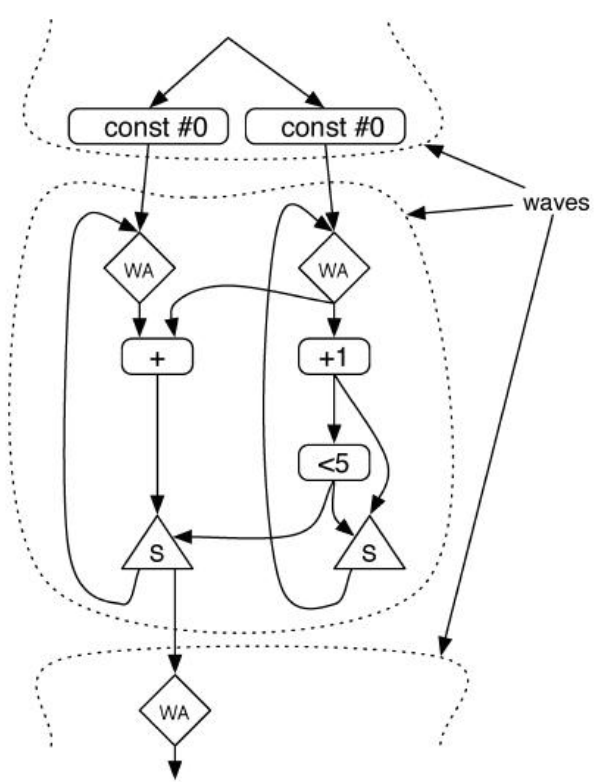

(c)

Figura 3.9: Loops no WaveScalar: (a) um loop simples; (b) uma implementação a fluxo de dados; e (c) implementação WaveScalar.

No topo de cada wave está um grupo de instruções chamadas WAVE-ADVANCE, cada qual incrementa o valor wave number que passa por ele.

Assumindo que o código antes do loop é wave number 0. Quando o código executa, as duas instruções CONST irão produzir 0.0 (wave number 0 , valor 0). A instrução WAVE-ADVANCE irá receber ele como entrada e produzirá saída 1.0 e assim sucessivamente.

Dentro de cada wave, o compilador anota o acesso das instruções na memória para codificar a ordem entre elas.

As arquiteturas baseadas no modelo a fluxo de dados não possuem mecanismos que assegurem que as instruções armazenadas na memória sejam executadas na ordem presente nos programas.

\footnotetext{
${ }^{5} \mathrm{O}$ hyperblock corresponde a uma estrutura com uma única entrada e múltiplas saídas laterais
} 
A Figura 3.10 mostra a diferença que pode acontecer entre a execução de um programa em uma linguagem imperativa e um programa em grafo a fluxo de dados. No grafo, a instrução load deve executar depois da instrução store. O grafo a fluxo de dados não expressa esta implícita dependência entre as duas instruções. Como já mostrado anteriormente, o WaveScalar fornece um mecanismo para codificar esta implícita dependência para suportar linguagens imperativas. Waveordered memory resolve o problema de ordenação de memória em grafos a fluxo de dados usando waves. A linha pontilhada na Figura 3.10 representa a esta implícita depedência entre as instruções. No interior de cada wave, o compilador anota o acesso das instruções à memória para codificar a ordem entre elas. Visto que o número de waves aumentam com a execução do programa, eles fornecem a ordem da execução dos waves.

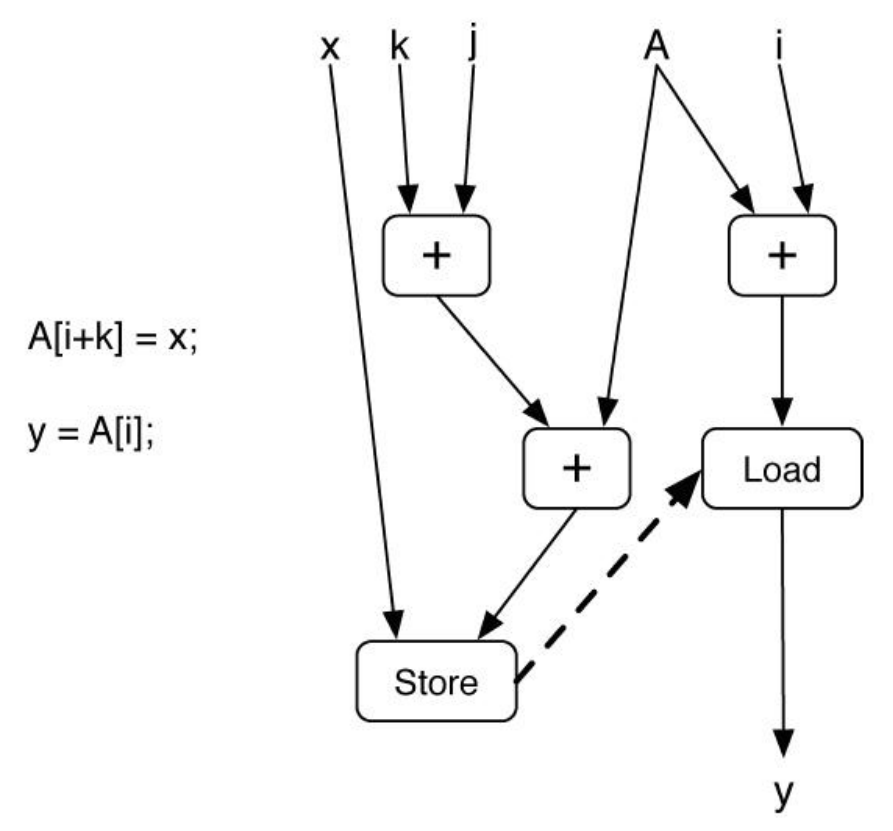

Figura 3.10: Problema relacionado a falta de dependência em um grafo a fluxo de dados.

A arquitetura do WaveScalar permite: 1) Wave-ordered memory permite ao WaveScalar fornecer a semântica que linguagens imperativas requerem e para expressar o paralelismo entre operações carregadas; 2) expressar explicitamente o paralelismo a nível de instruções, enquanto ainda mantém a semântica convencional da memória; 3) o modelo de execução WaveScalar é distribuído, ou seja, só instruções que tem que trocar dados com outras se comunicam.

O WaveCache inclui tudo, exceto memória principal, necessária para executar um programa WaveScalar. Ele contém uma rede escalonada de elementos de processamentos a fluxo de dados 
idênticos que são organizados hierarquicamente para reduzir os custos de comunicação. Cada nível de hierarquia usa uma estrutura de comunicação separada.

A Figura 3.11 mostra a organização hierárquica da micro-arquitetura do WaveCache. Ao invés de projetar um core monolítico que englobe o programa inteiro, um tiled processador cobre o programa com centenas ou milhares de tiles idênticos, cada qual é uma unidade de processamento simples, porém completa. Visto que eles são menos complexo que um core monolítico, os tiles tem o custo e a verificação do projeto amortizados.

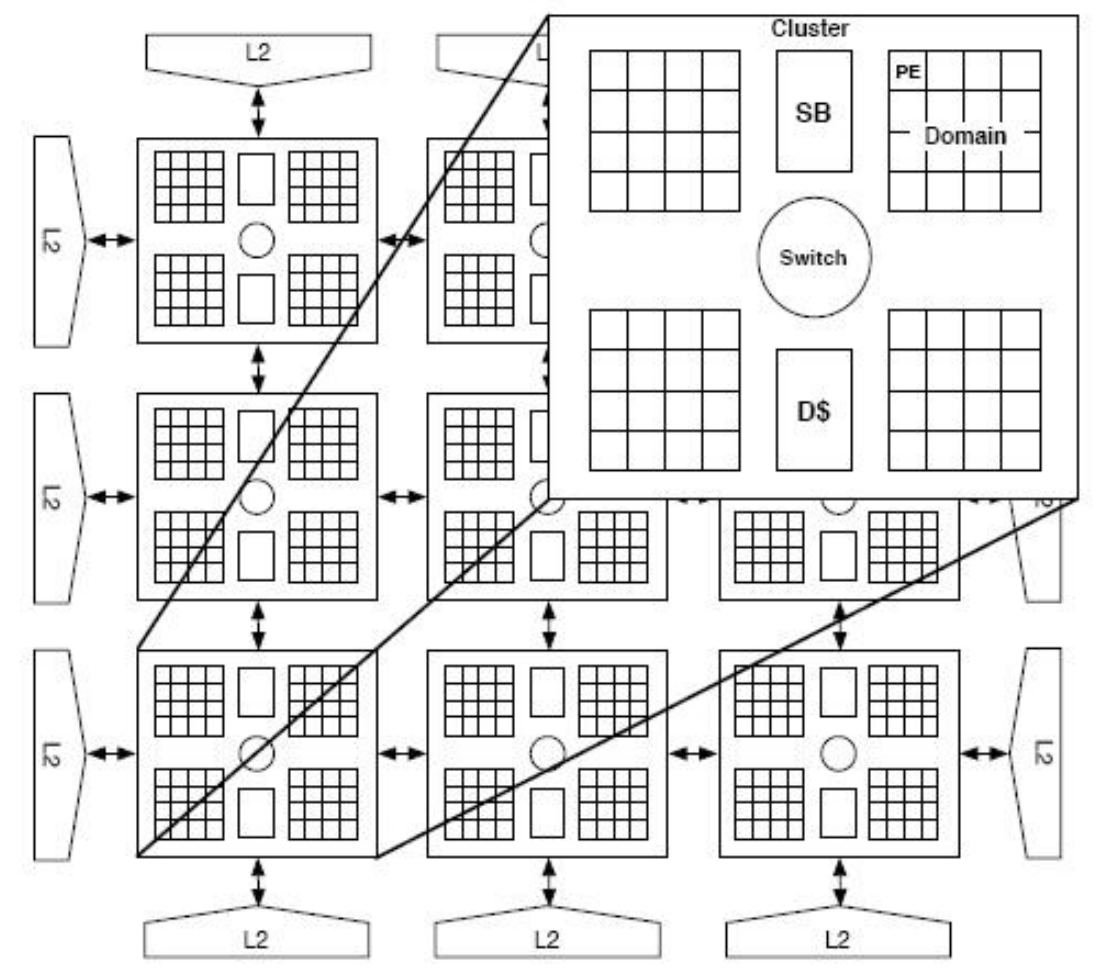

Figura 3.11: Organização hierárquica da micro-arquitetura do WaveCache.

No WaveCache, cada tile é chamado de cluster. Um cluster contém quatro domains idênticos, cada qual com oito elementos de processamento idênticos. Os domains da Figura 3.11 possuem 16 PEs cada.

Na Figura 3.12 é representado a execução do loop da Figura 3.9(c) mapeada sobre dois domains. Cada quadrado grande representa um elemento de processamento. Em adição, cada cluster possui quatro bancos de cachê de dados, interface em hardware para wave-ordered memory e uma rede de troca para comunicação com clusters adjacentes. Múltiplas instruções são dinamicamente colocadas em um número fixo de elementos de processamento, cada qual pode calcular 64 in- 
struções. Os PEs acessam a memória enviando requisições para a interface de memória em seu cluster local.

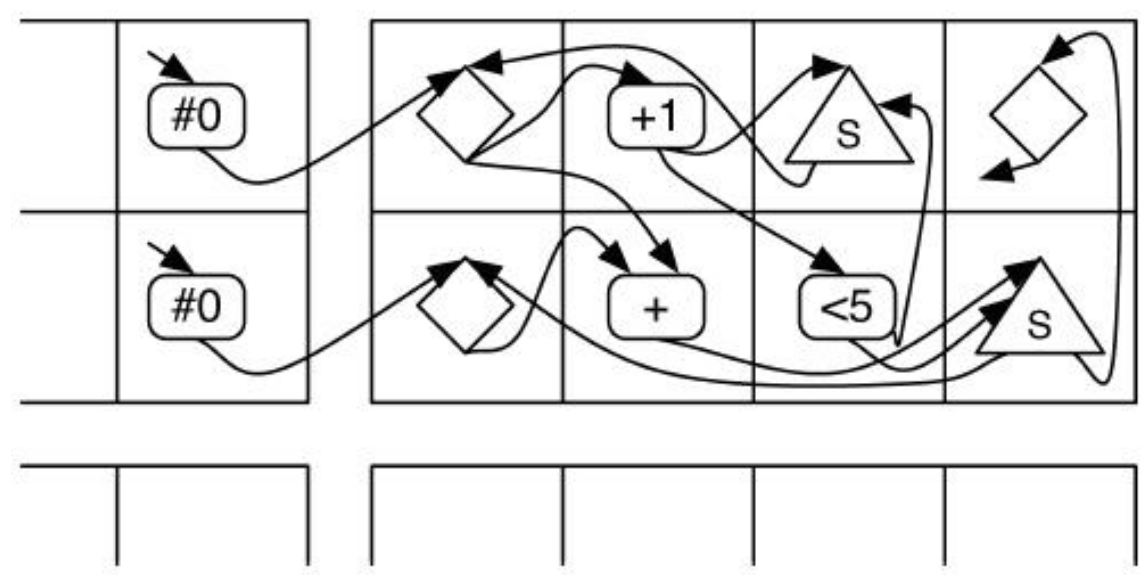

Figura 3.12: Loop da Figura 3.9(c) mapeado sobre dois domains WaveCache.

As instruções são mapeadas e colocadas nos PEs dinamicamente conforme a execução do programa.

As responsabilidades de um elemento de processamento são implementar a regra de disparo do modelo a fluxo de dados e executar as instruções.

Cada $P E$ contém uma unidade funcional, memórias especializadas para guardar operandos e lógica para controlar a execução das instruções e comunicação. Ele também contém buffers e armazenamento para várias instruções estáticas diferentes. Um $P E$ possui cinco estágios de pipeline, com redes de desvio, que permitem a execução de instruções dependentes no mesmo $P E$.

A Figura 3.13 mostra o elemento de processamento do WaveCache que foi implementado em cinco estágios de pipeline:

- Entrada (input): Mensagens de operandos chegam ao PE por meio de outro PE ou do próprio.

- Combinação (match): Os operandos entram na tabela de matching, que determina quais instruções estão prontas para disparar.

- Envio (dispatch): O PE escolhe uma instrução da fila de execução, lê seus operandos pela tabela de matching, e os envio para o estágio "execução". 
- Execução (execute): Executa a instrução e envia os resultados para a fila de saída e/ou para a rede de comunicação local.

- Saída (output): Uma saída de instrução é enviada para as instruções consumidoras por meio da rede de comunicação interna. Consumidores podem ser outros PEs ou o próprio. Para reduzir os custos de comunicação com a rede, os PEs são organizados hierarquicamente junto com suas infra-estruturas de comunicação. Um aspecto principal do projeto garante que ele evite o grande, centralizado armazenamento do tag-matching encontrado em algumas máquinas a fluxo de dados prévias.

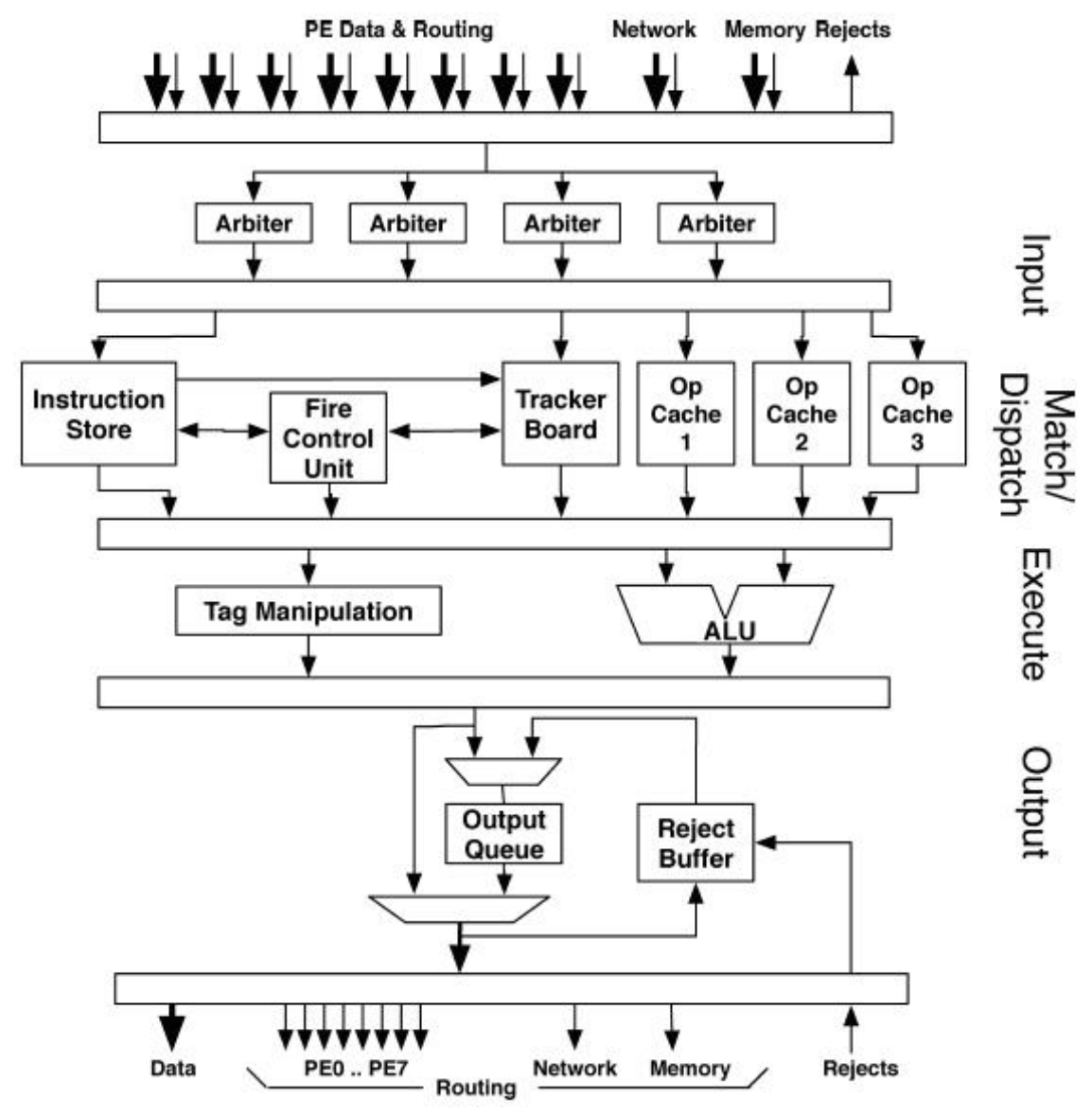

Figura 3.13: Diagrama de bloco de um $P E$.

A um alto nível, a estrutura do pipeline do $P E$ lembra uma estrutura convencional de pipeline. A grande diferença entre os dois é que a execução do $P E$ é inteiramente dirigida por dados ao invés da execução de instruções provida por um contador de programas, como as encontradas nas máquinas von-Neumann. 
Novos tokens são armazenados em um cachê matching. Se um token residir no matching por um tempo longo, outro token pode sucedê-lo. Neste caso o token antigo é enviado para a tabela matching na memória.

A tabela matching é separada em três colunas, uma para cada entrada de instrução (certas instruções WaveScalar podem ter três entradas).

O esquema de alocação de instruções no WaveScalar tem um compilador e um componente em tempo de execução. O compilador é responsável por agrupar as instruções em seguimentos, enquanto o componente em tempo de execução aloca o seguimento inteiro de instruções em um mesmo PE. Por causa disso, o compilador tenta agrupar as instruções em um mesmo seguimento se não for provável que essas instruções executem simultaneamente, mas compartilham operandos, então podem utilizar a rede local rápida disponível dentro de cada $P E$.

Em tempo de execução, o WaveCache carrega um seguimento de instruções quando uma instrução que não foi mapeada dentro dele necessita ser executada. Como mostrado acima, um seguimento inteiro é mapeado em um único $P E$. Por causa da ordenação que o compilador usa para gerar o seguimento, eles irão ser dependentes uns dos outros. Como resultado, eles não irão competir para a execução de recursos, mas ao invés disso, eles irão executar em ciclos consecutivos. O algoritmo preenche todos os PEs em um domain e então todos os domains em um cluster, antes de ir para o próximo cluster. Esse esquema de alocação faz o trabalho de escalonamento para minimizar a contenção de recursos e a latência de comunicação.

As instruções do WaveScalar descritas até aqui replicam a funcionalidade de um processador von-Neumann. Essa capacidade é essencial se o WaveScalar for utilizado como uma alternativa a arquiteturas von-Neumann, mas isso não limita o que o WaveScalar pode fazer.

WaveScalar possui uma segunda interface chamada unordered memory, construída para expressar o paralelismo em memória.

A interface wave-ordered memory é necessária para executar programas convencionais, mas pode apenas expressar paralelismo limitado.

A interface unordered memory do WaveScalar não fornece a ordenação seqüencial eficiente que os programas convencionais necessitam, mas expressa o paralelismo porque elimina a restrição de ordenação desnecessária (Swanson et al., 2007). Assim, ela permite aos programadores e compi- 
ladores explorar esse fato para expressar o paralelismo entre operações na memória, que podem ser executadas fora de ordem de forma segura. Para assegurar, por exemplo, que uma instrução load execute depois de uma operação de store, elas devem ter uma dependência de dados entre elas.

O processador TRIPS / GPA (Nagarajan et al., 2001; Sankaralingam et al., 2003) e WaveScalar estão investindo no mesmo desafio tecnológico e tendem a usar a mesma terminologia para descrever aspectos de seus projetos (Swanson et al., 2003).

TRIPS é uma arquitetura polimórfica, hibrida von-Neumann / modelo a fluxo de dados, a qual pode ser configurada para diferentes granularidades e tipos de paralelismo. Em (Swanson et al., 2003) o processador TRIPS é descrito como uma arquitetura híbrida VLIW a fluxo de dados.

TRIPS contém mecanismos que habilitam os cores de processamento e sistema em memória on-chip que pode ser configurado e combinado em diferentes nós para paralelismo ao nível de instruções, dados ou threads.

Para explorar o paralelismo da aplicação e prover um grande uso dos recursos disponíveis, TRIPS usa três nós de execuções diferentes: D-morph, que procura o paralelismo em nível de instruções; T-morph que trabalha ao nível de thread, mapeando múltiplos threads em um único core do TRIPS e S-morph que tem como objetivo aplicações como fluxo de mídia (streaming media), com alto nível de paralelismo ao nível de dados.

Segundo (Swanson et al., 2003), a única característica arquitetural que TRIPS e WaveScalar compartilham é o uso de ligações entre instruções no mesmo hyperblock (no TRIPS) e grafos acíclicos dirigidos ou wave (no WaveScalar).

No interior dos hyperblocks, as instruções disparam de acordo com a regra de disparo do modelo a fluxo de dados, enquanto a comunicação entre hyperblocks ocorre por meio de arquivo de registrador (Swanson et al., 2003).

No core TRIPS há resquícios da arquitetura von-Neumann, porque o contador de programa para guiar a execução, mas ao invés de selecionar instrução por instrução na memória, o contador de programas no sistema TRIPS seleciona frames (semelhantes a hyperblocks) de instruções de execução em um arranjo de dezesseis elementos de processamento que constituem o processador TRIPS (Swanson et al., 2007). 
TRIPS utiliza a estratégia de construção de chips heterogêneos, os quais contêm múltiplos cores de processamento, cada qual designado a executar uma classe distinta de carga de trabalho. O polimorfismo da arquitetura TRIPS deve-se a capacidade de configurar o hardware para executar de forma eficiente, grandes classes de aplicações.

A Figura 3.14 mostra algumas arquiteturas de granularidades diferentes. A arquitetura de granularidade fina, mostrado na figura, pode oferecer um alto desempenho em aplicações com paralelismo de grão fino (paralelismo ao nível de dados), mas terá dificuldade de alcançar bom desempenho em aplicações de propósito geral e aplicações seriais. No outro extremo da figura, pode ser visto uma arquitetura de granularidade grossa, que por sua vez, não tem a capacidade de usar o hardware interno para mostrar alto desempenho em aplicações de granularidade fina, ou seja, aplicações com alto paralelismo.

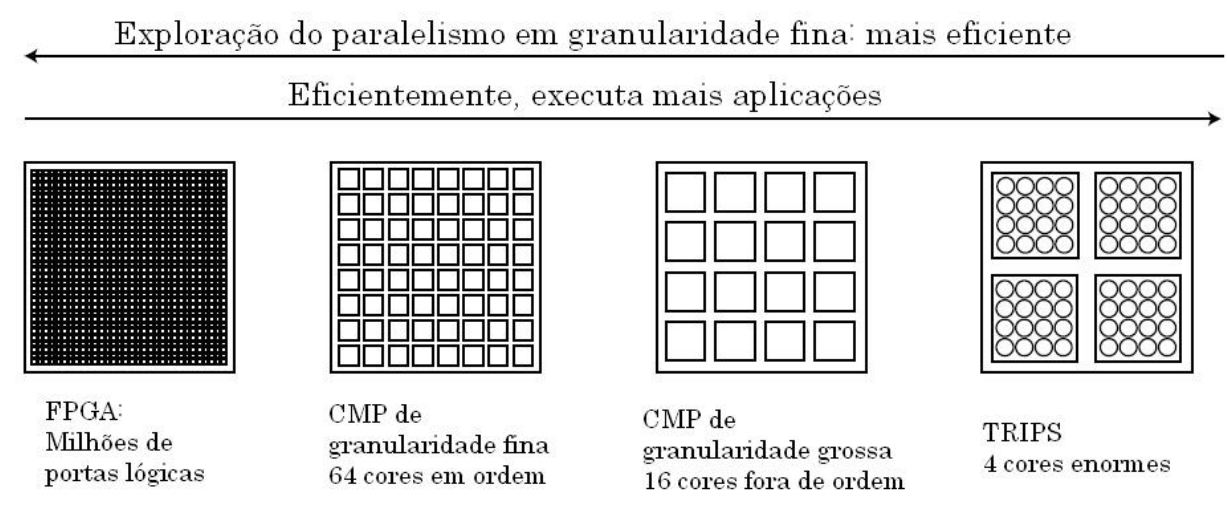

Figura 3.14: Granularidade de elementos de processamento paralelos em um chip.

O polimorfismo pode atravessar essa dicotomia com qualquer uma das duas abordagens. Uma aproximação de síntese usa a granularidade fina para explorar aplicações com grão fino e paralelismo regular; paralelismo de grão grosso sintetiza múltiplos elementos de processamento em um processador lógicos maior (Sankaralingam et al., 2003).

Uma aproximação de divisão implementa uma granularidade grossa em hardware e logicamente divide esse grande processador para explorar o paralelismo em grão fino, quando ele existe.

A arquitetura TRIPS usa uma abordagem de separação, combinando uma rede de cores de processadores polimórficos de granularidade grossa com um sistema polimórfico adaptativo de memória em chip. Assim, a arquitetura prove o máximo desempenho para aplicações singlethread, enquanto o restante do divisor explora o paralelismo de grão-fino. 
A Figura 3.15 ilustra a arquitetura do TRIPS. Como visto na figura, a arquitetura de TRIPS utiliza grandes cores de processamento de granularidade grossa para alcançar alto desempenho em aplicações single-thread com alto ILP (Instruction-Level Parallelism). A arquitetura é dividida para evitar grandes estruturas centralizadas e longos fios de execução. Esta divisão computacional e elementos de memória são conectados por canais ponto a ponto que são expostos por escalonadores de software para otimização. Segundo (Sankaralingam et al., 2003) o desafio chave em definir as características do polimorfismo está em balancear suas granularidades apropriadas para que cargas de trabalho envolvendo diferentes níveis de ILP, TLP (Thread Level Parallelism) e DLP (Data Level Parallelsim) possam maximizar seus usos de recursos disponíveis e ao mesmo tempo evitar estruturas complexas em ascensão e não escalonáveis. O sistema TRIPS emprega características polimórficas de granularidade grossa ao nível de bancos de memória e armazenamento de instruções, para minimizar a complexidade de software e hardware e overhead de configuração.

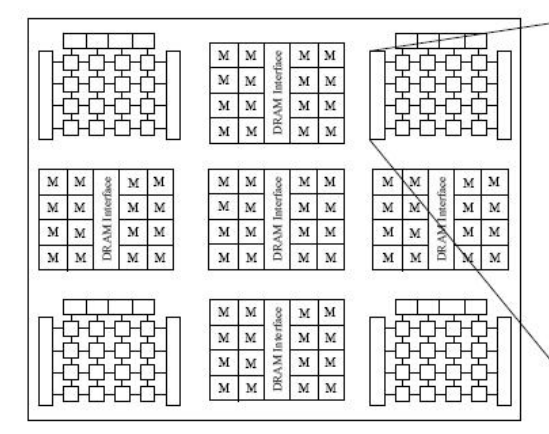

(a) TRIPS Chip

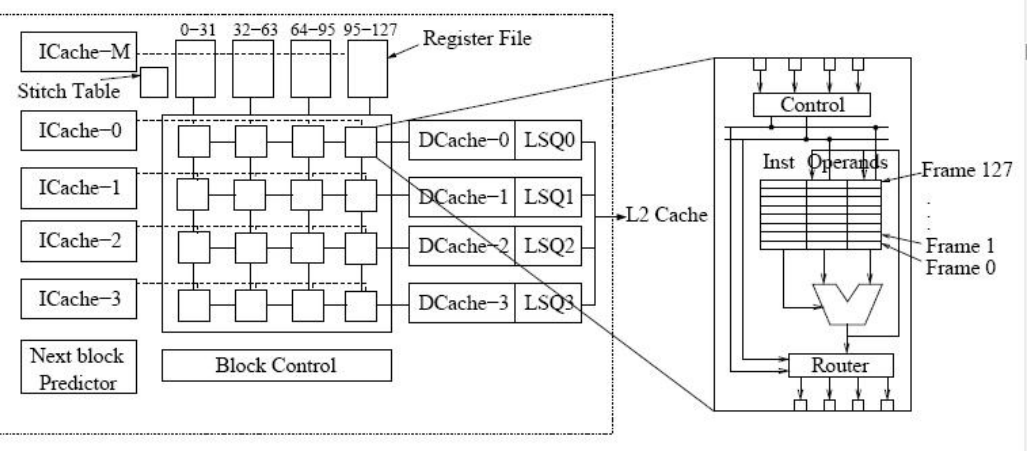

(b) TRIPS Core

(c) Execution Node

Figura 3.15: Arquitetura TRIPS.

A Figura 3.15 (a) mostra o diagrama da arquitetura TRIPS que irá ser implementada em um protótipo em chip. O protótipo consiste de quatro cores polimórficos, com dezesseis nós de execução em um arranjo de $32 \mathrm{~Kb}$ de tiles de memória conectados por uma rede de roteamento e um grupo de controladores de memória distribuídos com canais para memória externa.

A Figura 3.15 (b) mostra uma visão expandida de um core do sistema TRIPS e o sistema primário de memória. O core do sistema TRIPS é um exemplo de rede de processadores, os quais são tipicamente compostos por um arranjo nós de execução homogêneos, cada qual contém uma $U L A$ inteira, unidades de ponto flutuante, um grupo de estações de reserva e conectores de roteamento nas entradas e saídas. Cada estação de reserva tem armazenamentos para uma instrução 
e dois operandos de origem. Quando uma estação de reserva contém uma instrução válida e um par de operandos validos, o nó pode selecionar a instrução para execução. Depois da execução, o nó pode transferir o resultado para qualquer slot de operando localmente ou estações de reserva remotas dentro de arranjos da $U L A$. Os nós são diretamente conectados com seus vizinhos próximos, mas a rede de roteamento pode enviar os resultados a qualquer nó no arranjo. Detalhes sobre I-Cache, D-Cache e registradores utilizados no TRIPS pode ser visto em (Nagarajan et al., 2001; Sankaralingam et al., 2003).

A Figura 3.15 (c) mostra um nó de execução do sistema TRIPS. Cada nó de execução contém um grupo de estações de reservas. Estações de reserva com o mesmo índice atravessam todos os nós para formar um frame. Por exemplo: ao combinar-se o primeiro slot de todos os nós da rede, forma-se o frame 0. Uma coleção de frames é um recurso polimórfico no sistema TRIPS, como ele é administrado diferentemente por diferentes nós, ele suportar de forma eficiente a execução de alternadas formas de paralelismo.

A arquitetura TRIPS é fundamentalmente orientada a blocos. Em todos os nós de operações, os programas compilados para TRIPS são divididos em grandes blocos de instruções com um único ponto de entrada, nenhum laço de repetição e múltiplos pontos de saídas possíveis como encontrados nos hyperblocks.

Para todos os nós de execução, o compilador é responsável por escalonar estaticamente cada bloco de instruções em mecanismos computacionais tais que as dependências entre instruções são explicitas.

Em tempo de execução, o fluxo básico operacional do processador inclui recuperar um bloco da memória, abri-lo dentro do mecanismo computacional, executá-lo por completo, entregar seus resultados para o estado freqüente se necessário e então proceder para o próximo bloco.

Segundo (Swanson et al., 2007), apesar do alto nível de semelhanças entre waves (WaveScalar), frames (TRIPS), os projetos WaveScalar e PEs do sistema TRIPS, as duas arquiteturas são totalmente diferentes.

Devido ao uso de contador de programas para selecionar frames de instruções para execução, TRIPS deve especular agressivamente. Ao mapear um frame de instrução em um arranjo de PEs leva vários ciclos, então o processador TRIPS de forma especulativa organiza os frames nos PEs 
antes do tempo. WaveScalar por sua vez, não tem esse problema porque a execução do modelo na fluxo de dados dinâmico permite que as instruções continuem na rede para muitas execuções, livrando-se assim da necessidade de especulação (Swanson et al., 2007).

A desvantagem da abordagem WaveScalar é a necessidade de um complexo tag-matching em hardware para suportar a execução a fluxo de dados dinâmica.

Outras diferenças e semelhanças entre WaveScalar e TRIPS podem ser encontrados em (Swanson et al., 2007). 



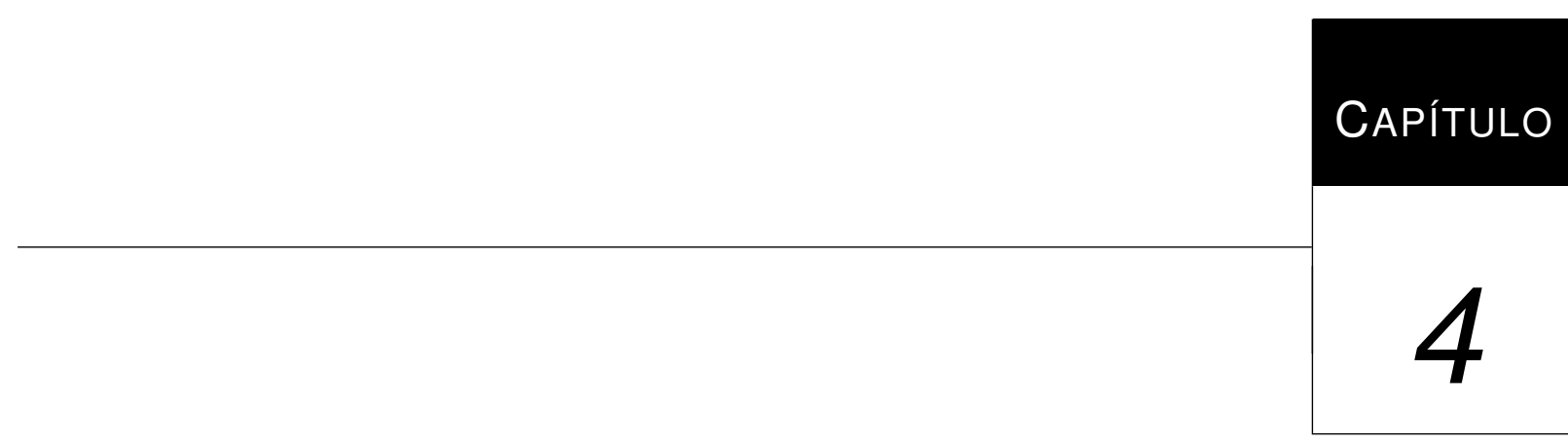

\section{Projeto ChipCflow}

O ChipCflow é o projeto de uma ferramenta para execução de algoritmos utilizando o modelo a fluxo de dados dinâmico em hardware reconfigurável. Tem como principal objetivo acelerar programas de aplicação escritos em C. Em particular, essa aceleração vai acontecer por meio da execução direta em hardware, aproveitando ao máximo o paralelismo considerado natural do modelo a fluxo de dados.

A Figura 4.1 descreve a seqüência de atividades para que uma aplicação seja utilizada na ferramenta ChipCflow.

A partir do programa de aplicação escrito originalmente na linguagem $\mathrm{C}$, se extrai os grafos a fluxo de dados tendo como referência para os operadores, uma base de grafos a fluxo de dados a ser gerada especificamente para essa ferramenta (Costa, 2008). O grafo a fluxo de dados gerado já estará otimizado. O grafo então é convertido em $V H D L$, tendo como base todo o conjunto de operadores propostos para o ChipCflow, previamente implementados em VHDL. O código VHDL é então sintetizado e simulado em ferramenta $E D A$ comercial, em particular trabalharemos com ISE da Xilinx, e o bitstream é então gerado para serem executados direto no hardware. 


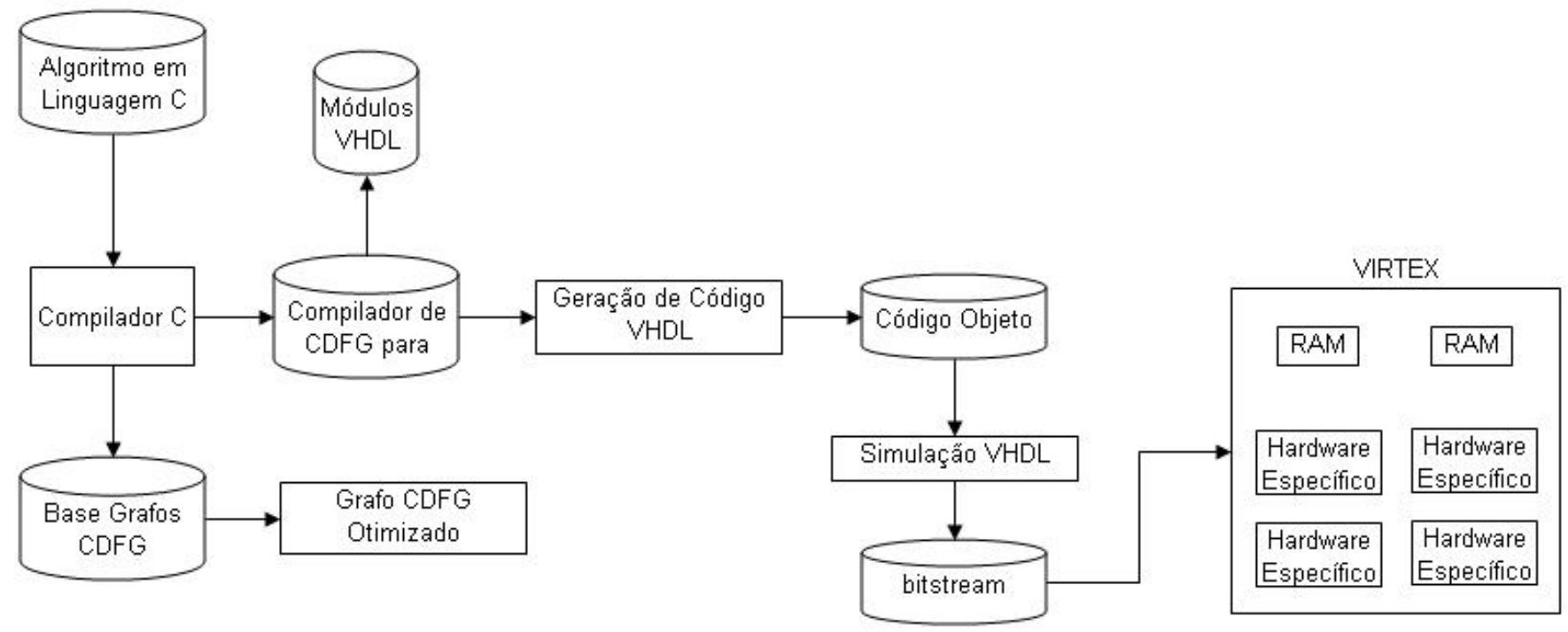

Figura 4.1: Diagrama de Fluxo da Ferramenta ChipCflow.

\subsection{Estrutura do Modelo a Fluxo de Dados}

O modelo de programação a fluxo de dados proposto aqui, segue a linha proposta por (Veen, 1986) que está baseada em uma linguagem gráfica contendo operadores e arcos interligando esses operadores.

Como a arquitetura a fluxo de dados escolhida é o modelo dinâmico, que permite a existência de mais que um dado em cada arco, a implementação do modelo é tal que novas instâncias dos operadores sejam geradas para cada dado que chegue em um arco. Assim, várias instâncias de um operador podem ser geradas, esperando por um dado parceiro.

\subsubsection{O Modelo de Instâncias}

O projeto ChipCflow é baseado em instâncias dos diferentes operadores, utilizando taggedtokens associados a cada dado, permitindo que diferentes instâncias de um mesmo operador possam ser executadas simultaneamente (Astolfi, 2007; Sanches, 2007; Junior, 2008). Cada vez que um operador receber um novo dado em um de seus arcos e o dado parceiro ainda não estiver presente, uma nova instância do operador deverá ser criada esperando a chegada do dado parceiro. Esse modelo será implementado para que dados que possuam o mesmo tagged-token façam parte da mesma instâncias de um operador. 
Na Figura 4.2 estão descritos várias instâncias de um operador "x"em um grafo a fluxo de dados dinâmico.

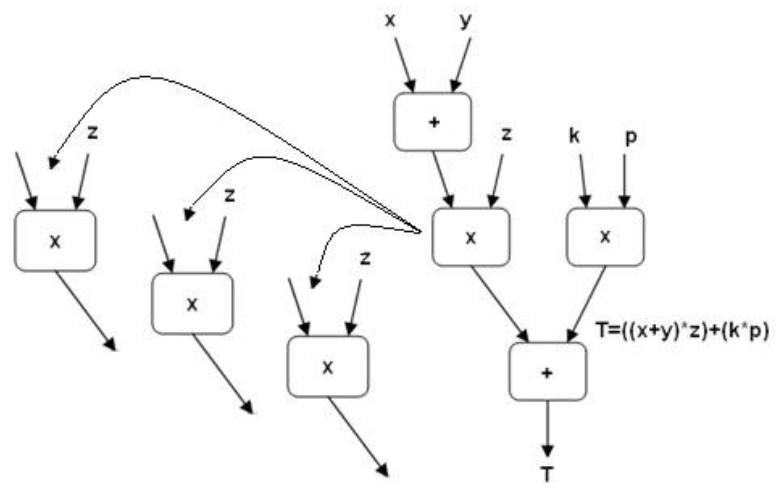

Figura 4.2: Instâncias diferentes para o operador " $x "$.

Para implementar a criação dinâmica de instâncias dos operadores em um grafo a fluxo de dados, foi necessário criar um processo para inserir e remover sub-grafos. Na Figura 4.3 é descrito um grafo $\mathrm{T}$ e um sub-grafo $\mathrm{F}$ que será inserido no grafo original $\mathrm{T}$.

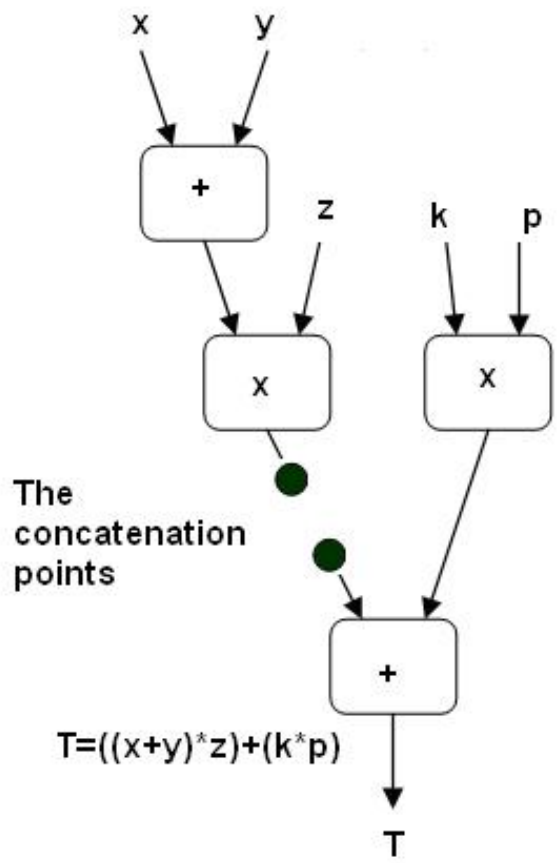

a) Graph T

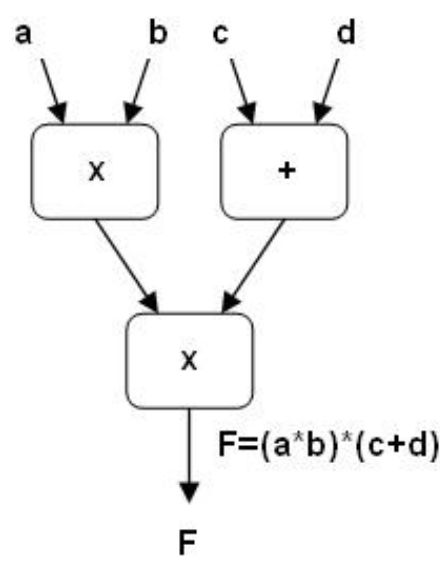

b) Sub-Graph F

Figura 4.3: Sub-grafo $\mathrm{F}$ a ser incluído no grafo original $\mathrm{T}$. 
O modelo para inserir e retirar sub-grafos foi baseado em uma estrutura de concatenação. $\mathrm{Na}$ Figura 4.3 parte (a), o grafo original $\mathrm{T}$ tem dois pontos de concatenação entre dois operadores onde o sub-grafo F parte (b) será concatenado.

Em termos de grafo, precisamos apenas ligar as linhas existentes entre os pontos do grafo $\mathrm{T}$ e os arcos do sub-grafo F, mas em termos do modelo, é necessário implementar um protocolo de comunicação que informa "se"e de "onde"um dado estará vindo e "se"e para "onde"um dado estará indo. O resultado da concatenação é descrito na Figura 4.4.

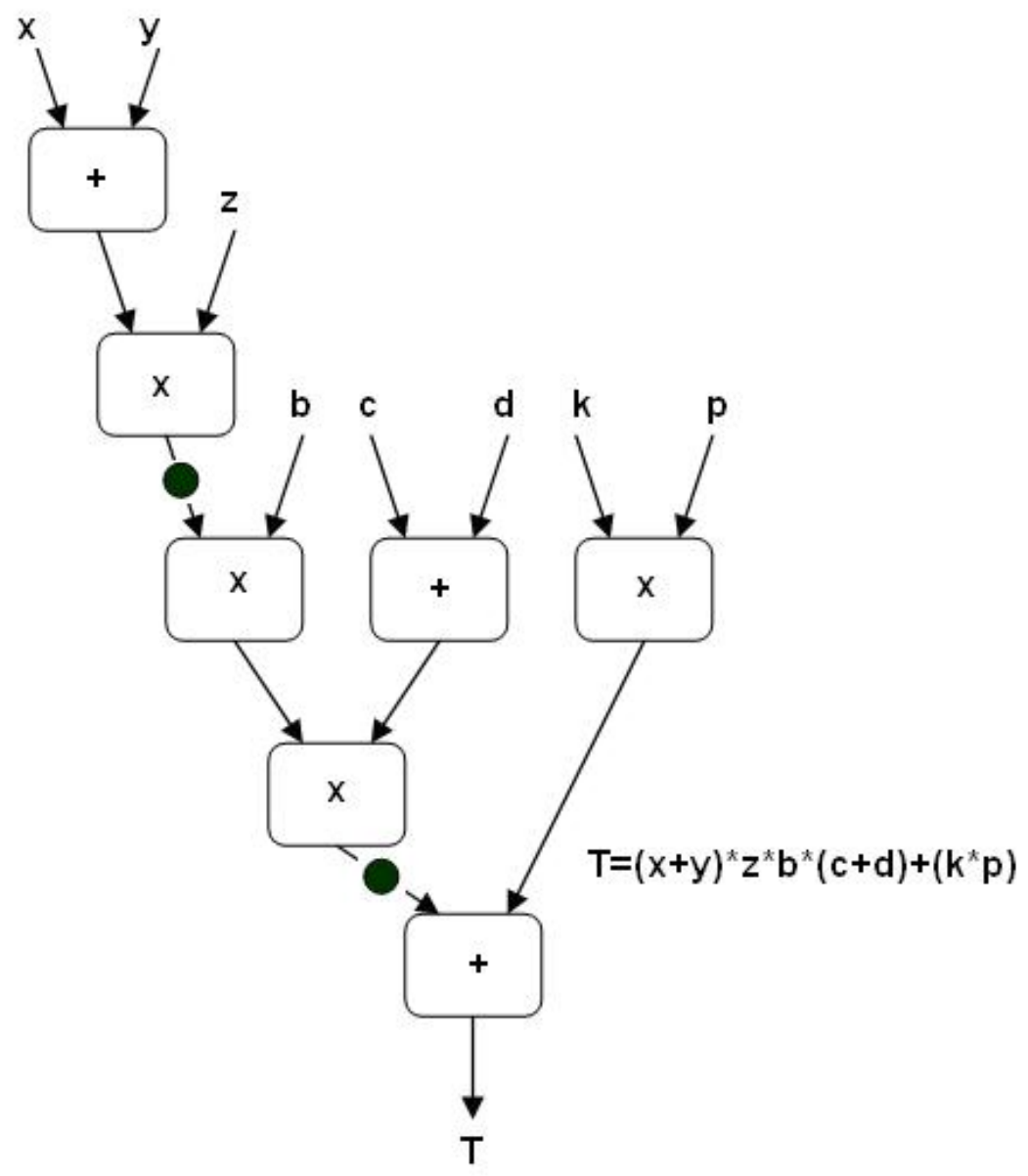

Figura 4.4: Resultado da concatenação do sub-grafo $F$ ao grafo $T$.

Para remover sub-grafos do grafo $\mathrm{T}$ conforme mostra a Figura 4.5, definimos pontos onde a concatenação deverá ocorrer e o mesmo processo acima deverá ser executado, mas agora concatenando os pontos onde o sub-grafo foi removido. O grafo resultante é mostrado na Figura 4.6. 


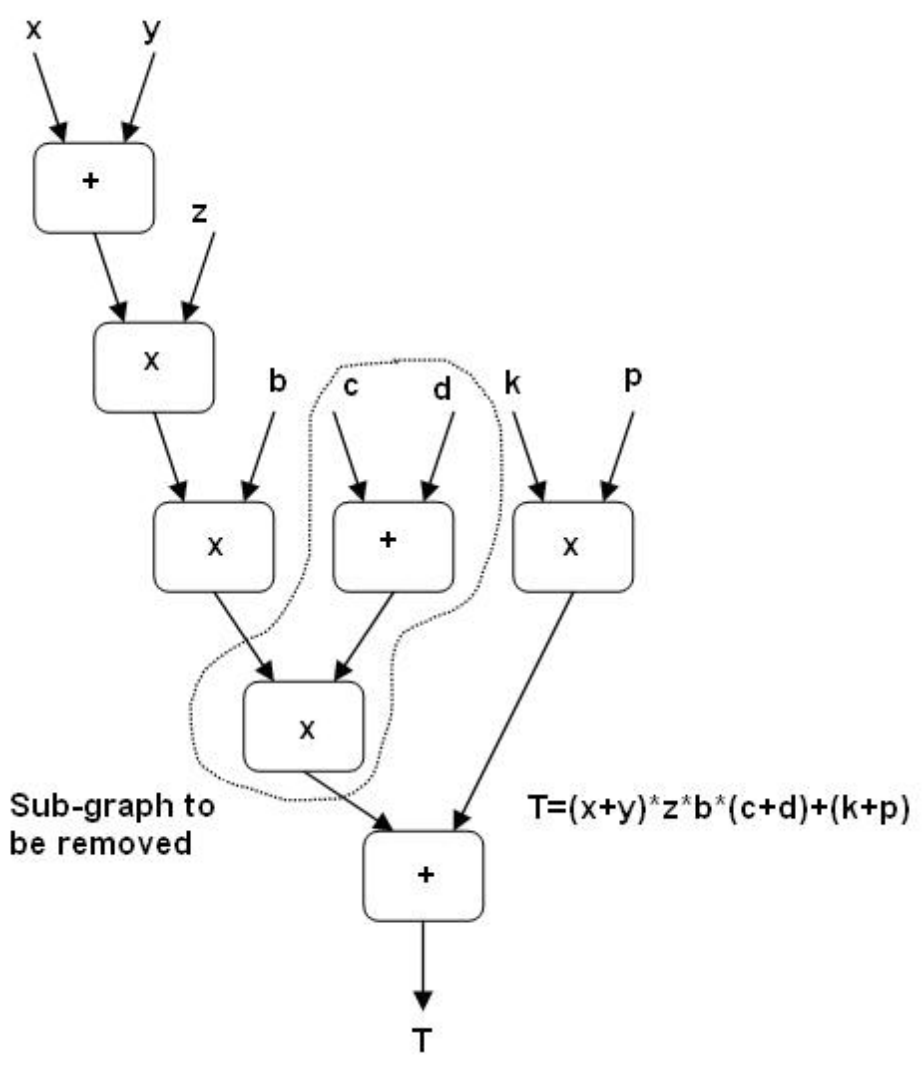

Figura 4.5: Sub-grafo a ser removido do grafo original $\mathrm{T}$.

Assim, quando for gerada uma instância de um operador, um sub-grafo é criado tendo como pontos de concatenação os mesmos pontos de entrada e saída de dados do operador. Da mesma forma, quando uma instância de um operador for disparado para execução, um dado de saída é gerado e aquela instância (sub-grafo do operador) é removida, restando apenas o operador e suas instâncias esperando por dados parceiros.

\subsubsection{Operadores utilizados no Modelo}

Os operadores a serem utilizado no modelo são: Decider, Non Deterministic Merge, Deterministic Merge, Branch, Copy e Operator, sendo esses os principais objetivos da dissertação aqui proposta, acrescidos de suas execuções em hardware através da implementação de grafos a fluxo de dados. O operadores estão descritos na Figura 4.7

Como mostra a Figura 4.8, há dois tipos de enlace sobre um grafo a fluxo de dados, um representado por linhas contínuas, que transporta dados ou estruturas de dados (data link), e outro que 


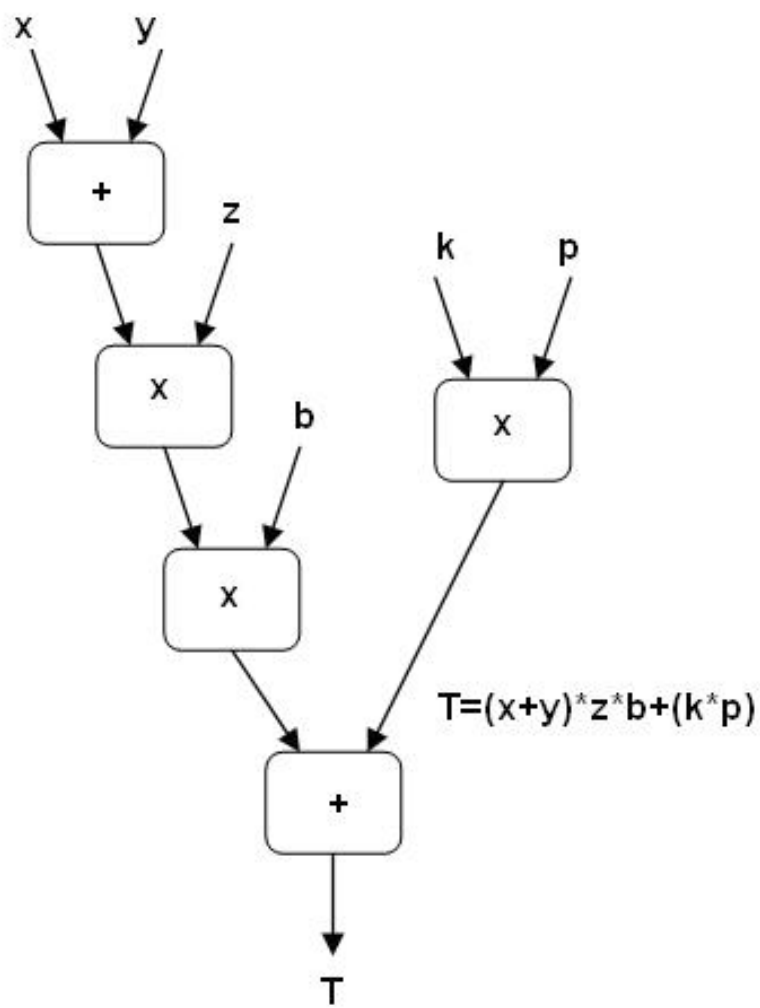

Figura 4.6: Grafo Resultante da remoção de sub-grafo.

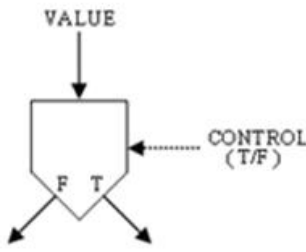

BRANCH

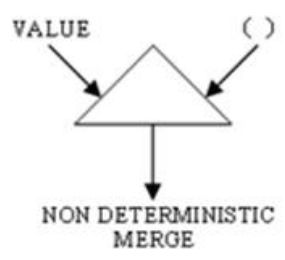

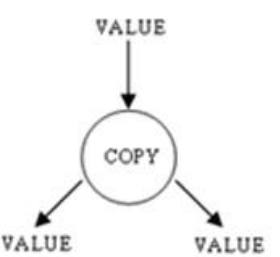

COPY

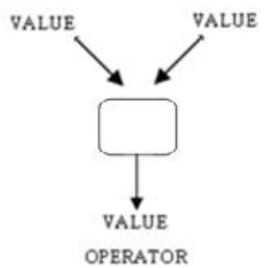

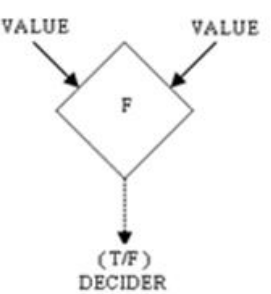

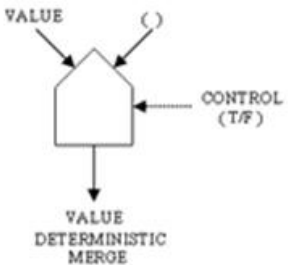

Figura 4.7: Operadores do Modelo ChipCflow.

transporta valores booleanos, que são utilizados com finalidade de controle (logical link), representado por linhas tracejadas.

Utilizando os operadores descritos na Figura 4.7 podemos construir grafos como o apresentado na Figura 4.9 que expressa alguns comando em C.

Os operadores de ramificação (branch), junção (merge) e decisão (decider), são usados para representar computações iterativas ou condicionais no grafo. O nó decider, como mostra a Figura 4.7, 


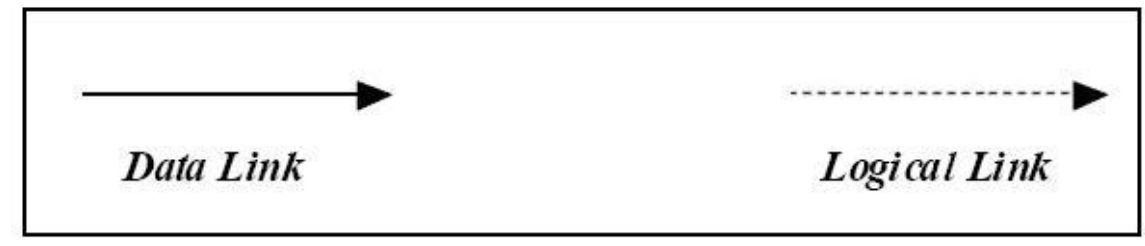

Figura 4.8: Tipos de enlace dos grafos a fluxo de dados.

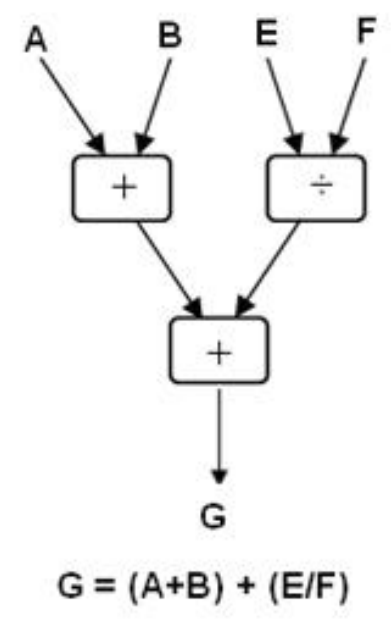

a) atribution command

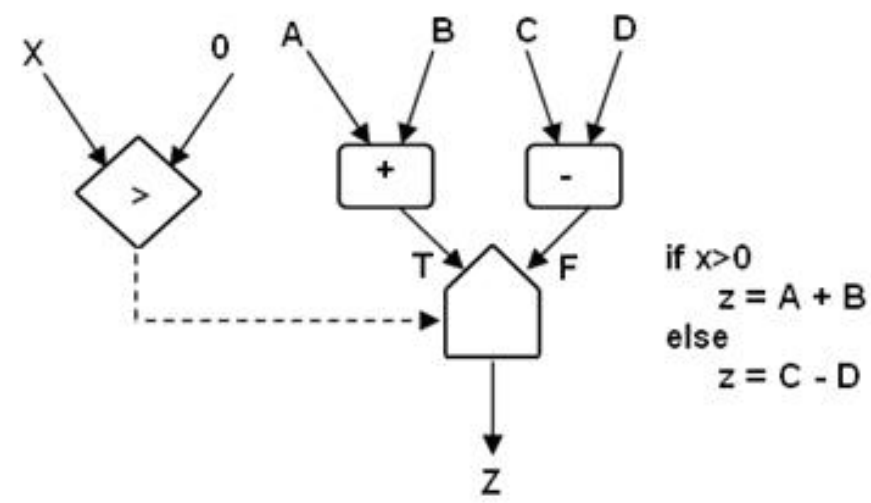

b) conditional command

Figura 4.9: Grafo representando comandos em C.

gera um pacote (ou token) de controle com valor booleano, dependendo de seus valores de entrada e da função de teste T. Em um nó de ramificação (branch), ilustrado pela Figura 4.7, uma cópia do token absorvido pela porta de entrada é colocada no arco de saída verdadeiro (T) ou falso (F), dependendo do valor booleano do token de controle.

Nos grafos a fluxo de dados, pacotes de dados podem ser dirigidos por meio dos nós de junção (merge). Em uma junção determinística (deterministic merge), um token de controle, que pode assumir valor verdadeiro ou falso, determina de qual porta de entrada um token é absorvido. Uma cópia do token absorvido é enviado para o arco de saída. O token não escolhido é descartado. Na junção não-determinística (nondeterministic merge), não existe uma regra de habilitação estrita, isto é, o nó é habilitado tão logo uma de suas portas de entrada contenha um token. Quando ele dispara, uma cópia de seu token de entrada é enviada para seu nó subseqüente. 
Como já visto, um token de dado é produzido por um operador (operator) como resultado de alguma operação aritmética ou lógica. Finalmente, copiador (copy) é um operador que duplica tokens de entrada.

\subsubsection{Construções Iterativas no Modelo}

As construções iterativas são estruturas que necessitam um sincronismo toda vez que um novo dado circula por qualquer uma dessas construções. Para isso foram definidos tags que serão utilizados para sincronizar os dados do grafo. O formato dos tags proposto no projeto ChipCflow está descrito na Figura 4.10.

\begin{tabular}{|l|c|c|c|}
\multicolumn{1}{c}{4 bits } & \multicolumn{2}{c}{4 bits } & \multicolumn{2}{c}{3 bits } & 32 bits \\
\hline Activation & Nesting & Iteraction & DATA \\
\hline
\end{tabular}

Figura 4.10: Formato dos dados contendo Tags.

Para cada dado sendo executado em um programa, função ou procedimento, é gerado um tag, representando uma ativação (campo activation na Figura 4.10). No caso de existirem loops implementados com operações iterativas (while, repeat e for), a entrada em cada uma dessas operações irá alterar o tag (campo iteration da Figura 4.10), especificando nova iteração.

Como as operações iterativas podem ser aninhadas, é necessário que o tag contenha também o nível de aninhamento (campo nesting na Figura 4.10).

Finalmente, ao final de cada programa, função ou procedimento, o tag será modificado informando que aquela ativação terminou.

Os operadores específicos para o controle dos construtores iterativos são: new tag manager (NTM); new iteration generation (NIG) e new tag destructors (NTD).

O operador NTM é responsável pela alocação de um novo tag. O operador NIG modifica o tag gerando um novo valor para o campo iteration. O operador NTD modifica os tags no campo activation, quando esse deixa um programa, função ou procedimento.

O exemplo de um programa utilizando construções iterativas é descrito na Figura 4.11. 


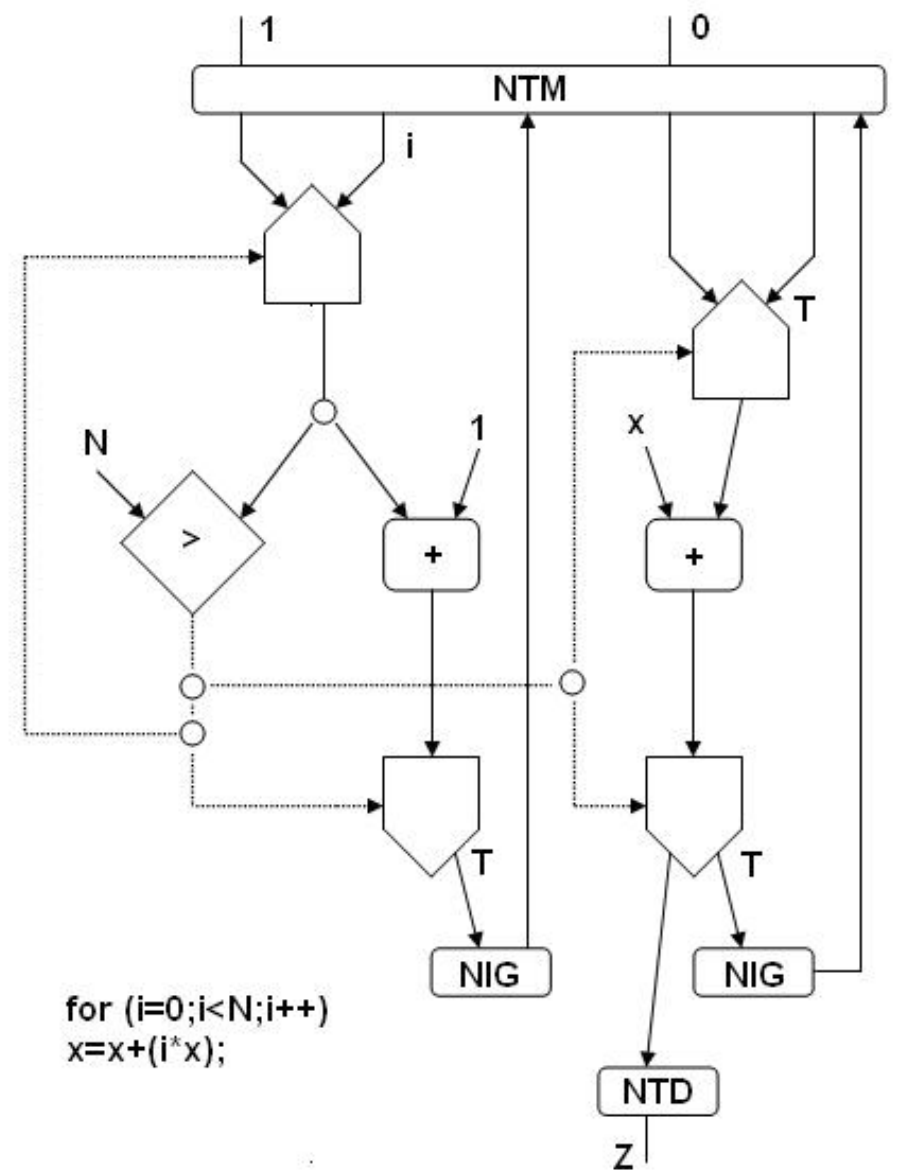

Figura 4.11: Exemplo de um programa com construtores iterativos.

\subsection{Estrutura "Matching"de Dados}

Como muitas instâncias de um mesmo operador podem existir ao mesmo tempo, foi necessário desenvolver um sistema que permitisse um processo de matching de dados de forma rápida com o objetivo de disparar a execução das instâncias cujos dados são parceiros (Lopes, 2008).

Como a identificação de dados parceiros dependem das informações contidas nas tags, um circuito de matching foi inserido em cada instância de um operador e a busca é feita simultaneamente em cada uma delas. Se uma instância possui um dado com o mesmo tag, esse novo dado será inserido naquela instância e se a mesma já possuir todos os dados para execução, ela então é executada e seus dados são retirados daquela instância. Caso contrário, se não houver nenhuma instância com aquele dado, uma nova instância será ocupado com esse dado e ficará aguardando a chegada de dados parceiros. 
Quando um dado é encontrado em alguma das instâncias, uma variável é "setada"indicando que existe uma instância com dado parceiro e portanto não será necessária utilizar uma nova instância para aquele dado. Caso contrário, se não ocorrer o matching daquele dado, essa mesma variável será "resetada", informando que uma nova instância deve ser utilizada. O circuito Matching é descrito na Figura 4.12.

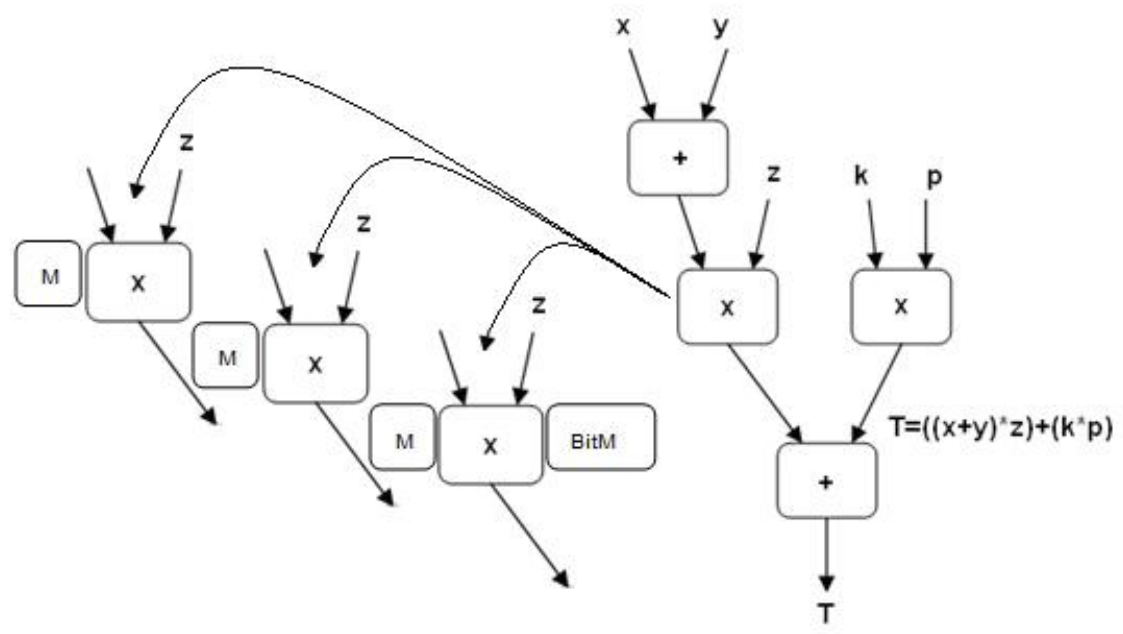

Figura 4.12: Instâncias com circuito de matching e variável comum.

Na Figura 4.12, " $M$ " representa o circuito de matching para cada instância, e a variável "BitM" é a variável que informa se ocorreu ou não o matching dos dados parceiros. 


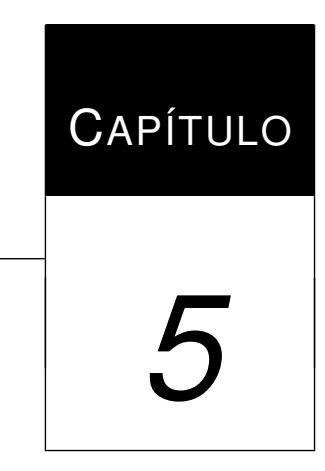

\section{Implementação e Resultados}

Neste capítulo o objetivo foi descrever os principais aspectos de implementação dos operadores propostos pelo projeto ChipCflow, bem como suas execuções em hardware. Para a execução em hardware dos operadores implementados por este trabalho de mestrado, serão construídos manualmente grafos a fluxo de dados estáticos e implementados na ferramenta ISE 8.2i da Xilinx para em seguida serem executados em um dispositivo FPGA.

\subsection{Operadores do modelo a Fluxo de Dados}

Os operadores implementados neste projeto foram os propostos no Capítulo 4.1.2. Estes foram implementados por meio de máquina finita de estados (MFS) e em seguida convertidos para a linguagem $V H D L$.

O estado inicial para cada operador, é responsável em receber os dados de entrada do operador. Uma vez que todos os dados estejam presentes nas entradas de um operador, a MFS faz com que 
o operador seja executado. Depois disso, a MFS é responsável por enviar os dados resultantes da execução do operador. Os dados que circulam pelos operadores são dados com 16 bits.

Todos operadores possuem sinais de strobe (str) associados aos sinais de saída de dados. Eles indicam que os sinais de saída de dados de um determinado operador estão disponíveis para serem consumidos pelo operador de destino em seus sinais de entrada de dados. Os operadores também possuem sinais de reconhecimento (ack) associados ao sinais de entrada de dados, cuja função é confirmar o recebimento de um dado ao operador que o produziu. Todos operadores possuem um sinal de clock. Cabe observar que este clock é utilizado somente para sincronismo interno do operador, mas do ponto de vista macro, os operadores se comunicam de forma assíncrona, pois trocam dados por protocolo de comunicação descrito acima.

O operador Branch possui um arco de entrada e dois arcos de saída. O dado contido no arco de entrada é copiado para o arco de saída verdadeiro (T) ou falso (F), dependendo do valor booleano contido no sinal de controle. O bloco esquemático do operador Branch e sua respectiva representação gráfica são apresentados na Figura 5.1.

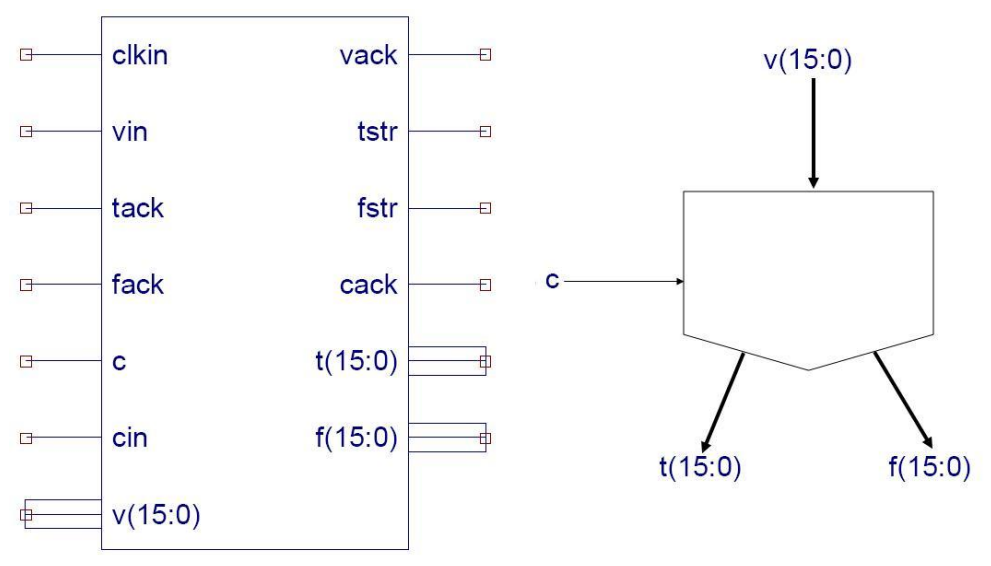

Figura 5.1: Bloco esquemático do operador Branch e sua representação gráfica.

Os sinais $v$, vin, $c$, cin, fack, tack, clkin são sinais de entrada e os sinais $t, f$, cack, $f s t r, t s t r$ e vack são sinais de saída. O sinal v é o sinal de entrada de dados; vin e vack são os sinais de strobe e de reconhecimento para o sinal de entrada $v$. O sinal $c$ é o sinal de controle do operador; cin e cack são os sinais de strobe e reconhecimento para o sinal de controle. Os sinais $t$ e $f$ são os sinais de saída de dados do operador; tstr e fstr são sinais de strobe para as saídas de dados $t$ e $f$; tack e fack são os sinais de reconhecimento dos sinais de saída de dados. A Figura 5.2 apresenta o diagrama de estados do operador Branch. 


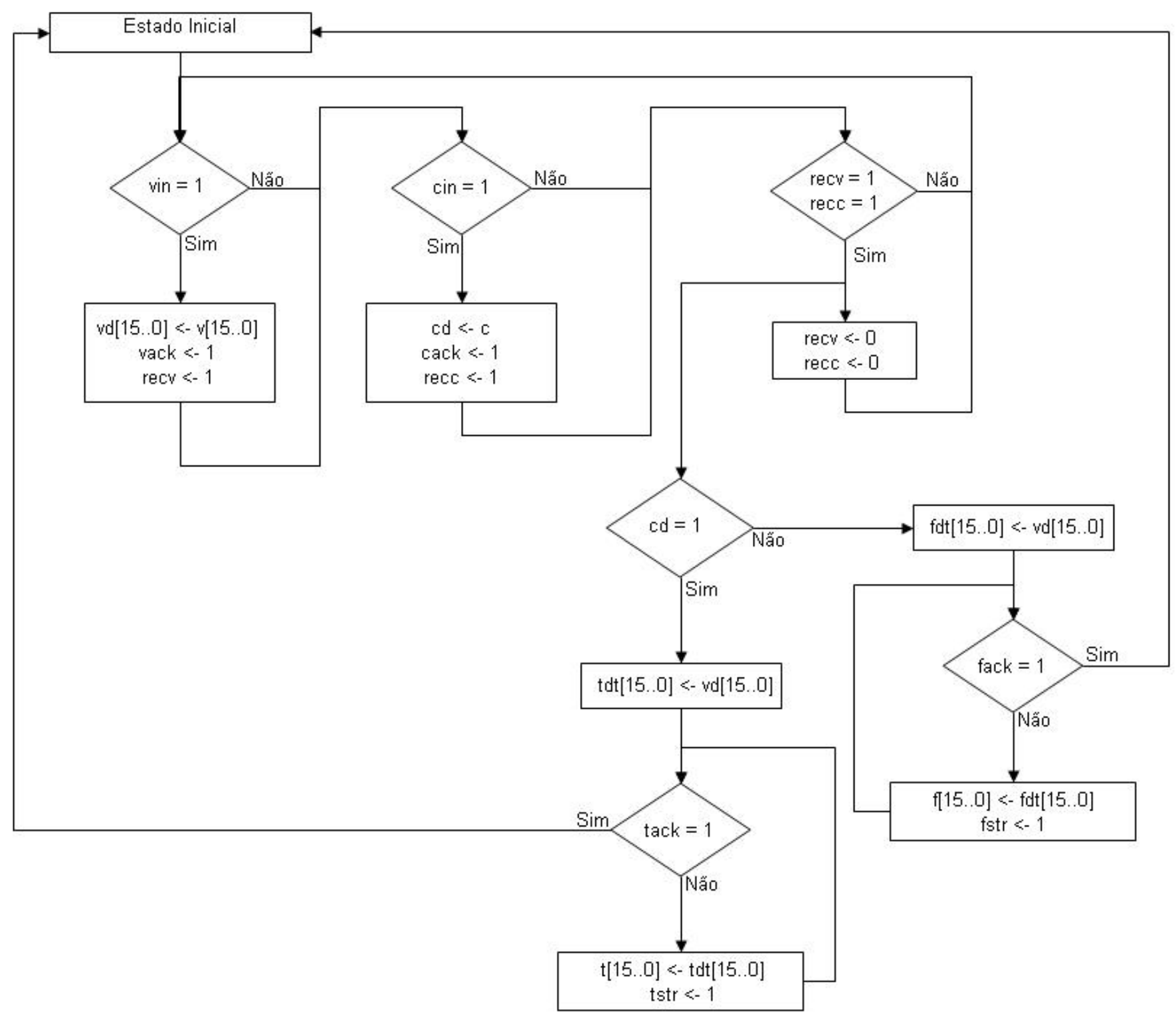

Figura 5.2: ASM chart do operador Branch.

O operador Copy simplesmente copia o dado contido no seu arco de entrada para os seus dois arcos de saída. O bloco esquemático do operador Copy e sua respectiva representação gráfica são apresentados na Figura 5.3.

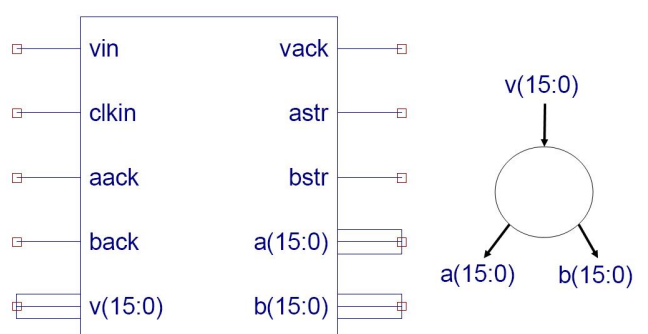

Figura 5.3: Bloco esquemático do operador Copy e sua representação gráfica. 
Os sinais $v$, back, aack, clkin, vin são sinais de entrada, já os sinais $a, b, a s t r, b s t r$, vack são de saída. O sinal vé o sinal de entrada de dados; vin e vack são os sinais de strobe e de reconhecimento para o sinal de entrada de dados $v$. Os sinais $a$ e $b$ são os sinais de saída de dados do operador; astr e bstr são os sinais de strobe para os sinais de saídas de dados; aack e back são os sinais de reconhecimento para os sinais de saída de dados do operador. A Figura 5.4 apresenta o diagrama de estados do operador Copy

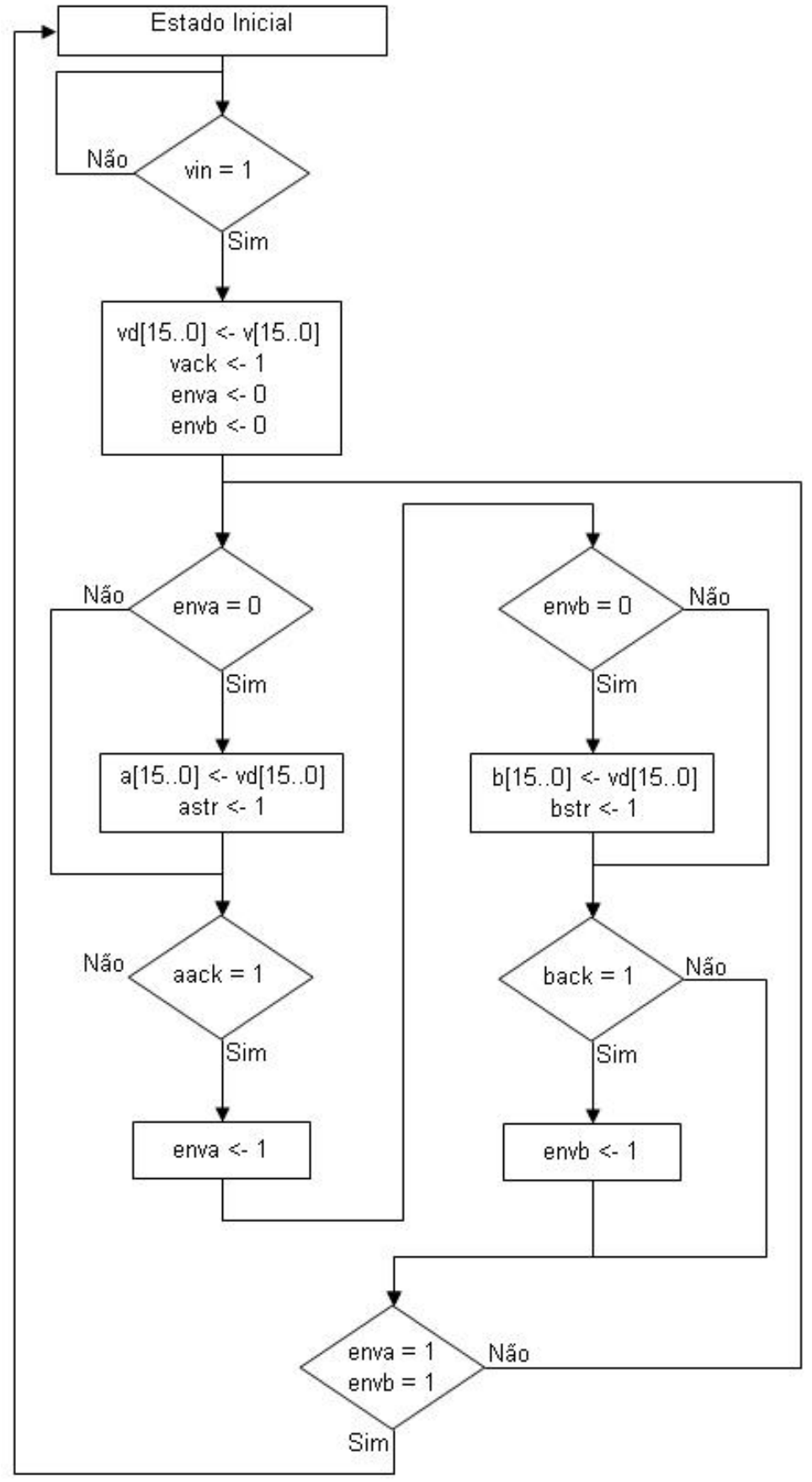

Figura 5.4: ASM chart do operador Copy. 
O operador Decider aplica uma operação lógica no dado de entrada e gera um dado como resultado contendo um valor booleano. O bloco esquemático do operador Decider e sua respectiva representação gráfica são apresentados na Figura 5.5.

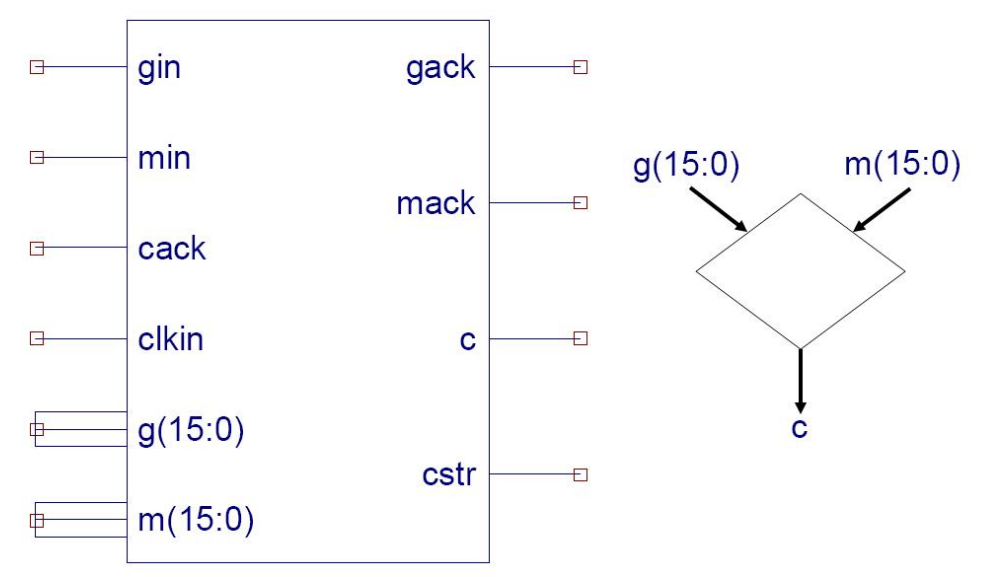

Figura 5.5: Bloco esquemático do operador Decider e sua representação gráfica.

Os sinais $m, g$, clkin, cack, min, gin são sinais de entrada do operador e os sinais gack, mack, $c$, cstr são sinais de saída. Os sinais $m$ e $g$ são os sinais de entrada de dados; min e gin são os sinais de strobe para os sinais de entrada de dados; mack e gack são os sinais de reconhecimento para os sinais de entrada de dados. O sinal de saída de dados $c$ contém o resultado de uma decisão lógica aplicado aos dados contidos nos sinais de entrada; cstr e cack são os sinais de strobe e reconhecimento para o sinal de saída de dados. A Figura 5.6 apresenta o diagrama de estados do operador Decider.

O operador Non Deterministic Merge não possui uma regra de habilitação específica, isto é, nem todos os seus arcos de entrada precisam conter um dado para que o operador possa executar, ele simplesmente copia o dado que recebeu em um dos seus arcos de entrada para o seu arco de saída. A Figura 5.7 apresenta o bloco esquemático do operador Non Deterministic Merge e sua respectiva representação gráfica.

Os sinais $a, b$, ain, bin, vack, clkin são sinais de entrada e os sinais v, vstr, aack, back são sinais de saída. Os sinais $a$ e $b$ são os sinais de entrada de dados; ain e bin são os sinais de strobe para os sinais de entrada de dados; aack e back são os sinais de reconhecimento para os sinais de entradas de dados. O sinal de sáida de dados $v$ contém o dado de umas das entradas $a$ ou $b$; vstr e vack 


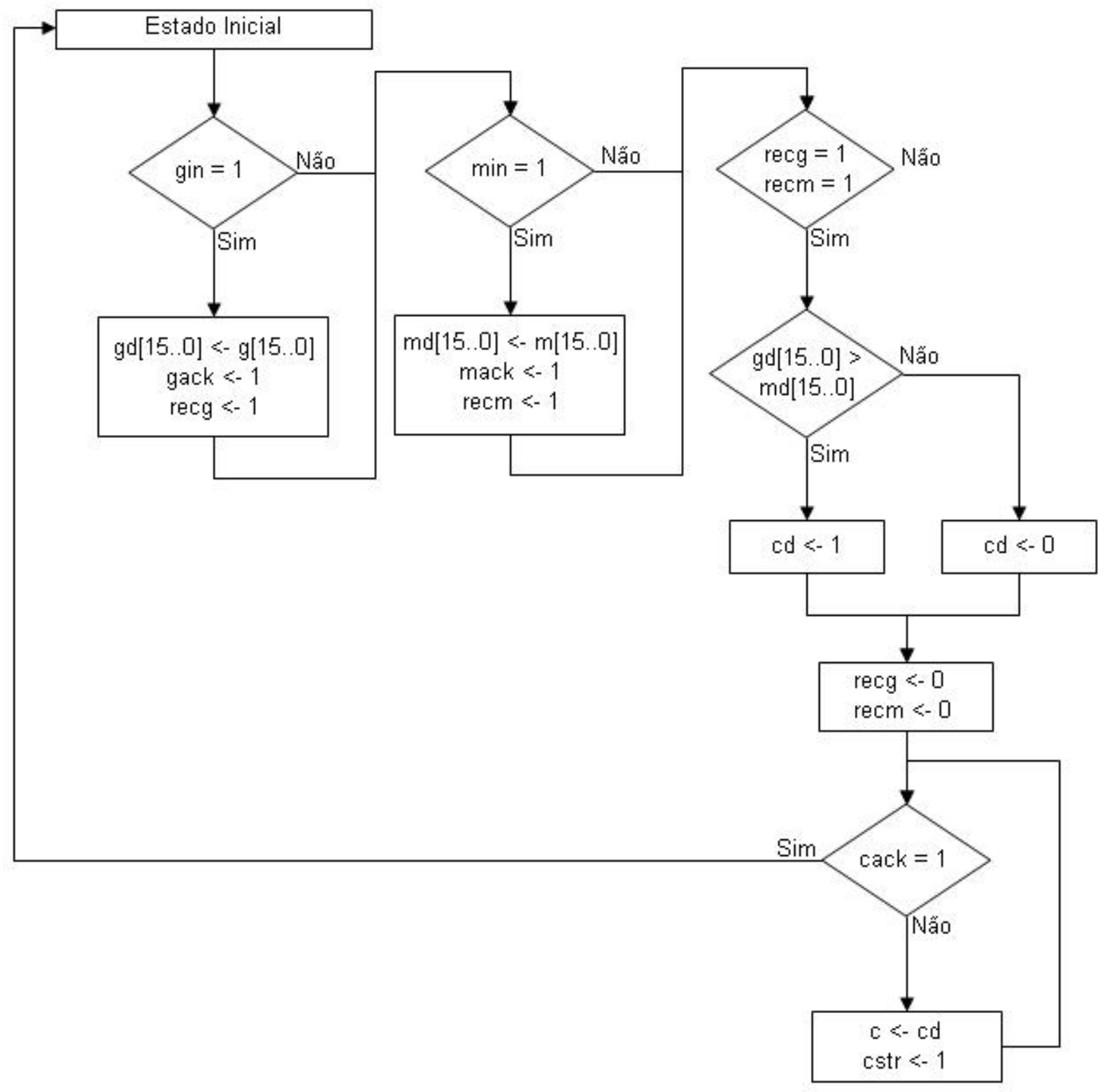

Figura 5.6: ASM chart do operador Decider.

são os sinais de strobe e reconhecimento para o sinal de saída de dados. A Figura 5.8 apresenta o diagrama de estados do operador Non Deterministic Merge.

Como a implementação das operações aritméticas realidas pelo operador Operator são similares, somente o operador $O P A D D$ que realiza a operação aritmética soma será descrito com maiores detalhes. O bloco esquemático do operador Operator responsável pela operação soma e sua representação gráfica são apresentados na Figura 5.9.

Os sinais $a, b, a s t r, b s t r, z a c k$, clkin são sinais de entrada e os sinais $z$, zstr, aack e back são sinais de saída. Os sinais $a$ e $b$ são sinais de entrada de dados; astr e bstr são os sinais de strobe 


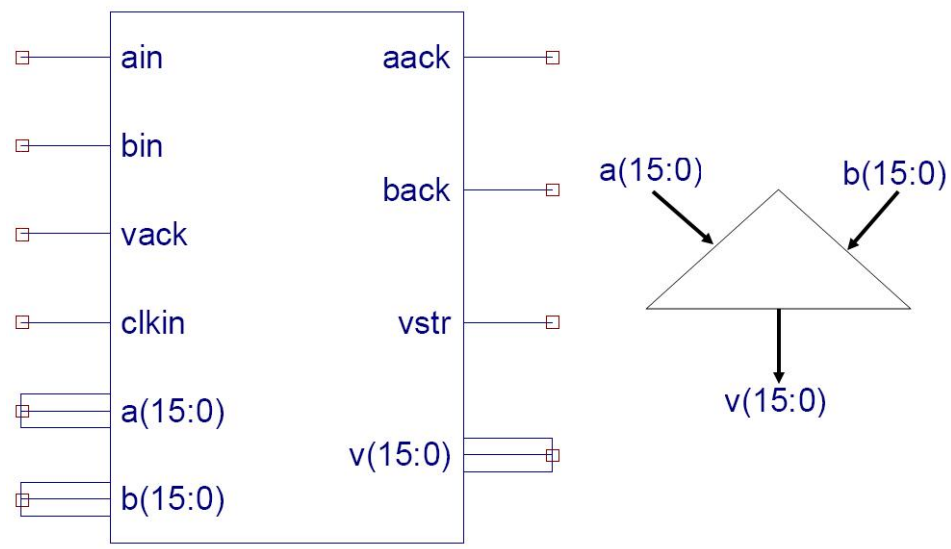

Figura 5.7: Bloco esquemático do operador Non Deterministic Merge e sua representação gráfica.

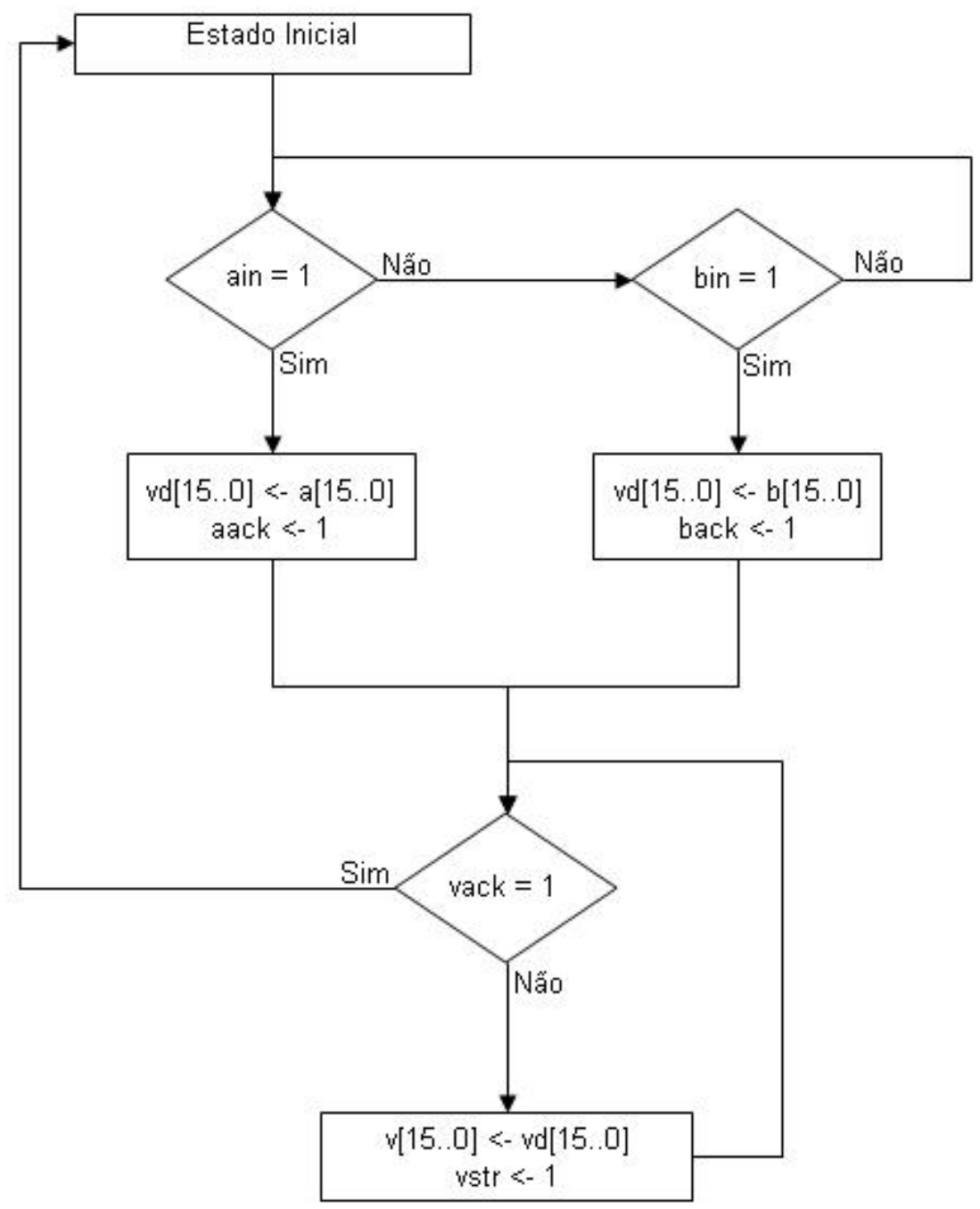

Figura 5.8: ASM chart do operador Non Deterministic Merge.

para os sinais de entradas $a$ e $b$ respectivamente; aack e back são os sinais de reconhecimento para os sinais de entrada. O sinal de saída de dados do operador $z$ contém a soma dos dados contidos 


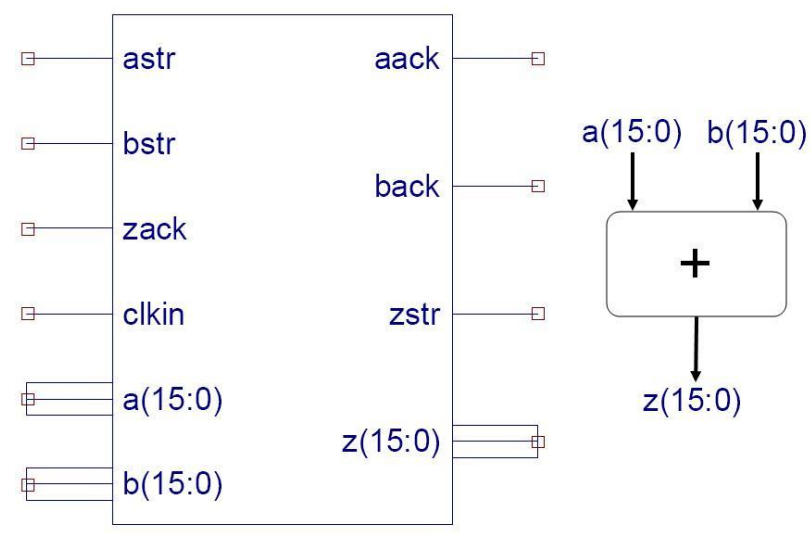

Figura 5.9: Bloco esquemático do operador Operator responsável pela operação soma e sua representação gráfica.

nos sinais de entrada $a$ e $b$; zstr e zack são sinais de strobe e reconhecimento para o sinal de saída de dados. A Figura 5.10 apresenta o diagrama de estados do operador Operator responsável pela operação soma.

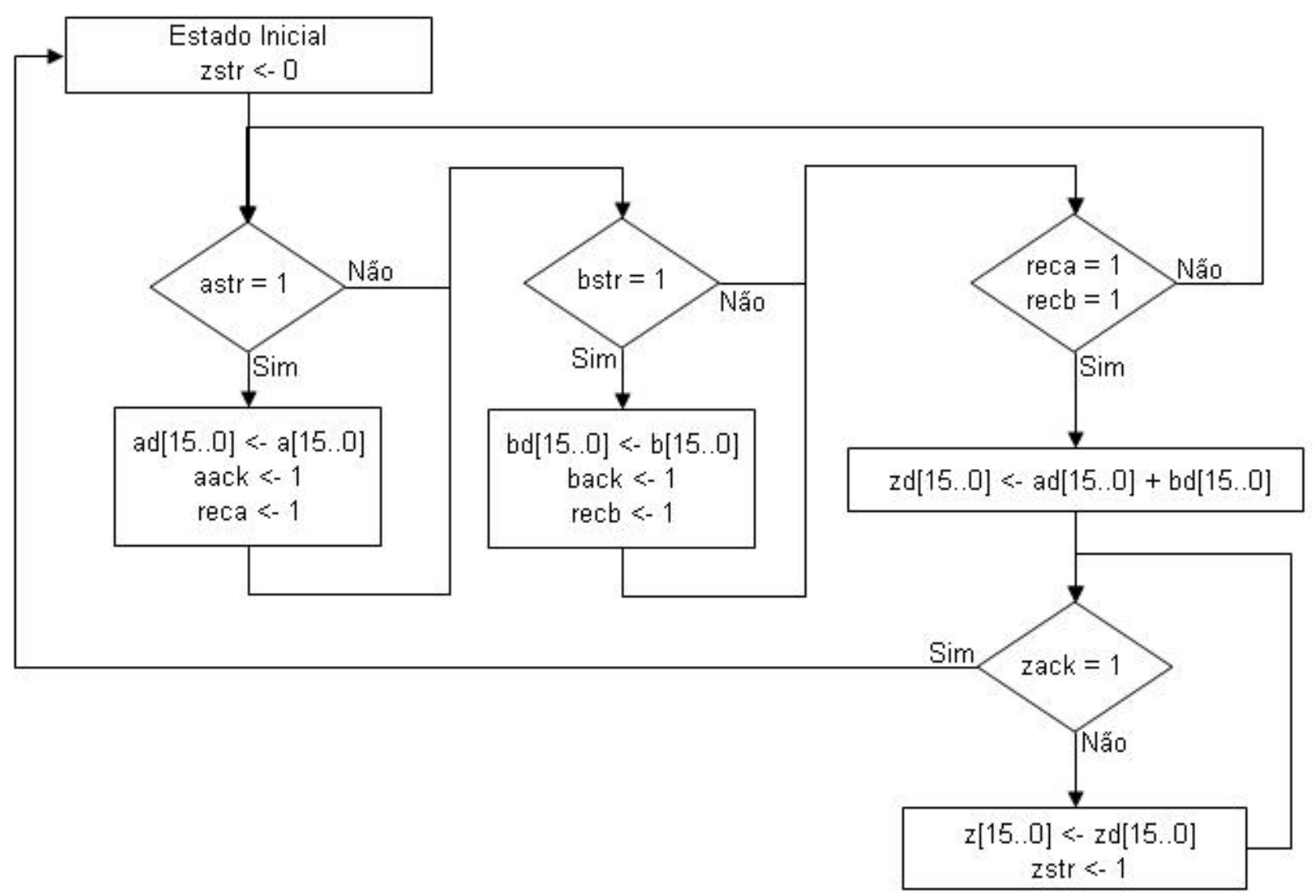

Figura 5.10: ASM chart do operador Operator responsável pela operação soma.

O operador Deteministic Merge precisa que todos os dados de entrada estejam disponívies para que ele possa executar, quando isso acontece um dos dados de entrada é copiado para o arco de 
saída de acordo com o valor booleano contido no sinal de controle. O bloco esquemático do operador Deterministic Merge e sua respectiva representação gráfica são apresentados na Figura 5.11.

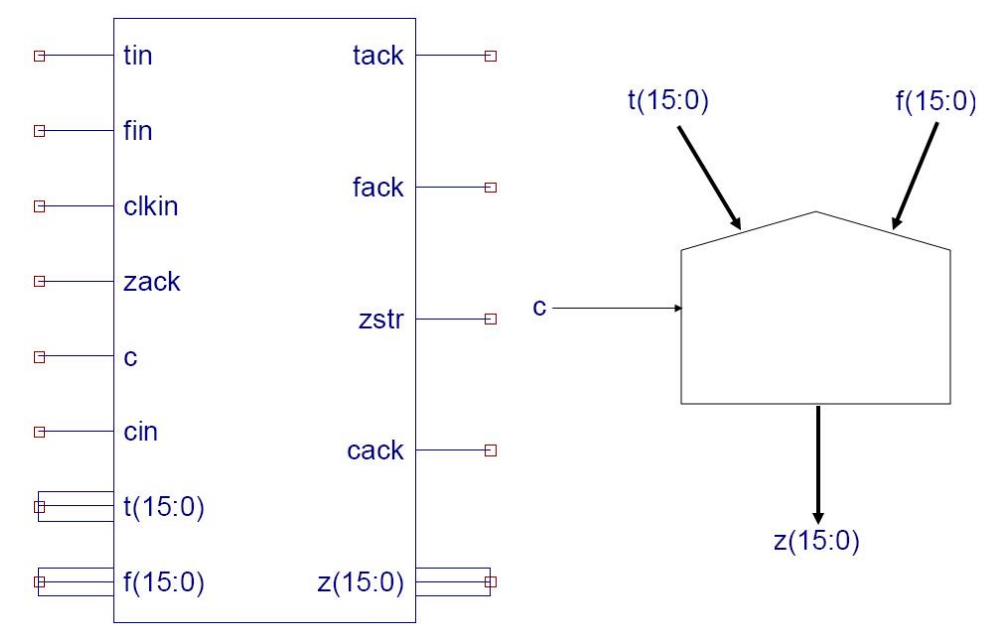

Figura 5.11: Bloco esquemático do operador Deterministic Merge e sua representação gráfica.

Os sinais $t, f$, tin, fin, $c$, cin, zack, clkin são sinais de entrada e os sinais $z$, zstr, tack, fack e cack são sinais de saída. Os sinais $t, f$ são os sinais de entradas de dados; tin e fin são os sinais de strobe para os sinais de entrada de dados; tack e fack são os sinais de reconhecimento para os sinais de entrada de dados. O sinal c é o sinal de controle do operador; cin e cack são os sinais de strobe e reconhecimento para o sinal de controle. O sinal de saída de dados $z$ contém um dos dados contidos nos sinais de entrada $t$ ou $f$ de acordo com o sinal de controle $c$; zstr e zack são os sinais de strobe e reconhecimento para o sinal de saída de dados $z$. A Figura 5.12 apresenta o diagrama de estados do operador Deterministic Merge.

\subsection{Implementação de Grafos a Fluxo de Dados}

Para a validação dos operadores implementados, eles foram executados em hardware. Para isso foram construídos manualmente grafos a fluxo de dados. Estes foram implementados utilizando a ferramenta ISE 8.2i da Xilinx. As simulações dos grafos a fluxo de dados foram realizadas utilizando o ISE Simulator da Xilinx.

Para implementar os grafos os grafos a fluxo de dados percebeu-se a necessidade de criar operadores extras, sendo eles INDATA, AOUT e ITMAN. 


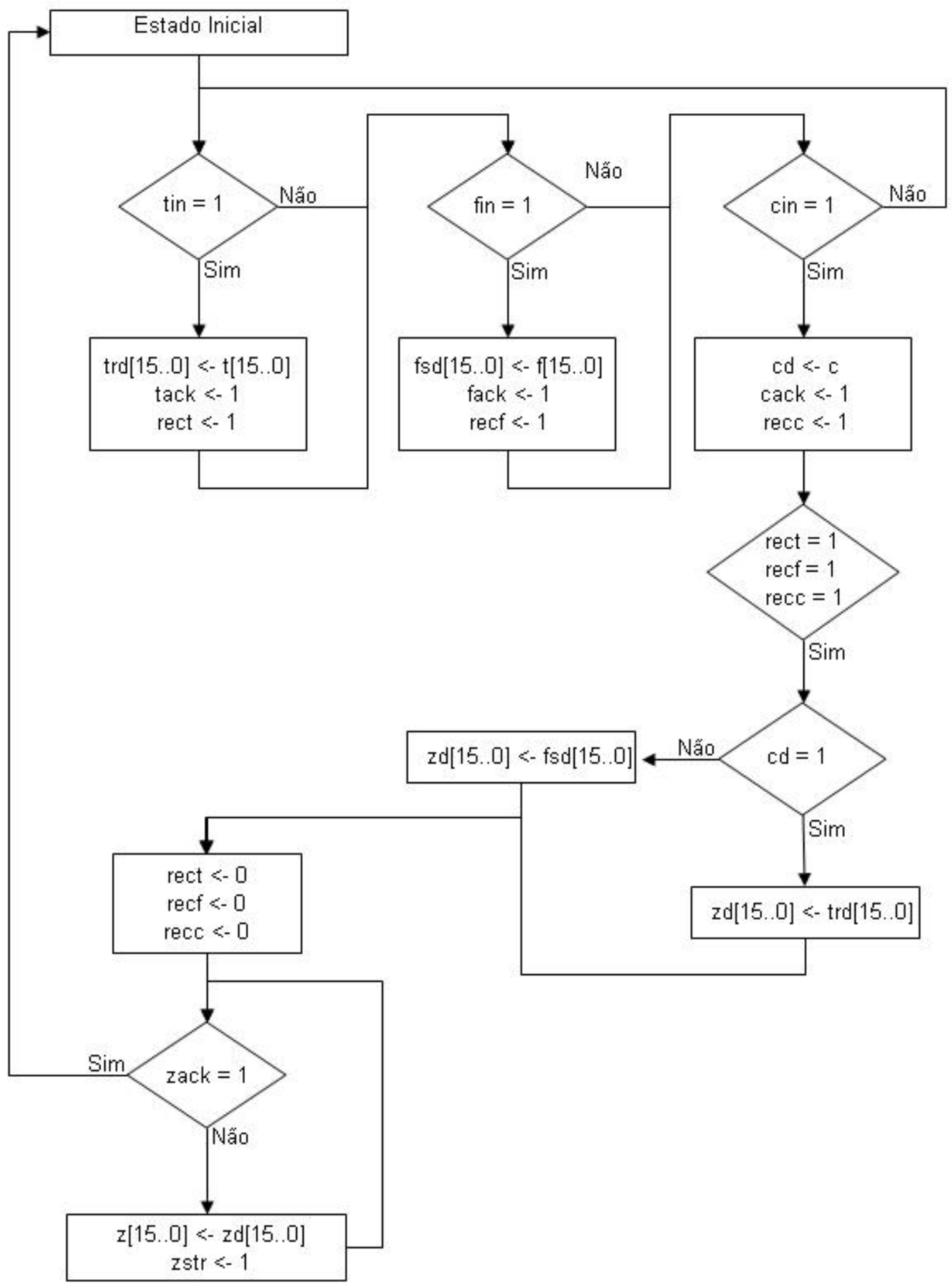

Figura 5.12: ASM chart do operador Deterministic Merge.

O operador INDATA é responsável em sincronizar os dados inseridos dentro do grafo. O bloco esquemático do operador INDATA é apresentado na Figura 5.13.

Os sinais $a$, aack, ain e clkin são os sinais de entrada e os sinais aout e astr são os sinais de saída. O sinal $a$ é o sinal de entrada de dados; ain é o sinal de strobe para o sinal de entrada de 


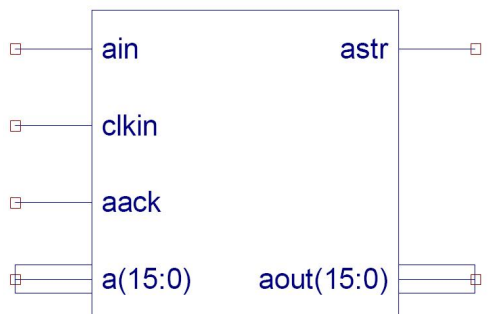

Figura 5.13: Bloco esquemático do operador INDATA.

dados. O sinal aout é o sinal de saída de dados; astr e aack são os sinais de strobe e reconhecimento para o sinal de saída de dados. A Figura 5.14 apresenta o diagrama de estados do operador INDATA.

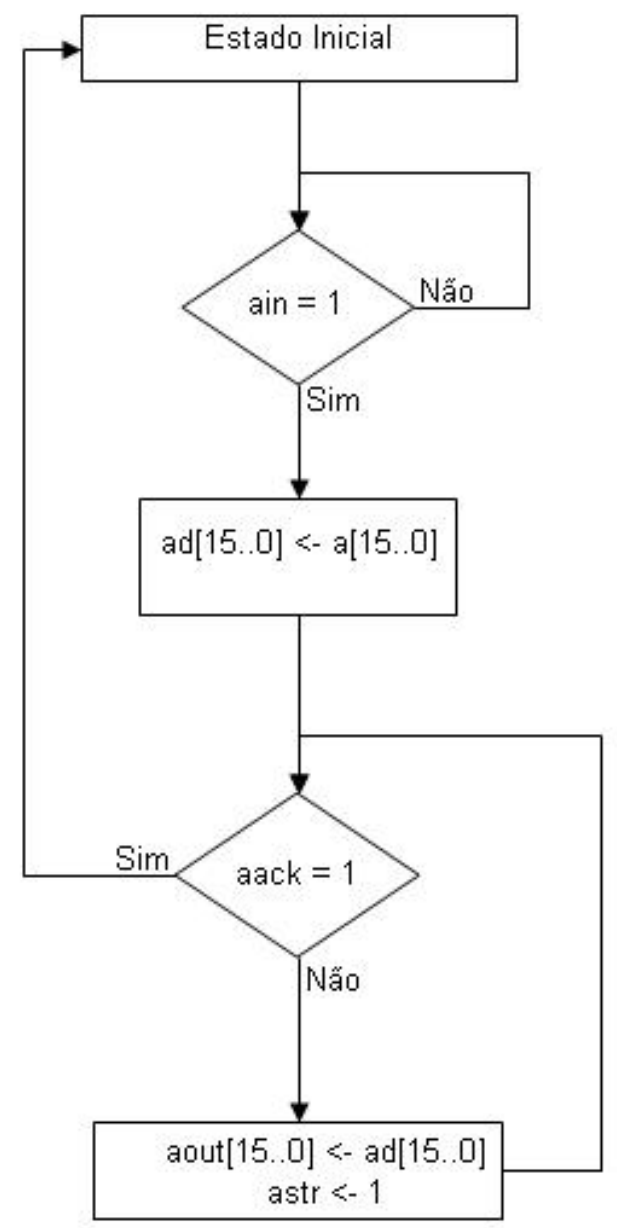

Figura 5.14: ASM chart do operador INDATA.

Similarmente ao operador INDATA, o operador AOUT é responsável em sincronizar os dados de saída do grafo. O bloco esquemático do operador AOUT é apresentado na Figura 5.15.

Os sinais $a$, astr e clkin são os sinais de entrada e os sinais $z$, zstr e aack são os sinais de saída. O sinal $a$ é o sinal de entrada de dados; astr e aack são respectivamente os sinais de strobe 


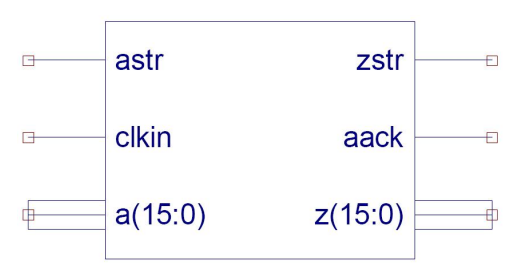

Figura 5.15: Bloco esquemático do operador AOUT.

e reconhecimento para o sinal de entrada de dados. O sinal z é o sinal de saída de dados; zstr é o sinal de strobe para o sinal de saída de dados. A Figura 5.16 apresenta o diagrama de estados do operador AOUT.

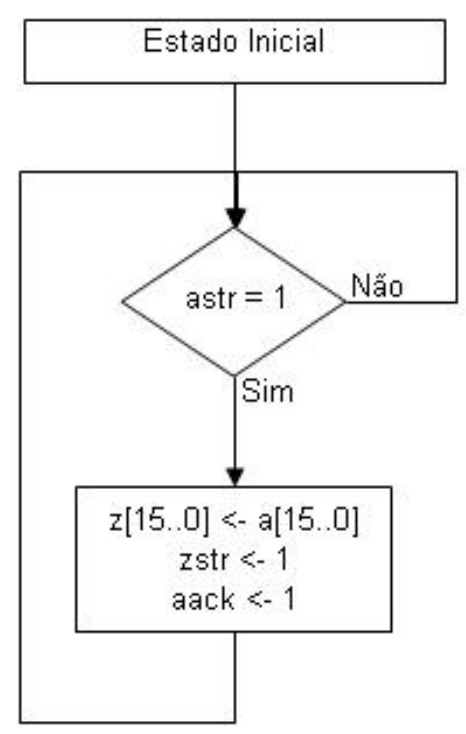

Figura 5.16: ASM chart do operador AOUT.

No caso de grafos que utilizam loops, o operador ITMAN é inserido para garantir que o operador Merge Deterministic possua todos os dados de entrada necessários para a primeira execução. O bloco esquemático do operador ITMAN é apresentado na Figura 5.17.

Os sinais $v 1, v 2, v 1$ in, v2in, intsgnack, aack, back e clkin são os sinais de entrada de dados e os sinais $a, b$, astr, bstr, vlack, v2ack, intsgnstr e intsgn são os sinais de saída. Os sinais v1 e $v 2$ são os sinais de entrada de dados; vlin e $v 2$ in são os sinais de strobe para os sinais de entrada de dados; vlack e v2ack são os sinais de reconhecimento para o sinal de entrada de dados. Os sinais $a$ e $b$ são os sinais de saída de dados; astr e bstr são os sinais de strobe para o sinal de saída de dados; aack e back são os sinais de reconhecimento para os sinais de saída de dados. O sinal intsgn é o sinal de controle do operador; intsgnstr e intsgnack são respectivamente os sinais de 


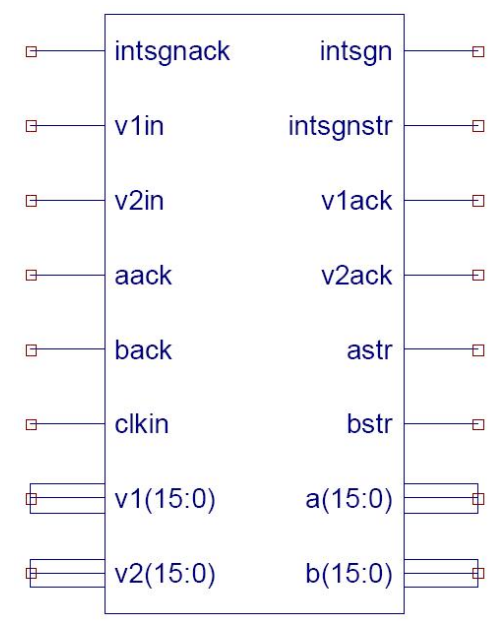

Figura 5.17: Bloco esquemático do operador ITMAN.

strobe e reconhecimento para o sinal de controle. A Figura 5.18 apresenta o diagrama de estados do operador ITMAN.

Enquanto todos operadores foram implementados utilizando a linguagem $V H D L$, os grafos a fluxo de dados foram implementados utilizando diagramas esquemáticos por permitirem uma representação visual do grafo.

Os grafos implementados expressam decisões e iterações (loops).

Para expressar decisões os grafos a fluxo de dados implementados representam os comandos If-Else e Switch. Na Figura 5.19 é descrito o grafo para o comando If-Else e sua implementação é apresentada na Figura 5.20, onde é possível verificar a utilização dos operadores INDATA e OUTDATA para sincronizar os dados de entrada e saída do grafo.

A Figura 5.21 apresenta as simulações realizadas para o grafo a fluxo de dados do comando If-Else. Na Tabela 5.1 são descritos os conjuntos de dados de entrada e saída apresentados na Figura 5.21.

Tabela 5.1: Dados utilizados na simulação apresentada na Figura 5.21.

\begin{tabular}{|c|c|c|c|c|c|}
\hline \multicolumn{5}{|c|}{ Entradas } & Saída \\
\hline $\mathrm{a}$ & $\mathrm{b}$ & $\mathrm{c}$ & $\mathrm{d}$ & $\mathrm{x}$ & $\mathrm{z}$ \\
\hline 2 & 3 & 5 & 1 & 2 & 5 \\
\hline 3 & 4 & 9 & 9 & 0 & 0 \\
\hline
\end{tabular}




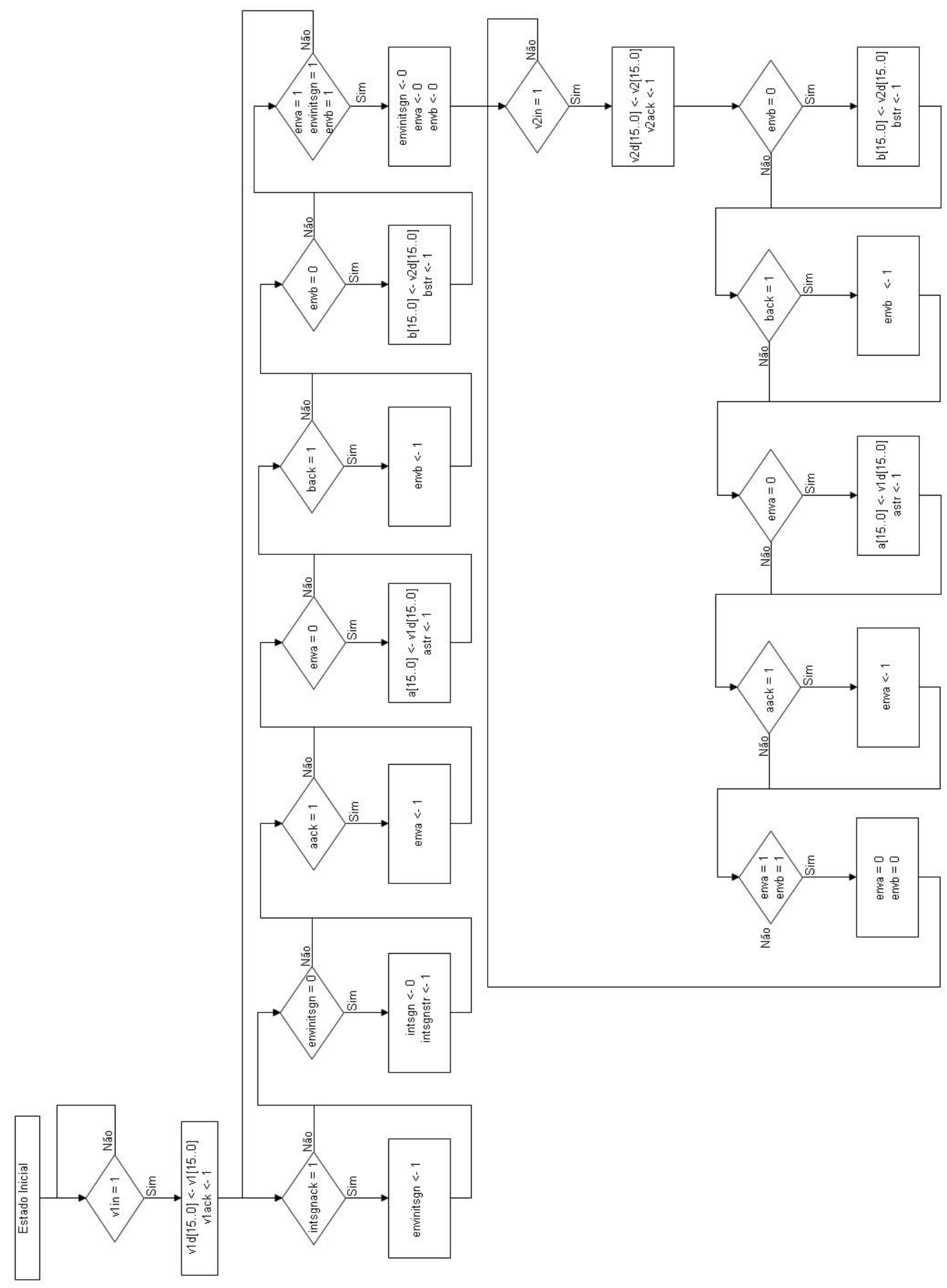

Figura 5.18: ASM chart do operador ITMAN.

Podemos verificar na Tabela 5.1 que no primeiro conjunto de dados, para $x$ igual a 2 o resultado obtido por $z$ é 5 (soma dos dados de entrada $a$ e $b$ ). No segundo conjunto de dados, para $x$ igual a 0 o resultado obtido por $z$ é 0 (subtração dos dados de entrada $c$ e $d$ ). 


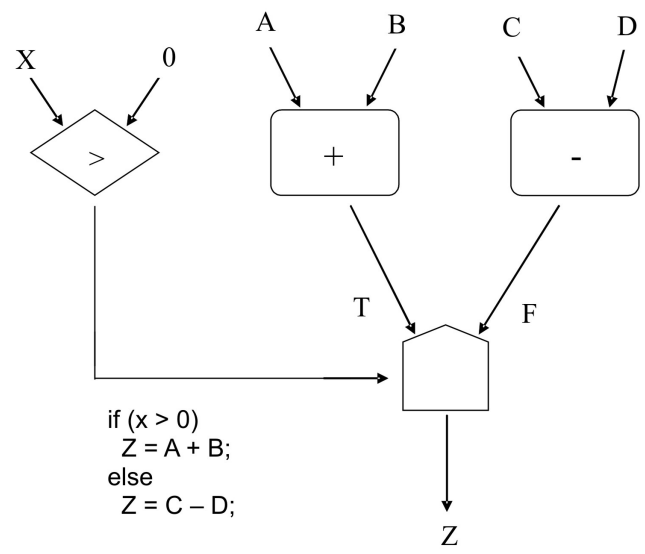

Figura 5.19: Grafo a fluxo de dados para o comando If-Else.

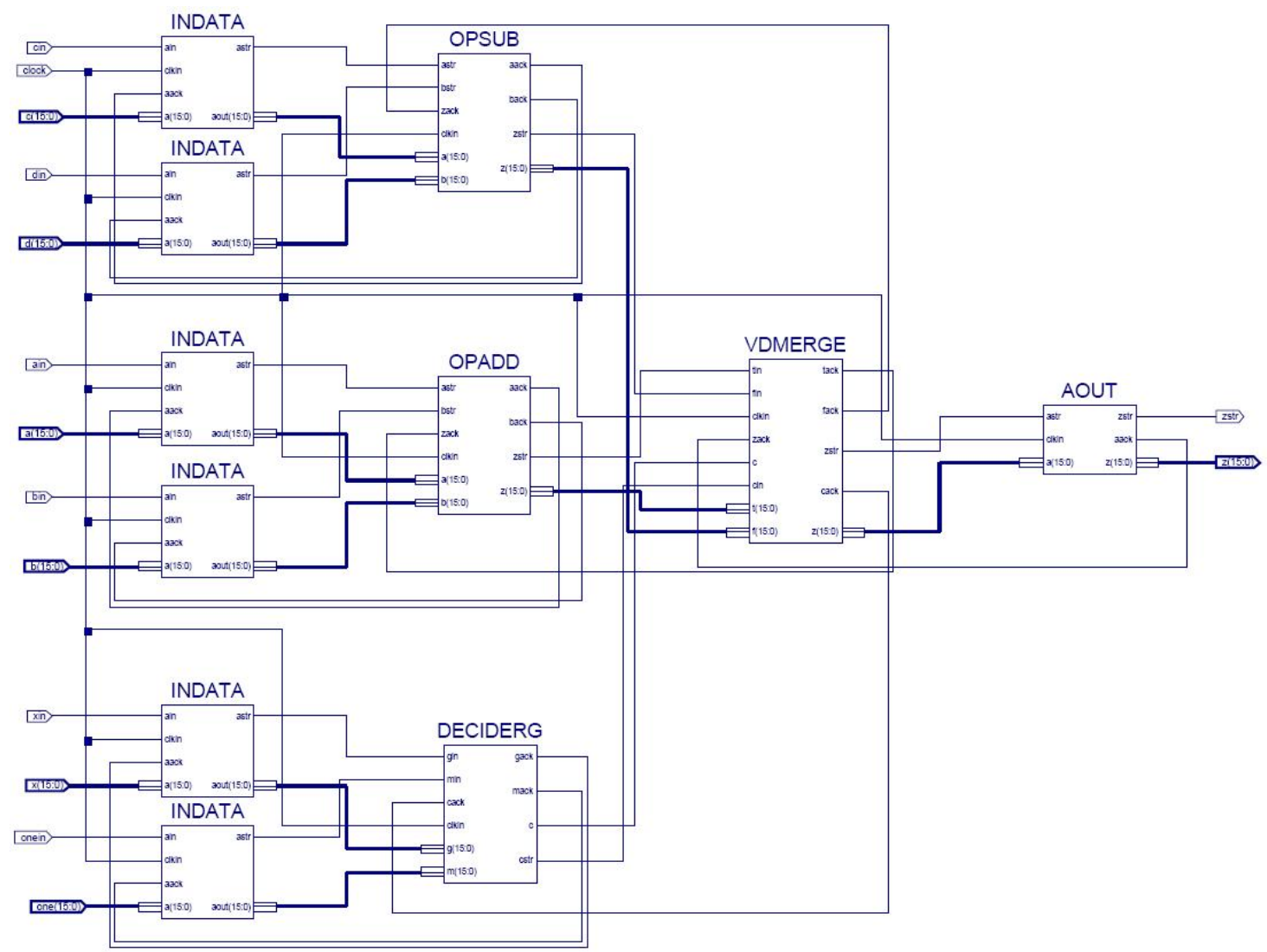

Figura 5.20: Implementação do grafo a fluxo de dados para o comando If-Else.

A Figura 5.22 descreve o grafo a fluxo de dados do comando Switch, onde uma variável é testada em relação a diversos valores pré-estabelecidos. A implementação do grafo para o comando Switch é apresentada no Apêndice A.

A Figura 5.23 apresenta a simulação do grafo a fluxo de dados implementado para o comando Switch. Na Tabela 5.2 são descritos os conjuntos de dados de entrada e saída apresentados na Figura 5.21. 


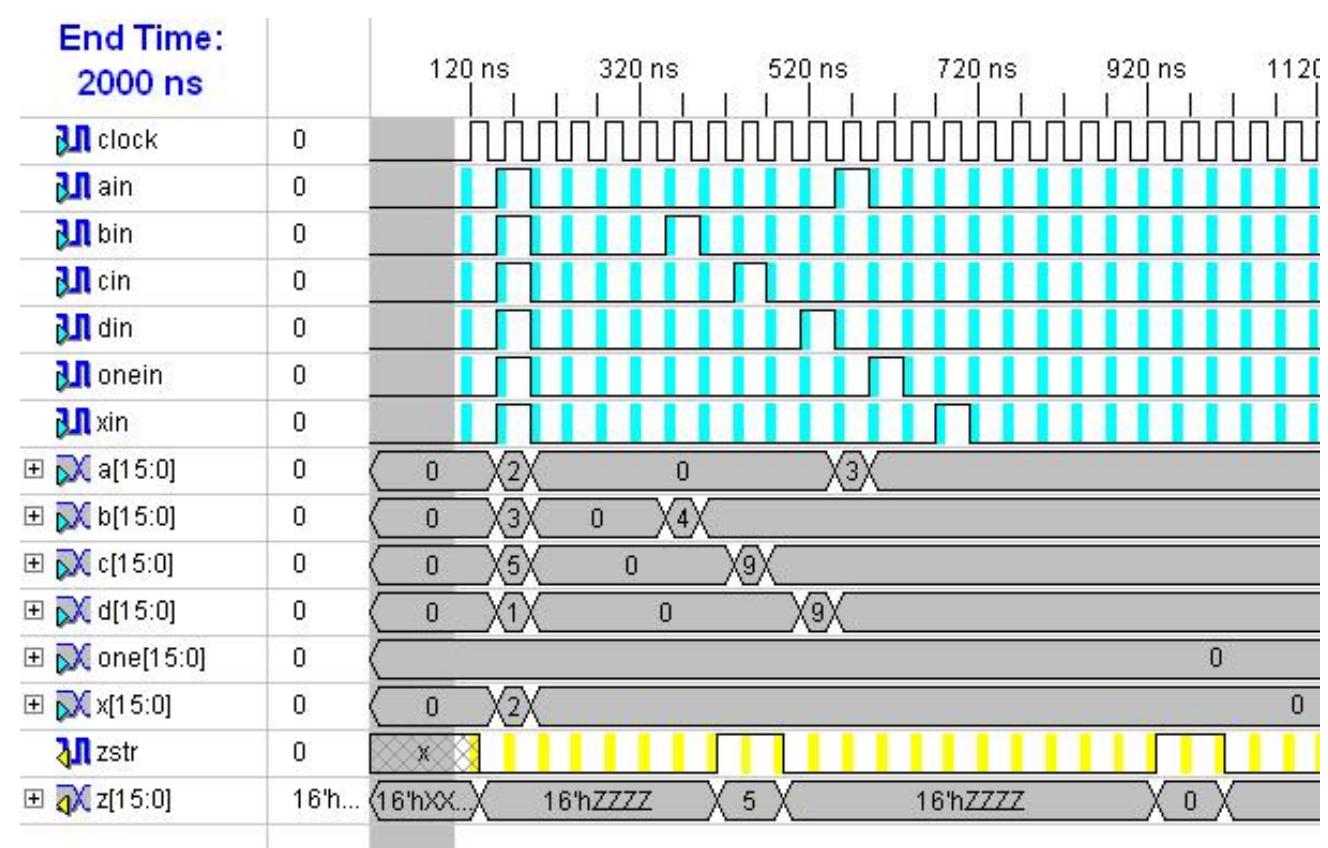

Figura 5.21: Simulação do grafo a fluxo de dados implementado para o comando If-Else.

Tabela 5.2: Dados utilizados na simulação apresentada na Figura 5.23.

\begin{tabular}{|c|c|c|c|c|c|c|c|c|c|c|c|}
\hline \multicolumn{10}{|c|}{ Entradas } & Saída \\
\hline brch0 & brch1 & brch2 & brch3 & case0 & case1 & case2 & case3 & defaultbrch & z & x & Z \\
\hline 5 & 3 & 4 & 6 & 0 & 1 & 2 & 3 & 5 & 5 & 0 & 5 \\
\hline 5 & 3 & 4 & 6 & 0 & 1 & 2 & 3 & 5 & 5 & 1 & 3 \\
\hline 5 & 3 & 4 & 6 & 0 & 1 & 2 & 3 & 5 & 5 & 2 & 4 \\
\hline 5 & 3 & 4 & 6 & 0 & 1 & 2 & 3 & 5 & 5 & 4 & 10 \\
\hline
\end{tabular}

Podemos verificar na Tabela 5.2 que o valor inicial de $z$ é 5, a entrada $x$ assume os seguintes valores $0,1,2$, e 4 . O resultado da saída $z$ é igual a 5, 3, 4 e 10 respectivamente.

O comando While é usado para repetir a execução de um bloco de comandos enquanto a condição de teste seja verdadeira. Como a condição de teste é feita no começo da iteração, o bloco pode ocasionalmente não executar. A Figura 5.24 apresenta o grafo a fluxo de dados para o comando While.

A implementação do grafo para o comando While é apresentada no Apêndice A.

O grafo a fluxo de dados do comando For é uma generalização do grafo do comando While. A Figura 5.25 mostra o grafo a fluxo de dados do comando For. Similarmente ao grafo a fluxo de dados do comando While, a condição do teste é executada no começo da iteração. Por esta razão a estrutura geral de ambos os grafos são praticamente as mesmas. A diferença entre eles consiste no 


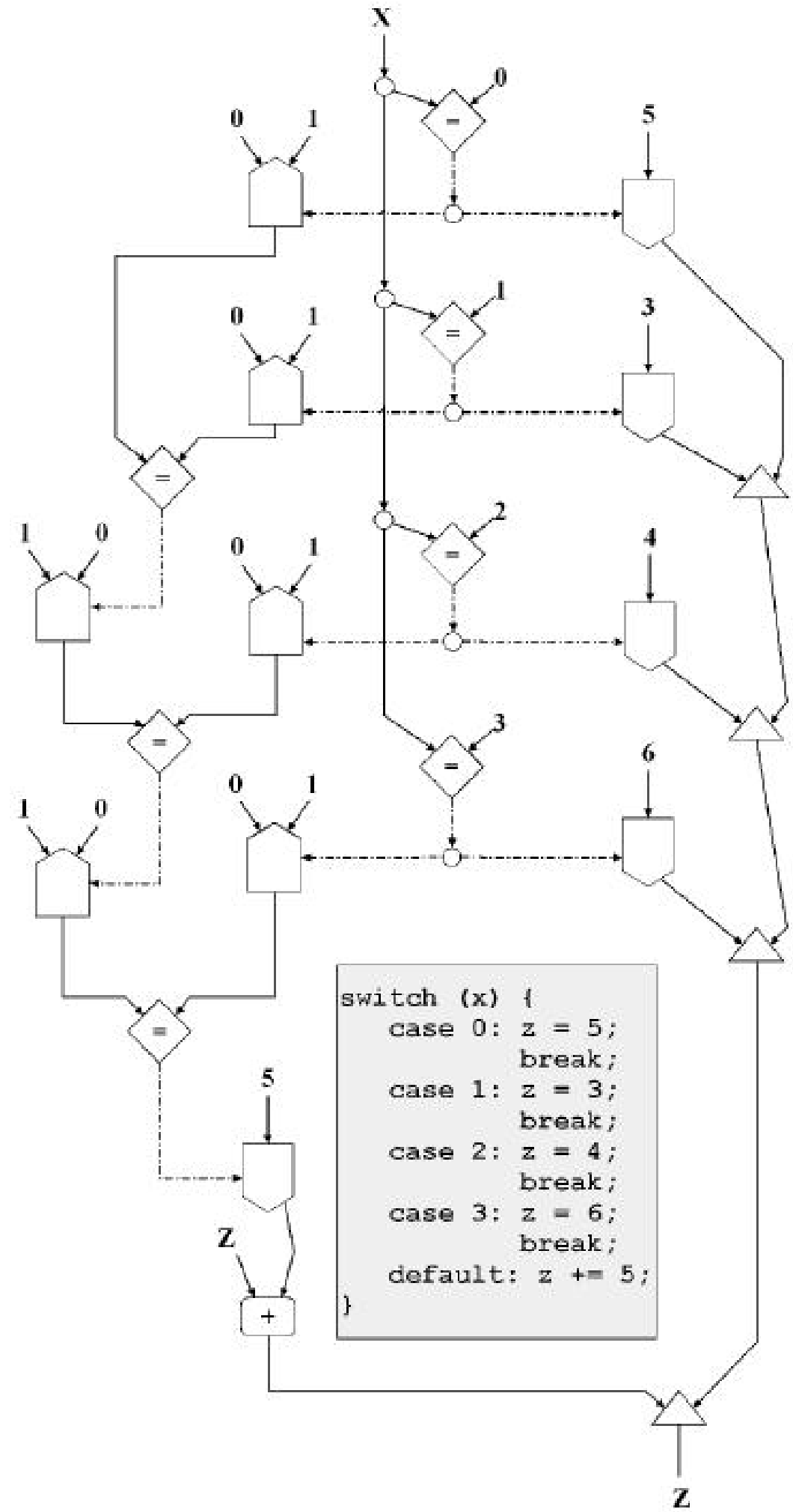

Figura 5.22: Grafo a fluxo de dados para o comando Switch.

incremento do contador $(i++)$ do comando For, que é a última operação a ser executada dentro do laço. A implementação do grafo para o comando For é apresentada no Apêndice A. 


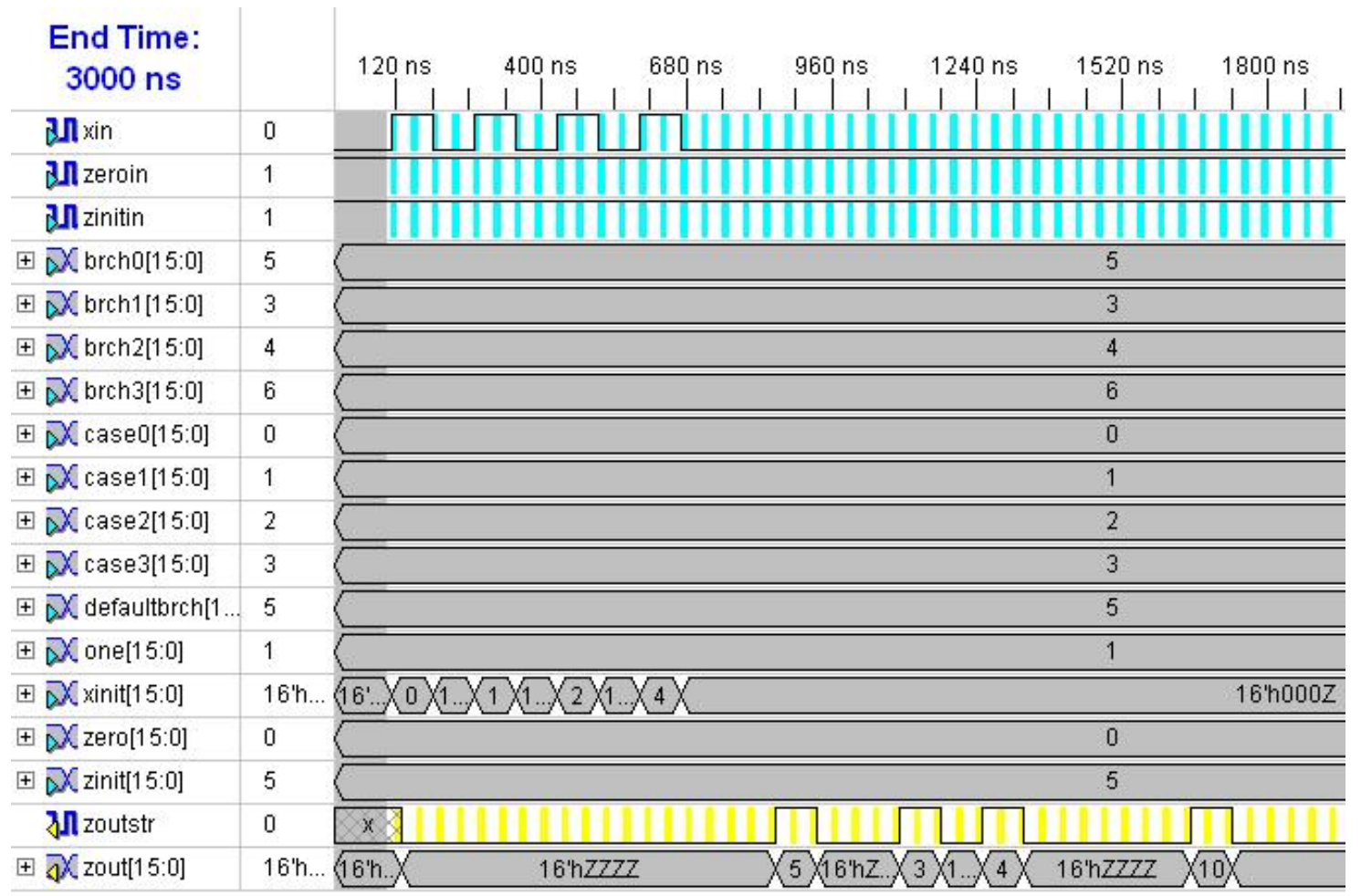

Figura 5.23: Simulação do grafo a fluxo de dados implementado para o comando Switch.

Na Figura 5.26 é apresentado o grafo a fluxo de dados do comando Do-While, onde a condição do teste é executado no final da iteração. Por este motivo, pelo menos uma vez os blocos de comandos dentro do laço são executados. Isto faz o grafo do comando Do-While ligeiramente diferente dos grafos dos comandos While e For. A implementação do grafo a fluxo de dados para o comando Do-While é apresentada no Apêndice A.

As Figuras 5.27, 5.28 e 5.29 apresentam os resultados obtidos com as simulações dos grafos implementados que expressam os comandos While, For e Do-While. A Tabela 5.3 apresenta os conjuntos de dados utilizados nas simulações. O valor inicial de $z$ é 2 (zinit); o valor de $n$ é 3; o valor para o contador $i$ é 0 (iinit) e o valor de incremento do contador é 1 (incr). O resultado final obtido por $z$ é 8,5 e 8 respectivamente para os grafos While, For e Do-While.

Tabela 5.3: Dados utilizados nas simulações apresentadas nas Figuras 5.27, 5.28 e 5.29.

\begin{tabular}{|c|c|c|c|c|c|}
\hline & \multicolumn{4}{|c|}{ Entradas } & Saída \\
\cline { 2 - 6 } & iinit & incr & zinit & $\mathrm{n}$ & $\mathrm{z}$ \\
\hline While & 0 & 1 & 2 & 3 & 8 \\
\hline For & 0 & 1 & 2 & 3 & 5 \\
\hline Do-While & 0 & 1 & 2 & 3 & 8 \\
\hline
\end{tabular}




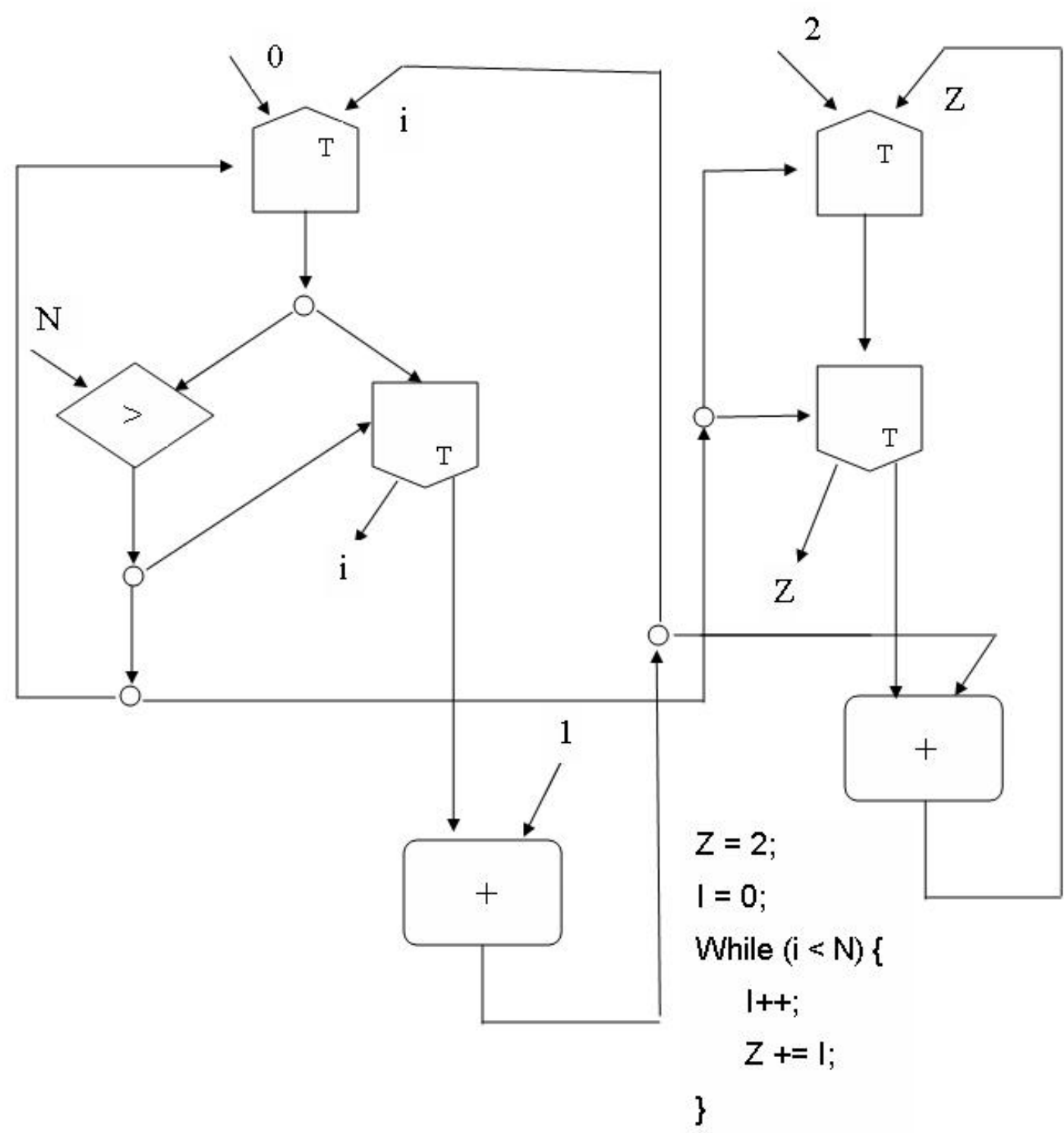

Figura 5.24: Grafo a fluxo de dados para o comando While.

A Figura 5.30 apresenta o resultado da execução dos programas escritos em linguagem C dos quais os grafos a fluxo de dados dos comandos While, For e Do-While foram convertidos.

\subsubsection{Implementação da Sequência de Fibonacci}

A sequência de FIbonacci é uma construção iterativa, onde cada elemento é formado pela soma dos dois elementos anteriores, com execeção dos dois primeiros elementos que são respectivamente 0 e 1.

A Figura 5.31 apresenta o grafo a fluxo de dados para a Sequência de Fibonacci. A implementação do grafo é apresentada no Apêndice A. 


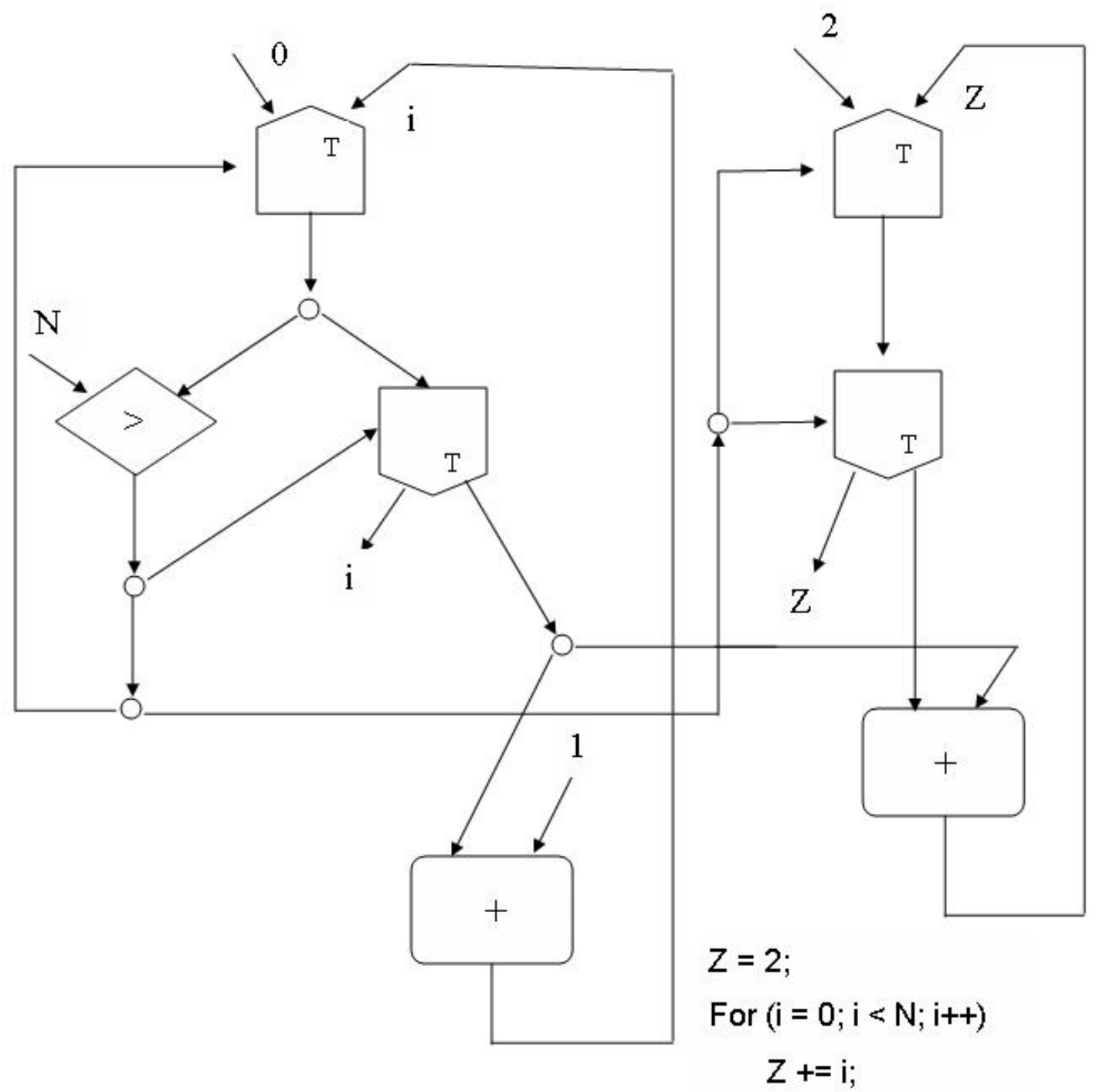

Figura 5.25: Grafo a fluxo de dados para o comando For.

A Figura 5.32 apresenta a simulação do grafo a fluxo de dados implementado para a sequência de Fibonacci e a Tabela 5.4 é descrito o conjunto de dados utilizado na simulação, onde o valor dos dois primeiros elementos são $0(a)$ e $1(b)$; o valor de $n$ é 3; o valor para o contador $i$ é 0 (iinit) e o valor de incremento do contador é 1 (incr). O resultado do cálculo da sequência de Fibonacci é 987, que corresponde ao décimo sexto número da sequência.

Tabela 5.4: Dados utilizados na simulação apresentada na Figura 5.32.

\begin{tabular}{|c|c|c|c|c|c|}
\hline \multicolumn{5}{|c|}{ Entradas } & Saída \\
\hline $\mathrm{a}$ & $\mathrm{b}$ & iinit & incr & $\mathrm{n}$ & fibonacci \\
\hline 0 & 1 & 0 & 1 & 16 & 987 \\
\hline
\end{tabular}




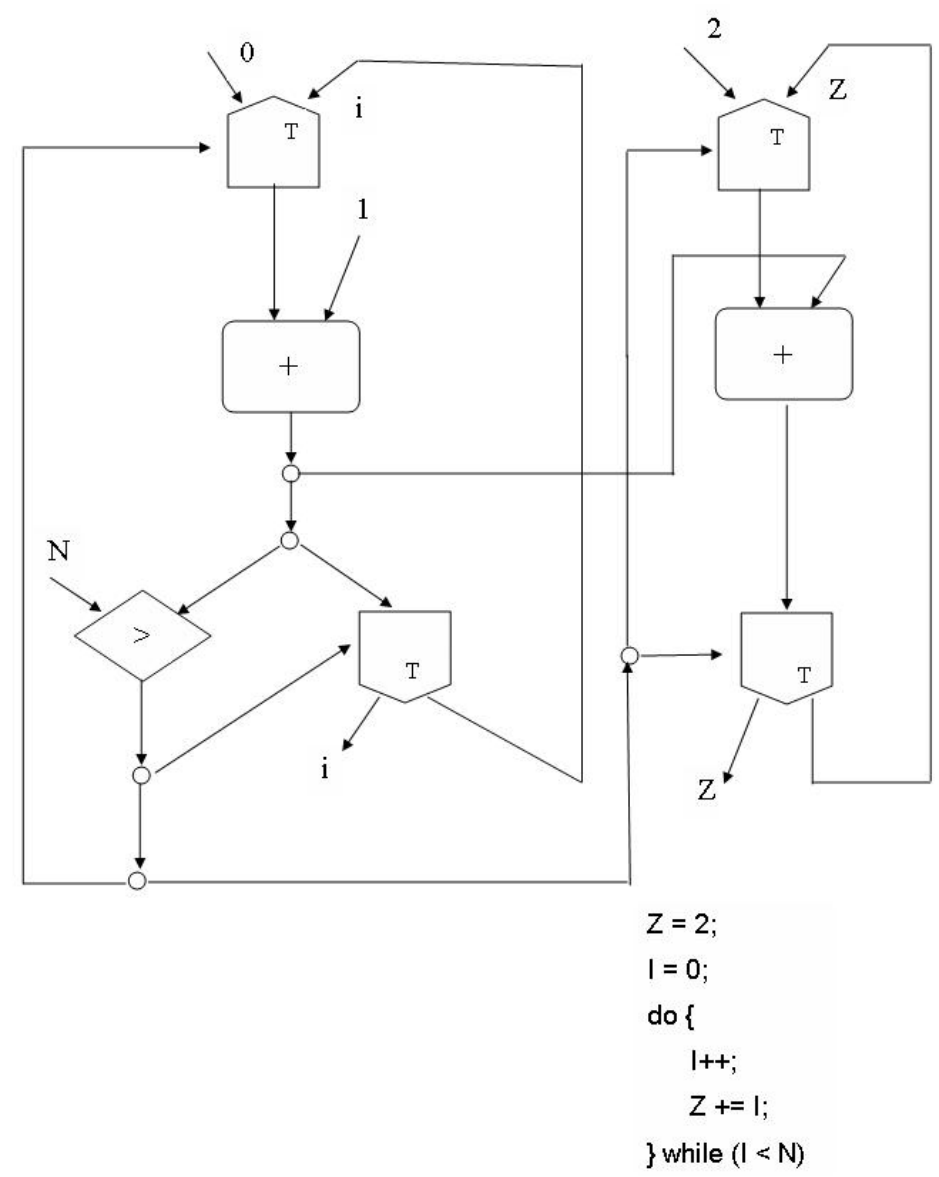

Figura 5.26: Grafo a fluxo de dados para o comando Do-While.

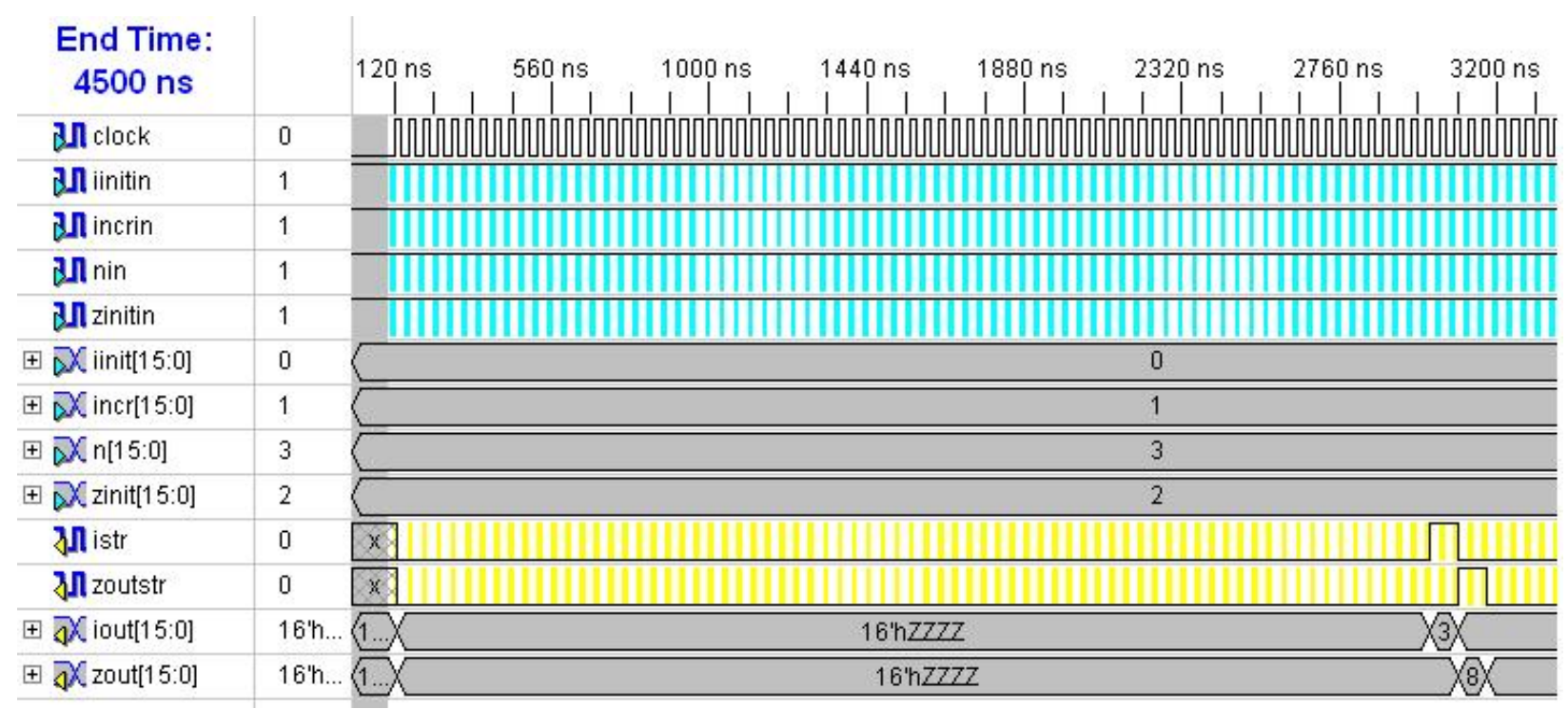

Figura 5.27: Simulação do grafo a fluxo de dados implementado para o comando While.

A Figura 5.33 apresenta o resultado da execução do programa escrito em $\mathrm{C}$ do qual o grafo a fluxo de dados para a sequência de Fibonacci foi convertido. 


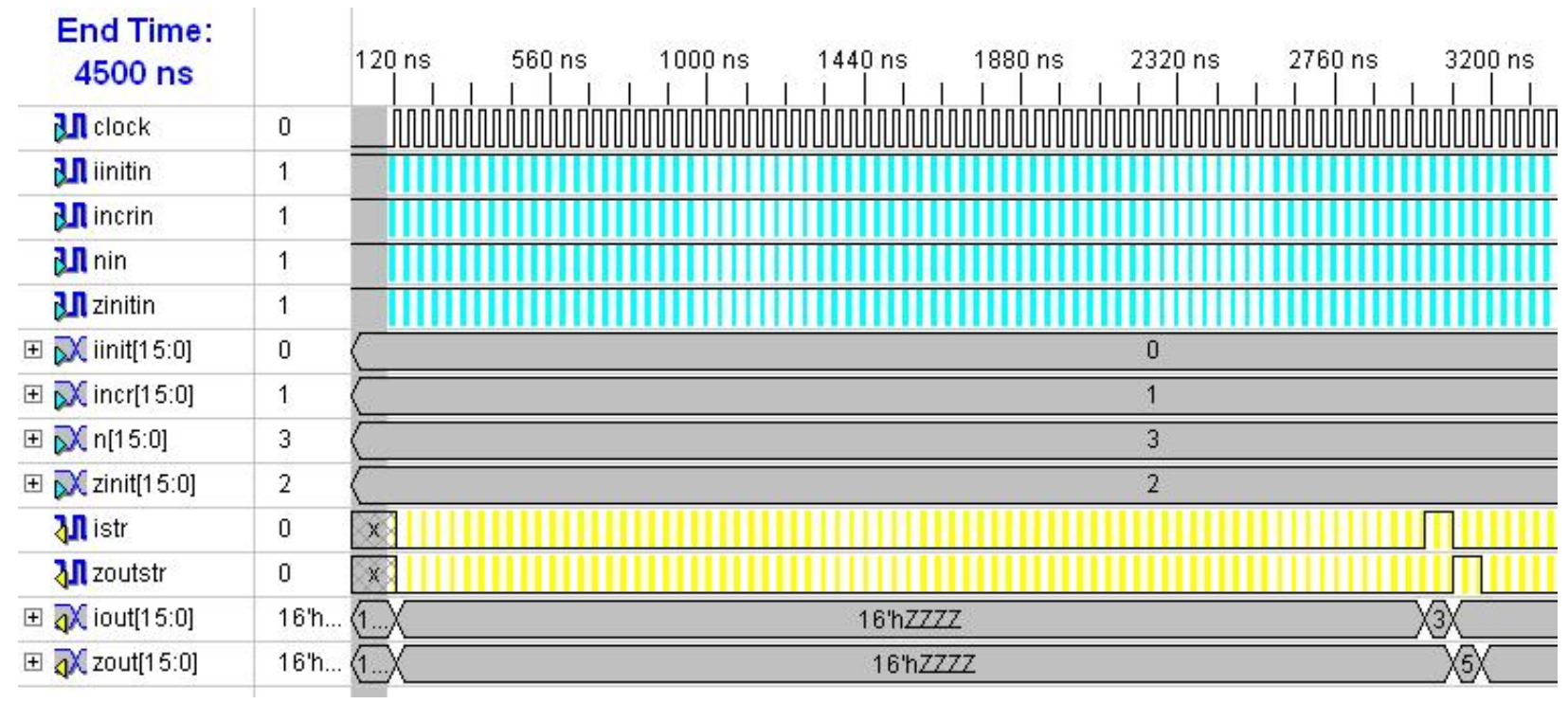

Figura 5.28: Simulação do grafo a fluxo de dados implementado para o comando For.

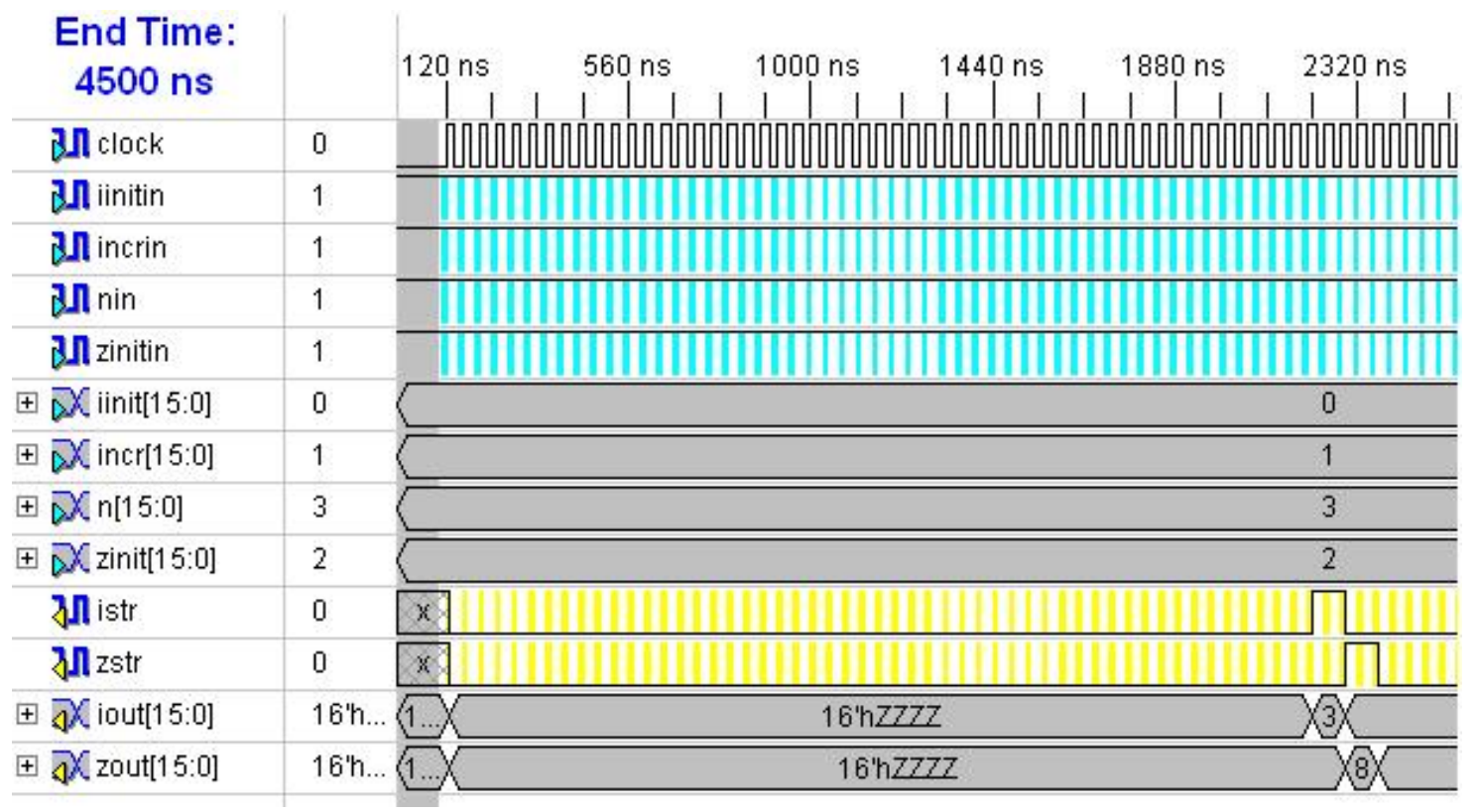

Figura 5.29: Simulação do grafo a fluxo de dados implementado para o comando Do-While.

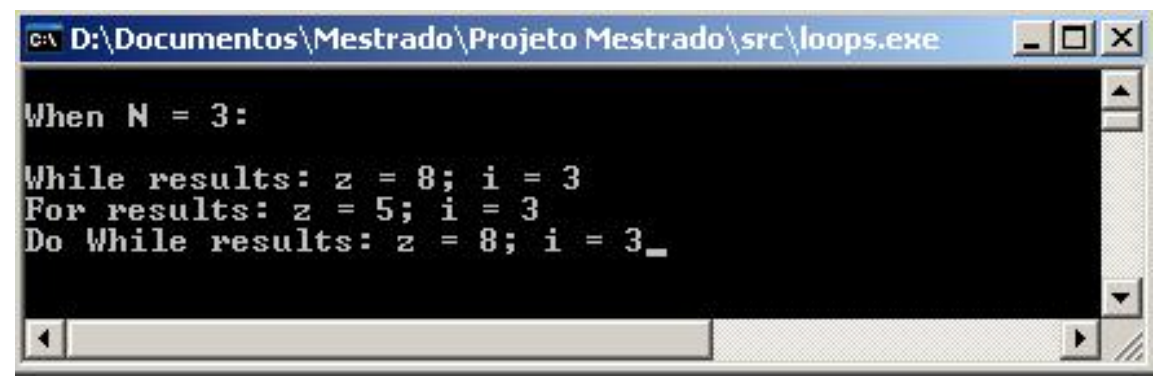

Figura 5.30: Resultado da execução de programas em $\mathrm{C}$ dos comandos While, For e Do-While. 


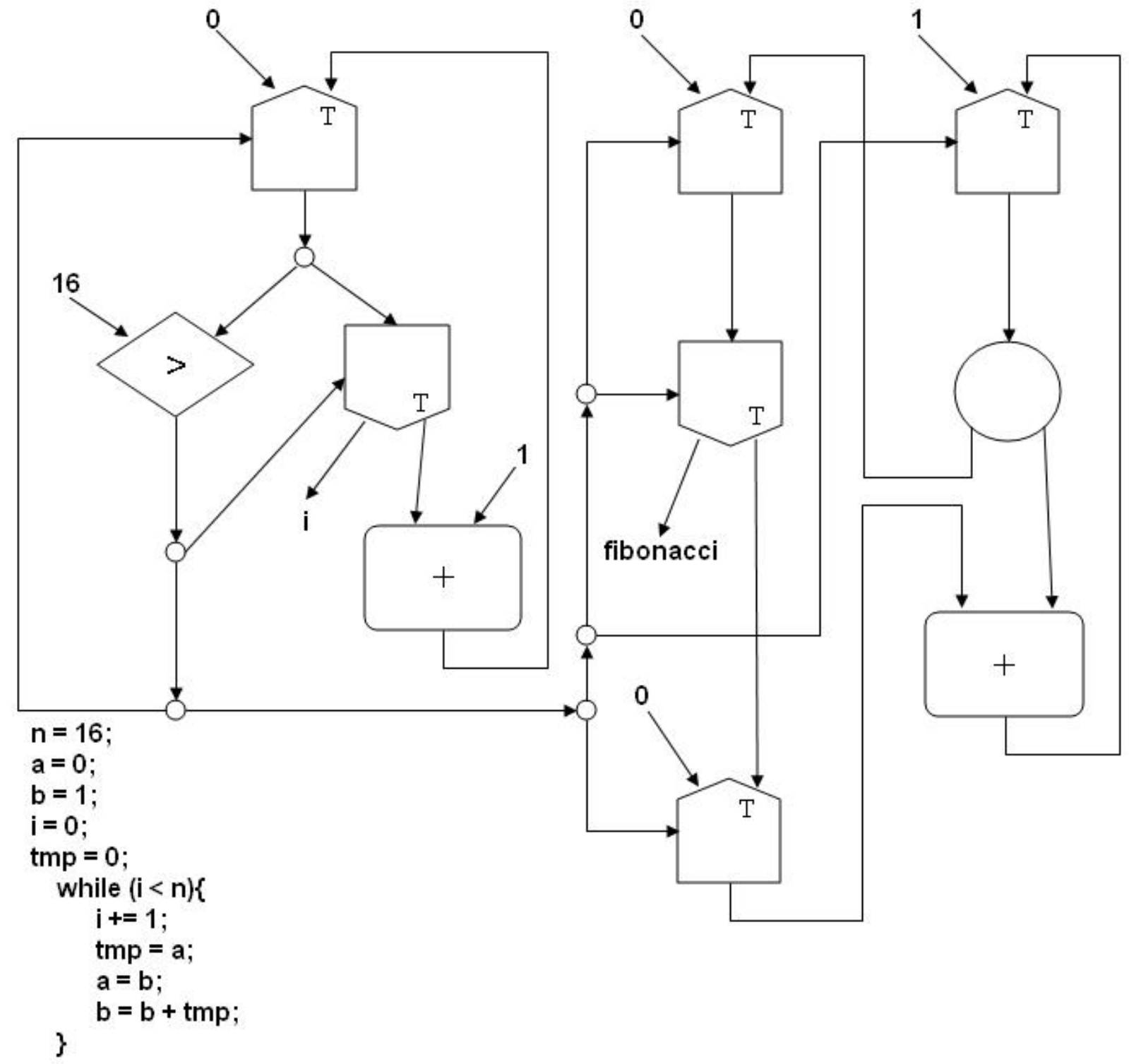

Figura 5.31: Grafo a fluxo de dados para a Sequência de Fibonacci.

A Tabela 5.5 mostram os recursos de hardware gastos para implementar o grafo a fluxo de dados para a sequência de Fibonacci, no FPGA Virtex II-pro xc2vp2-5-fg256.

Tabela 5.5: Recursos gastos para implementação do grafo para a Sequência de Fibonacci.

\begin{tabular}{|c|c|c|}
\hline Elementos do dispositivo & Quantidade & Porcentagem de recurso utilizada \\
\hline Número de slices & 701 de 1408 & 49 \\
\hline Número de slice flip flops & 1172 de 2816 & 41 \\
\hline Número de Luts de 4 entradas & 936 de 2816 & 33 \\
\hline Número bounded IOs & 120 de 140 & 85 \\
\hline
\end{tabular}




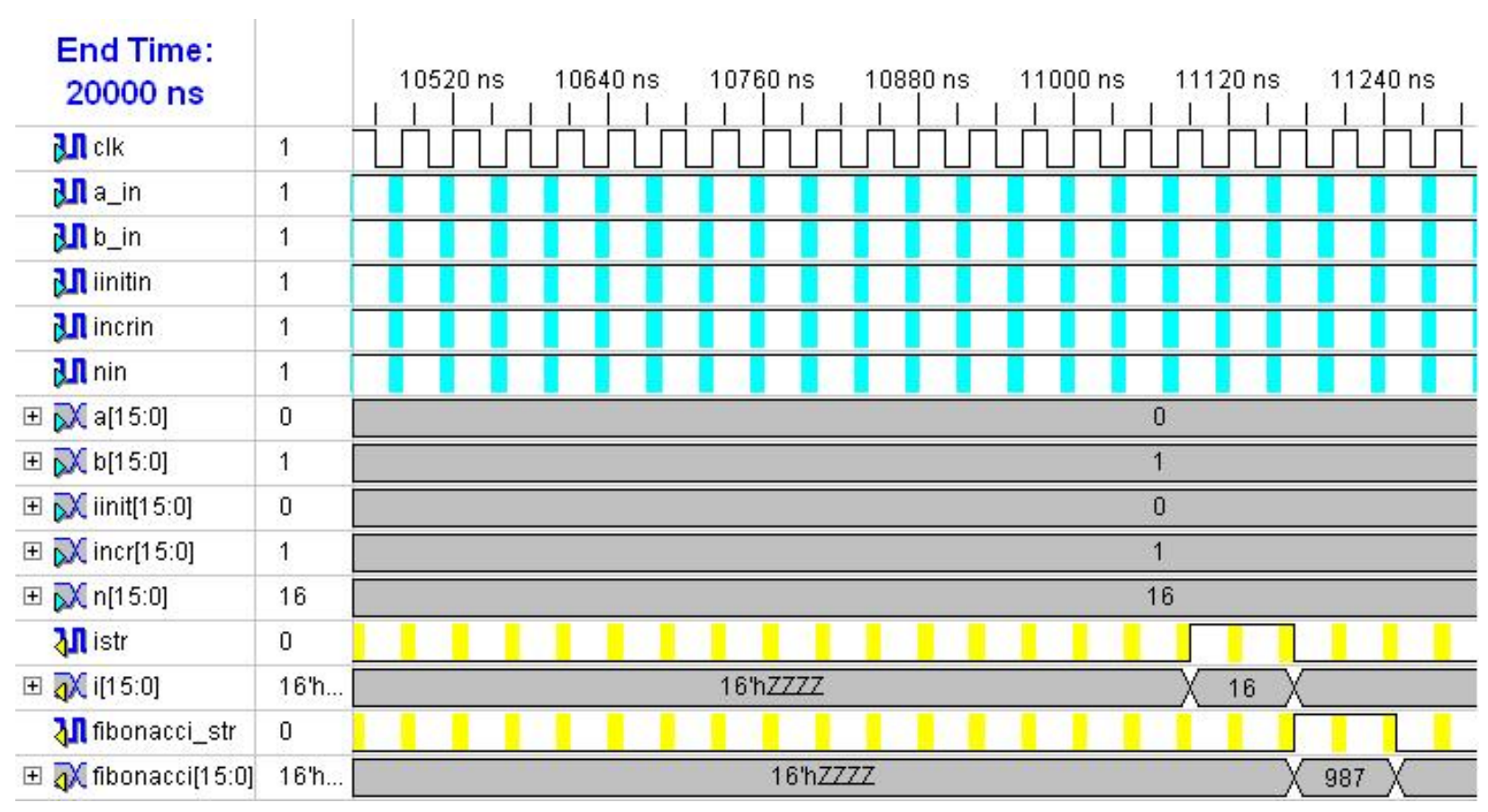

Figura 5.32: Simulação do grafo a fluxo de dados implementado para a Sequência de Fibonacci.

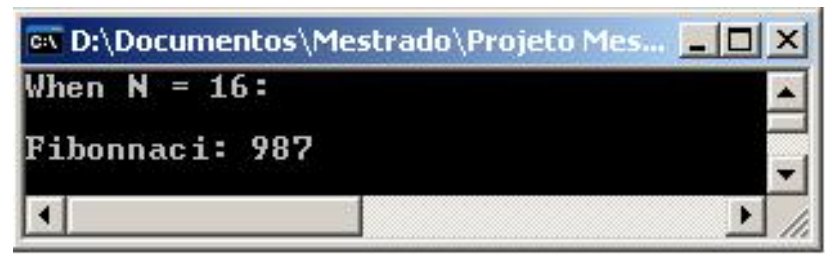

Figura 5.33: Resultado da execução do programa em C para a Sequência de Fibonacci. 


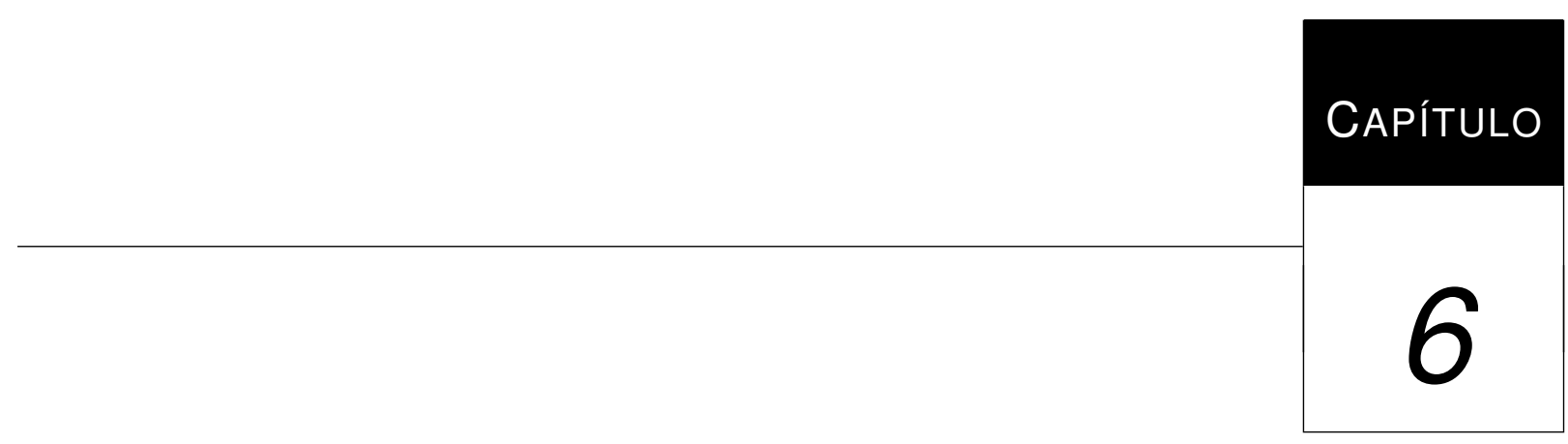

Conclusão

A partir dos objetivos deste trabalho de mestrado, que eram basicamente estudar e implementar os operadores propostos no projeto ChipCflow; implementar manualmente grafos a fluxo de dados estáticos com o objetivo de validar os operadores implementados, dominar os conceitos de programação a fluxo de dados e na conversão de algoritmos em linguagens de alto nível para grafos que foram executados diretamente em hardware, são descritos a seguir os resultados obtidos com o desenvolvimento do projeto.

Inicialmente no projeto foi realizada uma descrição sobre computação reconfigurável, apresentando a evolução dos circuitos digitais, as características de reconfigurabilidade dos FPGAs, dando destaque aos seus modelos de programação, plataforma e arquitetura.

Em seguida, foram apresentadas as características das máquinas a fluxo de dados, a linguagem original para programas a fluxo de dados, a máquina que foi proposta para execução da linguagem, sua arquitetura, considerando máquinas a fluxo de dados estáticas e máquinas a fluxo de dados dinâmicas, foram apresentadas também as arquiteturas de algumas máquinas a fluxo de dados existentes. 
A partir dessa descrição, foi apresentado o projeto ChipCflow em detalhes, apresentando os diferentes módulos em desenvolvimento e em particular a contribuição deste trabalho dentro do projeto ChipCflow.

Inicialmente foram apresentados a implementação de cada operador, com a sua representação em esquemático e em diagrama de estados. Em seguida, diferentes comandos em linguagem de alto nível foram apresentados em forma de grafo a fluxo de dados e suas respectivas implementações, validando assim diferentes comandos em alto nível que, permitem implementar diferentes programas escritos em alto nível, mas sendo executados direto em hardware. Finalmente foi descrita a sequência de Fibonacci, com uma implementação originalmente escrita em linguagem de alto nível convertida para grafo a fluxo de dados e executada diretamente em hardware.

Como o objetivo deste trabalho foi a prova de conceitos dos operadores a fluxo de dados, nenhuma consideração foi feita em relação a desempenho dos algoritmos a fluxo de dados implementados, que será tratado em outra parte do projeto

A síntese de arquiteturas a fluxo de dados é uma alternativa poderosa para a síntese de circuitos digitais de alto desempenho, pois a computação depende do processamento dos dados e não do fluxo de controle existente no modelo von Neumann.

Este trabalho é uma primeira contribuição para o projeto ChipCflow fornecendo os recursos necessários para programação a fluxo de dados para os demais trabalhos de pesquisa que se encontram em desenvolvimento.

Como continuidade do projeto, está a implementação de grafos a fluxo de dados dinâmicos, desenvolvendo um protocolo de comunicação entre os operadores, onde cada novo dado que circula pelo grafo contenha informações (tags) que o identifiquem, para que um circuito de matching de dados possa identificar os dados que são "parceiros"e consequentemente disparar a execução do operador. Outro ponto que pode ser explorado é a avaliação de desempenho de grafos a fluxo de dados em relação ao seu respectivo programa em linguagem de alto nível. 
ARVIND Dataflow: Passing the token. In: ISCA Keynote, 2005.

Arvind; Culler, D. E. Dataflow architectures. Annual review of computer science, v. vol. 1, p. 225-253, 1986.

ARVIND; KATHAIL, V. A multiple processor data flow machine that supports generalized procedures. In: ISCA '81: Proceedings of the 8th annual symposium on Computer Architecture, Los Alamitos, CA, USA: IEEE Computer Society Press, 1981, p. 291-302.

Astolfi, V. F. Chipcflow - em hardware dinâmicamente reconfiguráve. Dissertação de Mestrado, Qualificação apresentada ao ICMC/USP, 2007.

BoBDA, C. Introduction to reconfigurable computing - architectures, algorithms, and applications. Hardcover, 362 p., 2007.

Budiu, M.; Artigas, P.; Goldstein, S. Dataflow: A complement to superscalar. Performance Analysis of Systems and Software, 2005. ISPASS 2005. IEEE International Symposium on, p. $177-186,2005$.

Budiu, M.; Goldstein, S. C. Compiling application-specific hardware. In: FPL '02: Proceedings of the Reconfigurable Computing Is Going Mainstream, 12th International Conference on Field-Programmable Logic and Applications, London, UK: Springer-Verlag, 2002, p. 853863. 
CAppelli, A.; Lodi, A.; Mucci, C.; Toma, M.; CAMPI, F. A dataflow control unit for c-toconfigurable pipelines compilation flow. In: IEEE Symposium on Field-Programmable Custom Computing Machines, 2004, p. 332-333.

CARdoso, J. M. P. Compilação de algoritmos em java para sistemas computacionais reconfiguráveis com exploração do paralelismo ao nível das operações. Tese de Doutoramento, Universidade Técnica de Lisboa, 2000.

Compton, K.; HaUCK, S. Reconfigurable computing: a survey of systems and software. ACM Comput. Surv., v. 34, n. 2, p. 171-210, 2002.

Costa, K. A. P. Chipcflow - uma ferramenta para execução de algoritmos utilizando o modelo a fluxo de dados dinâmico em hardware reconfigurável - módulo de conversão c em grafo a fluxo de dados. Tese de Doutoramento, Qualificação apresentada a EESC/USP, 2008.

CrAVEn, S. D. Structured approach to dynamic computing application development. Tese de Doutoramento, Bradley Department of Electrical and Computer Engineering, 2008.

DAVID, P.; ScOTT, T. Practical fpga programming in c. Prentice Hall PTR, 464 p., 2005.

DAVIS, A. L. The architecture and system method of ddm1: A recursively structured data driven machine. In: ISCA '78: Proceedings of the 5th annual symposium on Computer architecture, New York, NY, USA: ACM Press, 1978, p. 210-215.

DeHon, A. Dpga utilization and application. In: FPGA '96: Proceedings of the 1996 ACM fourth international symposium on Field-programmable gate arrays, New York, NY, USA: ACM, 1996, p. 115-121.

DENNIS, J. B.; MisunAS, D. P. A preliminary architecture for a basic dataflow processor. In: in Proceedings of the 2nd Annual Sysmposium on Computer Architecture, 1974, p. 126-132.

Grafe, V. G.; Davidson, G. S.; Hoch, J. E.; Holmes, V. P. The epsilon dataflow processor. In: ISCA '89: Proceedings of the 16th annual international symposium on Computer architecture, New York, NY, USA: ACM Press, 1989, p. 36-45. 
Gurd, J. R.; Kirkham, C. C.; WATSOn, I. The manchester prototype dataflow computer. Commun. ACM, v. 28, n. 1, p. 34-52, 1985.

JUNIOR, F. S. Chipcflow - validação e implementação do modelo de partição e protocolo de comunicação no grafo a fluxo de dados dinâmico. Dissertação de Mestrado, Qualificação apresentada ao ICMC/USP, 2008.

Kishi, M.; Yasuhara, H.; Kawamura, Y. Dddp-a distributed data driven processor. In: ISCA '83: Proceedings of the 10th annual international symposium on Computer architecture, Los Alamitos, CA, USA: IEEE Computer Society Press, 1983, p. 236-242.

LOPES, J. J. Chipcflow - uma ferramenta para execução de algoritmos utilizando o modelo a fluxo de dados dinâmico em hardware reconfigurável. Tese de Doutoramento, Qualificação apresentada ao ICMC/USP, 2008.

Montminy, D. P.; Baldwin, R. O.; Williams, P. D.; Mullins, B. E. Using relocatable bitstreams for fault tolerance. In: AHS '07: Proceedings of the Second NASA/ESA Conference on Adaptive Hardware and Systems, Washington, DC, USA: IEEE Computer Society, 2007, p. 701-708.

Nagarajan, R.; Sankaralingam, K.; Burger, D.; Keckler, S. A design space evaluation of grid processor architectures. Microarchitecture, 2001. MICRO-34. Proceedings. 34th ACM/IEEE International Symposium on, p. 40 - 51, 2001.

Papadopoulos, G. M.; Culler, D. E. Monsoon: an explicit token-store architecture. In: ISCA '90: Proceedings of the 17th annual international symposium on Computer Architecture, New York, NY, USA: ACM Press, 1990, p. 82-91.

Ribeiro, A. A. L. Reconfigurabilidade dinâmica e remota de fpgas. Dissertação de Mestrado, Universisdade de São Paulo, 2002.

SANCHES, L. B. Chipcflow - partição e protocolo de comunicação no grafo a fluxo de dados dinâmico. Dissertação de Mestrado, Qualificação apresentada ao ICMC/USP, 2007. 
Sankaralingam, K.; Nagarajan, R.; LiU, H.; Kim, C.; Huh, J.; Burger, D.; Keckler, S. W.; Moore, C. R. Exploiting ilp, tlp, and dlp with the polymorphous trips architecture. In: ISCA '03: Proceedings of the 30th annual international symposium on Computer architecture, New York, NY, USA: ACM, 2003, p. 422-433.

Sato, M.; Kodama, Y.; Sakai, S.; Yamaguchi, Y.; Koumura, Y. Thread-based programming for the em-4 hybrid dataflow machine. In: ISCA '92: Proceedings of the 19th annual international symposium on Computer architecture, New York, NY, USA: ACM Press, 1992, p. 146-155.

Shimada, T.; Hiraki, K.; Nishida, K.; SeKiguchi, S. Evaluation of a prototype data flow processor of the sigma-1 for scientific computations. In: ISCA '86: Proceedings of the 13th annual international symposium on Computer architecture, Los Alamitos, CA, USA: IEEE Computer Society Press, 1986, p. 226-234.

Silva, J. L. Processamento a fluxo de dados tolerante a falhas em um computador paralelo. Tese apresentada no programa de pós-graduação em engenharia elétrica, FEEC - Universidade de Campinas, 1992.

SouZA, A. A. C. O. Uma arquitetura sistólica para solução de sistemas lineares implementada com circuitos fpgas. Dissertação de Mestrado, Universidade de Sâo Paulo, 1998.

Swanson, S.; MiChelson, K.; SChWERIn, A.; Oskin, M. Wavescalar. In: MICRO 36: Proceedings of the 36th annual IEEE/ACM International Symposium on Microarchitecture, Washington, DC, USA: IEEE Computer Society, 2003, p. 291.

Swanson, S.; Schwerin, A.; Mercaldi, M.; Petersen, A.; Putnam, A.; Michelson, K.; Oskin, M.; Eggers, S. J. The wavescalar architecture. ACM Trans. Comput. Syst., v. 25, n. 2, p. 4, 2007.

Tadigotla, V.; Sliger, L.; Commuri, S. Fpga implementation of dynamic run-time behavior reconfiguration in robots. Intelligent Control, 2006. IEEE International Symposium on, p. 1220 $-1225,2006$. 
Treleaven, P. C.; Brownbridge, D. R.; Hopkins, R. P. Data-driven and demand-driven computer architecture. ACM Comput. Surv., v. 14, n. 1, p. 93-143, 1982.

UPEGUI, A.; SANCHEZ, E. Evolving hardware by dynamically reconfiguring xilinx fpgas. International conference on evolvable systems (ICES), v. 3637, p. 56-65, 2005.

VEEN, A. H. Dataflow machine architecture. In: ACM Computing Surveys, 1986, p. 365-396.

ZhenG, W. H.; MARZWELl, N.; ChaU, S. In-system partial run-time reconfiguration for fault recovery applications on spacecrafts. Systems, Man and Cybernetics, 2005 IEEE International Conference on, v. 4, p. $3952-3957,2005$. 



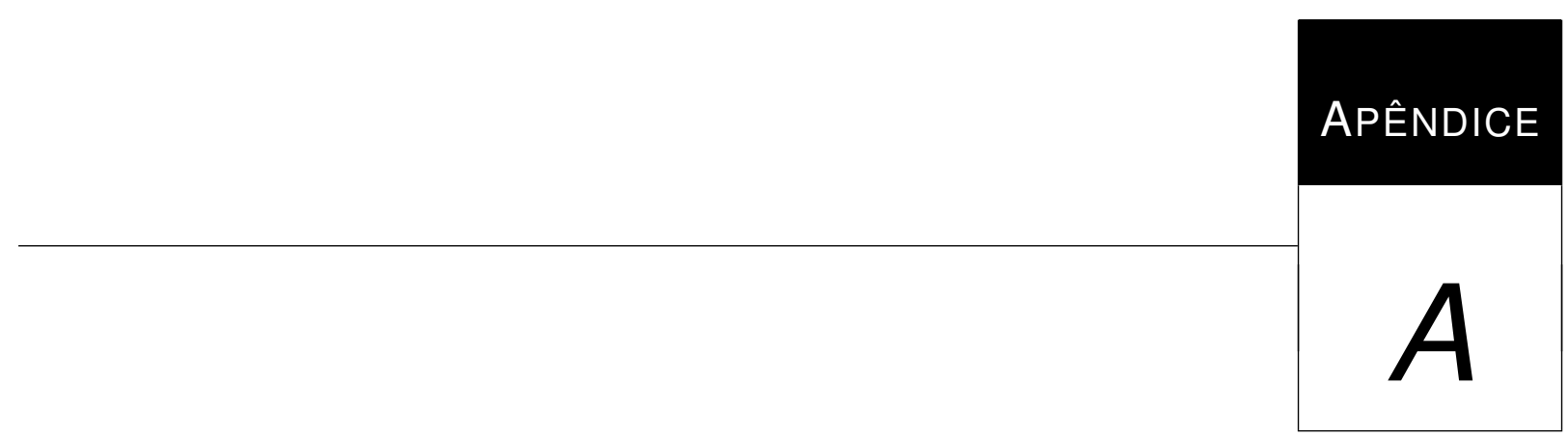

\section{Implementação de grafos a fluxo de}

dados

Listing A.1: Código VHDL para o operador Branch.

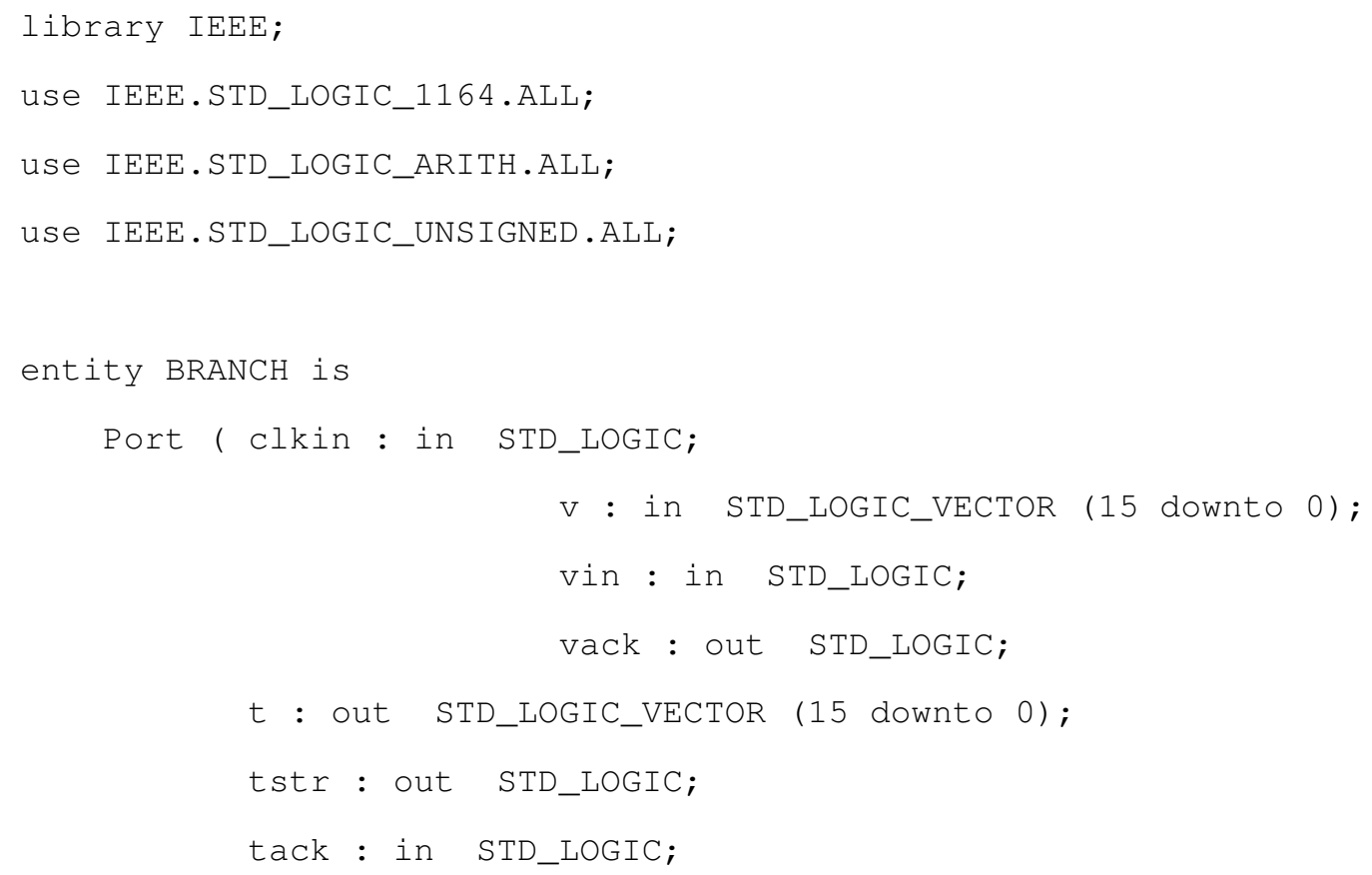




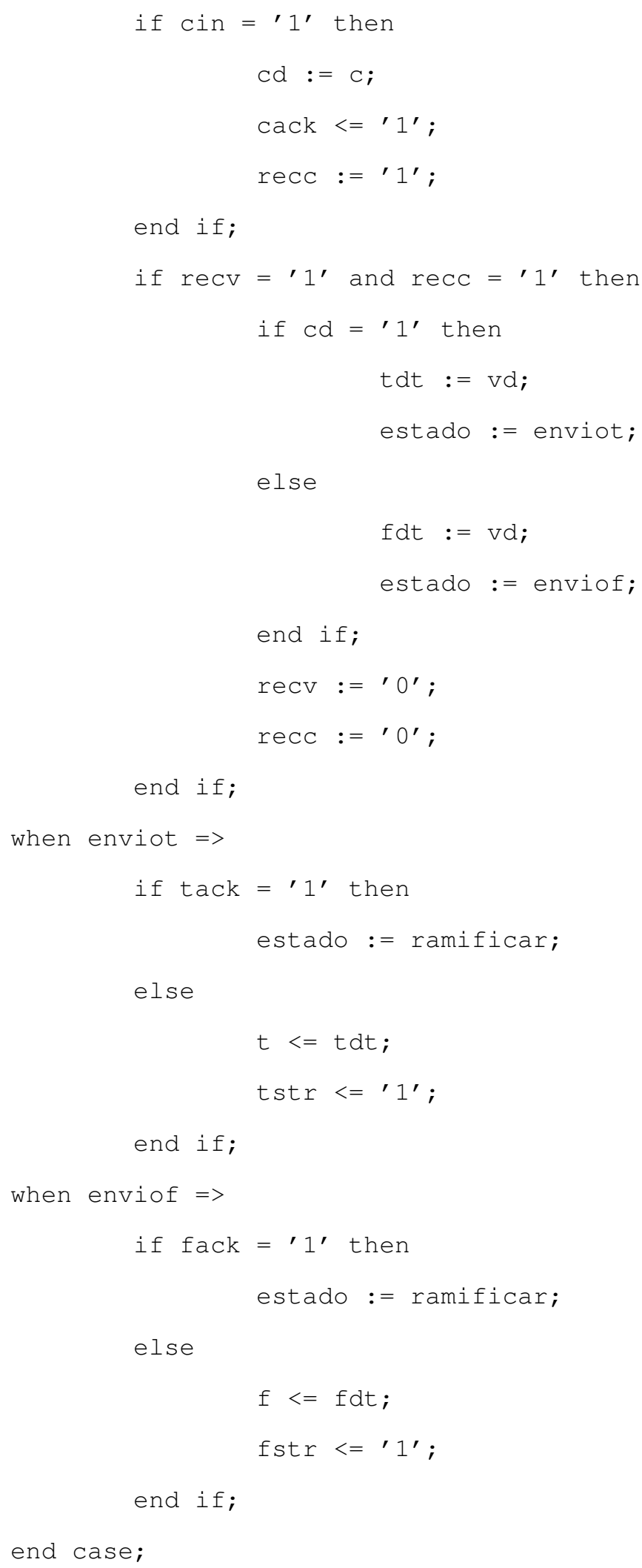


Listing A.2: Código VHDL para o operador Copy.

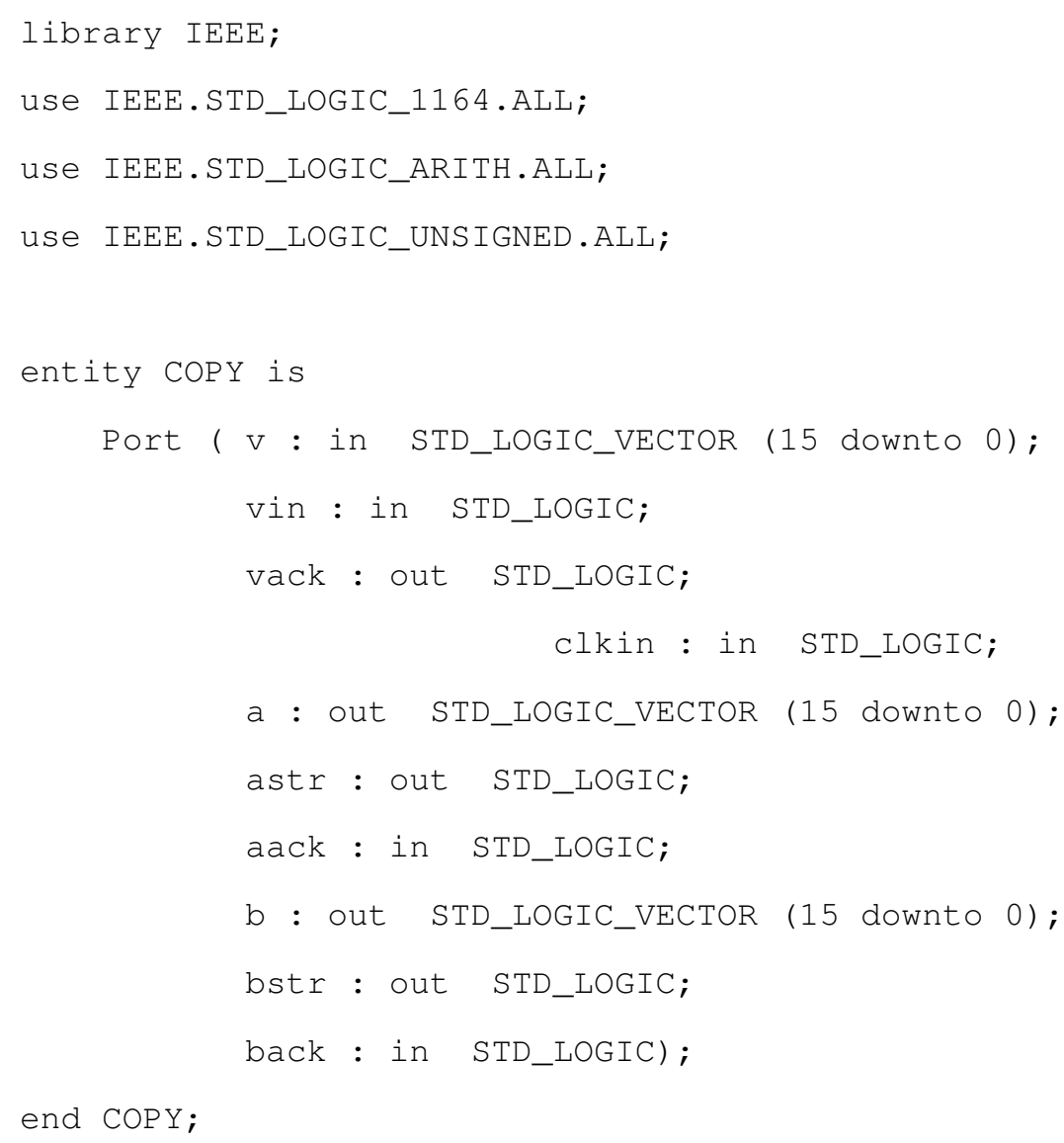




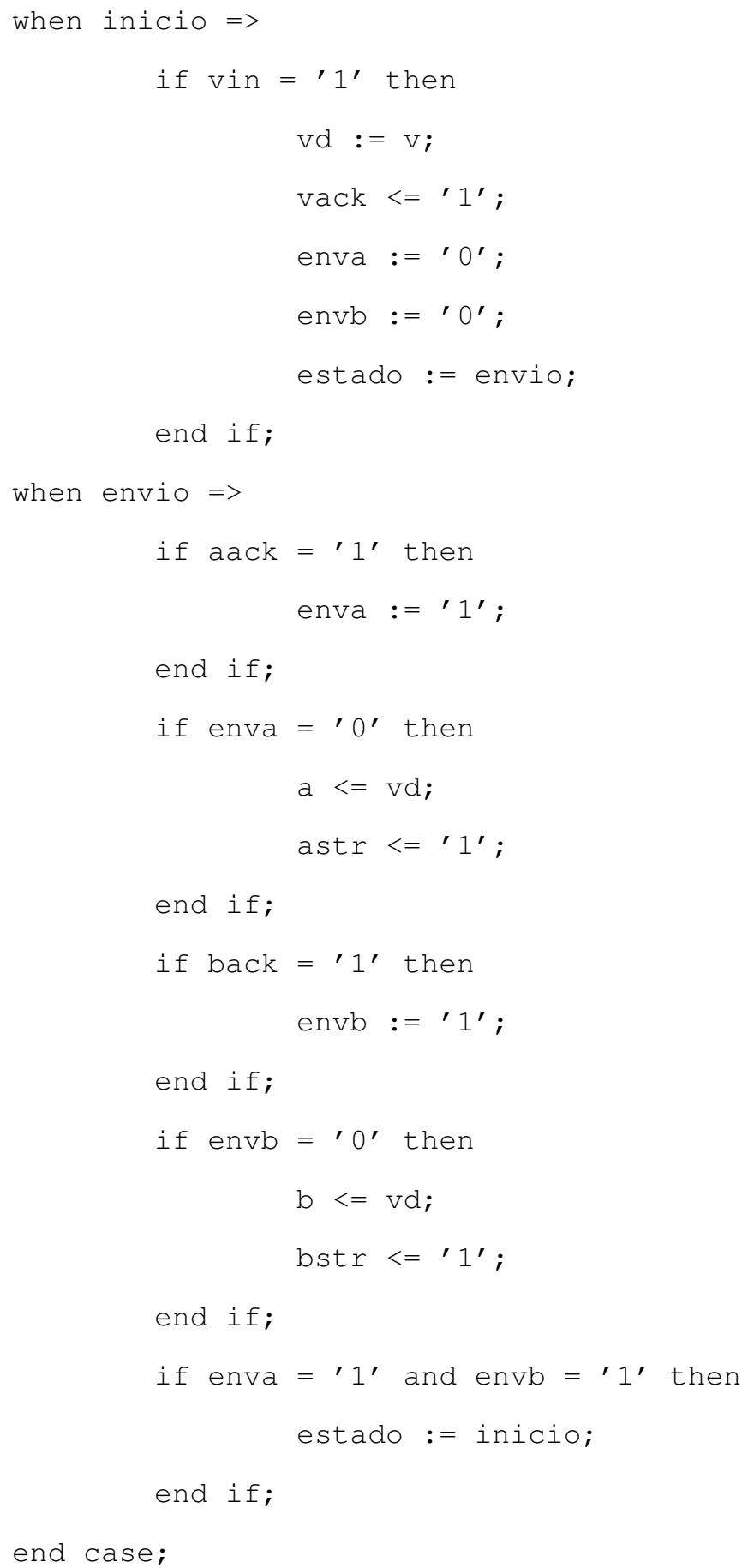

end Behavioral;

Listing A.3: Código VHDL para o operador Decider.

library IEEE;

use IEEE.STD_LOGIC_1164.ALL;

use IEEE.STD_LOGIC_ARITH.ALL; 
use IEEE.STD_LOGIC_UNSIGNED.ALL;

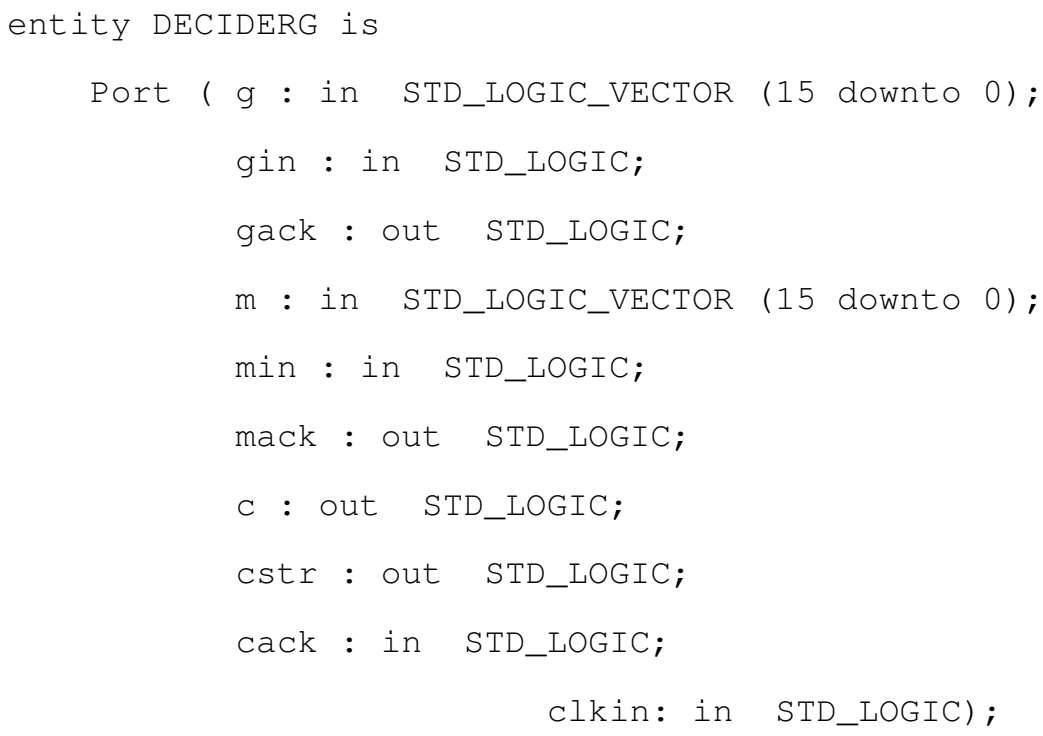

end DECIDERG;

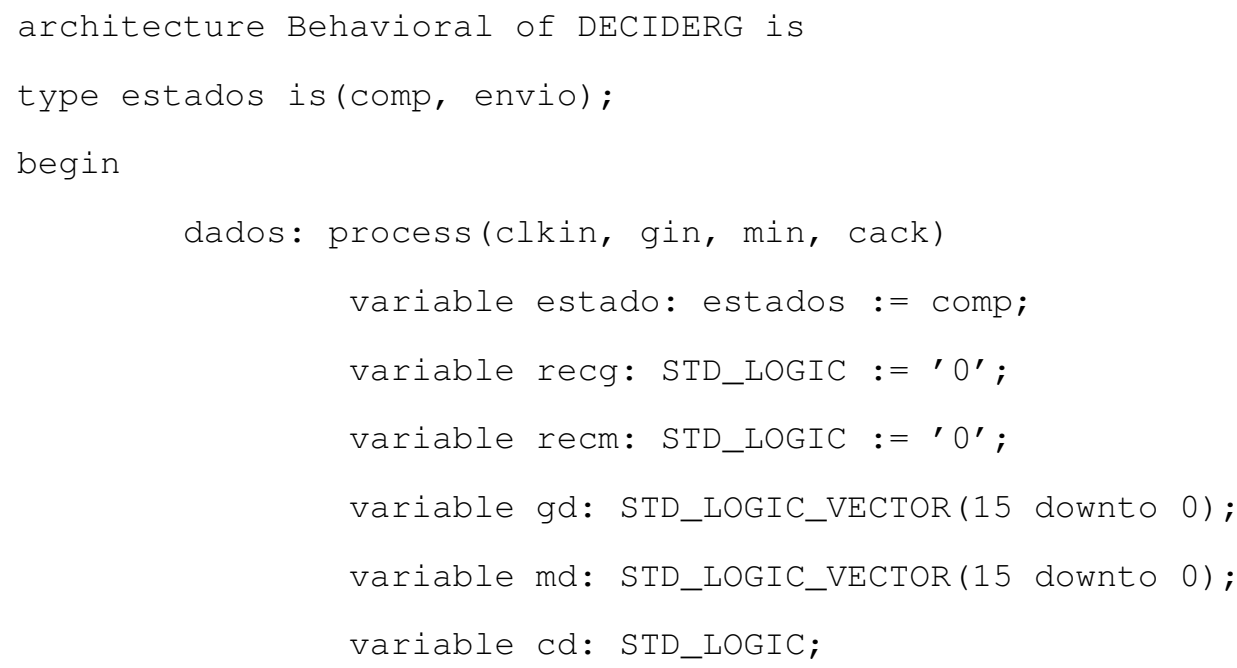




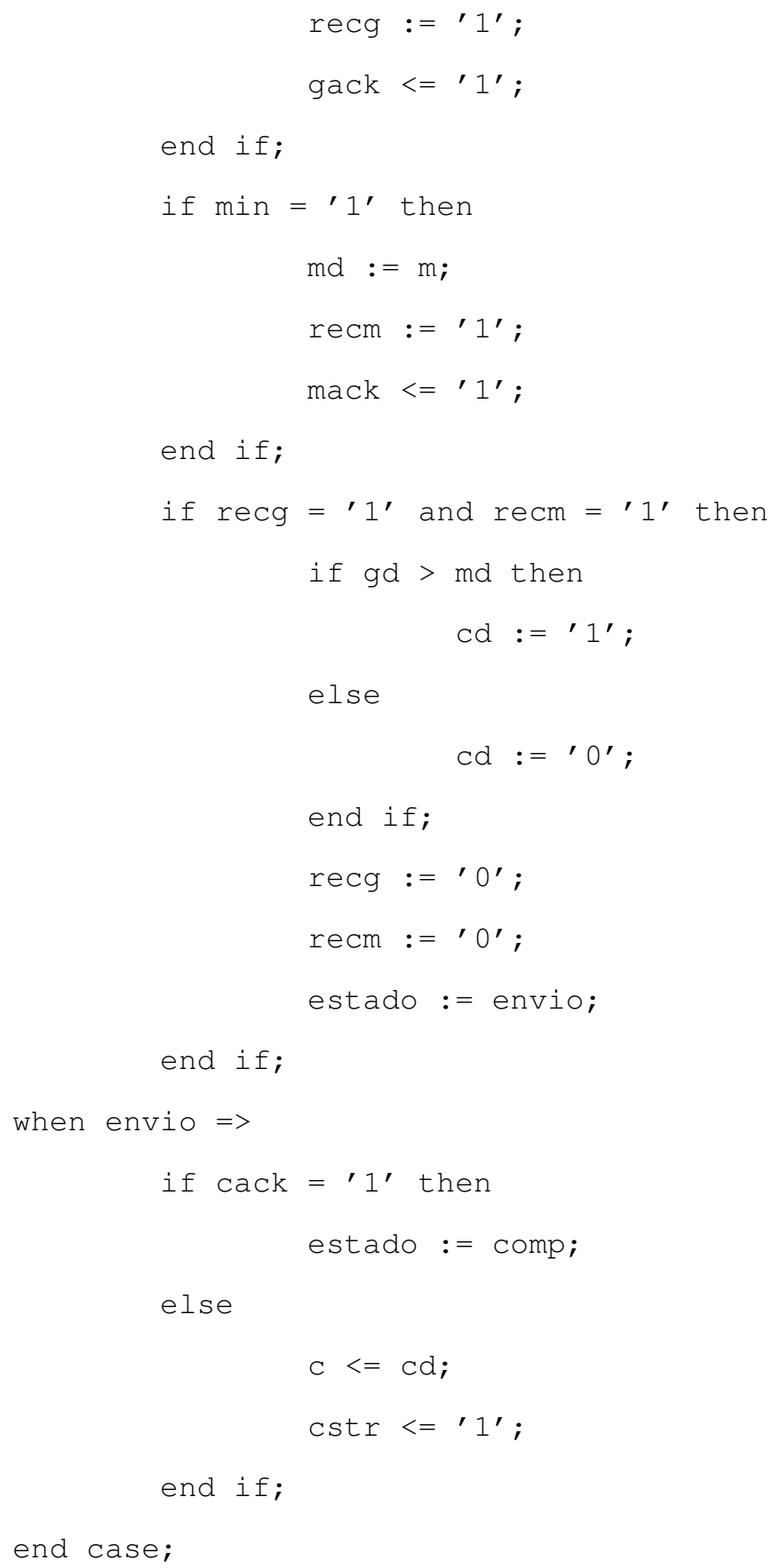

Listing A.4: Código VHDL para o operador Deterministic Merge.

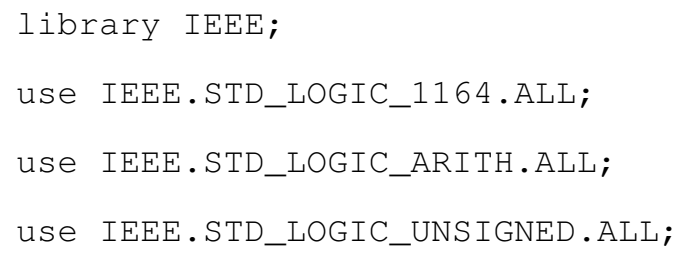


entity VDMERGE is

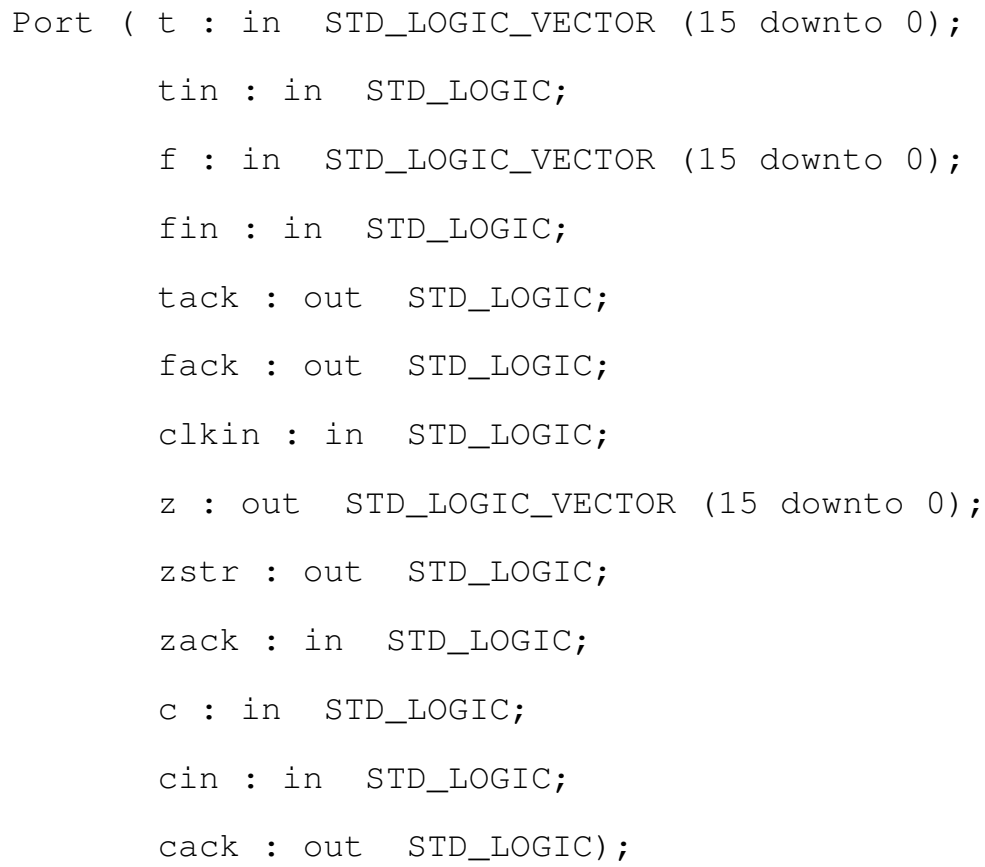

end VDMERGE;

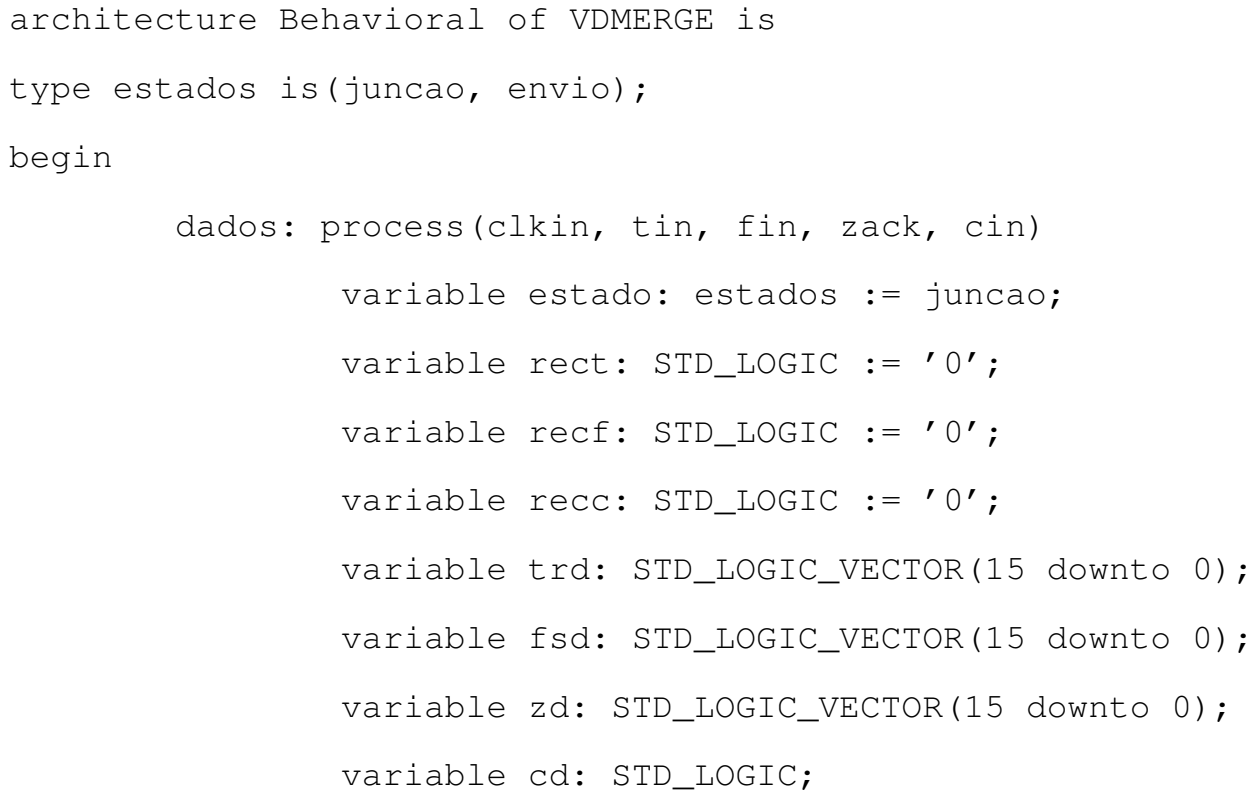




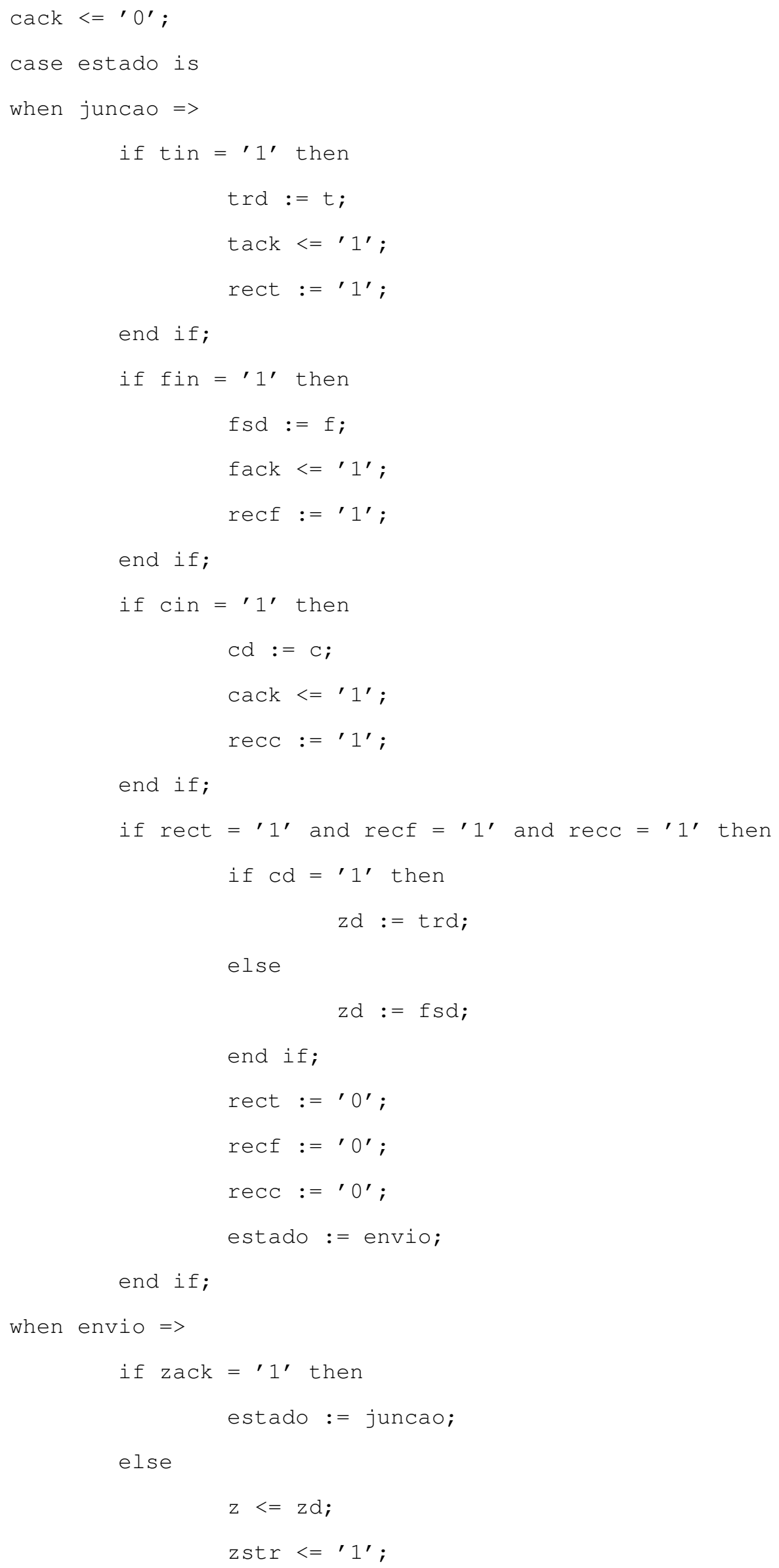


end if;

end case;

end if;

end process dados;

end Behavioral;

Listing A.5: Código VHDL para o operador Operator.

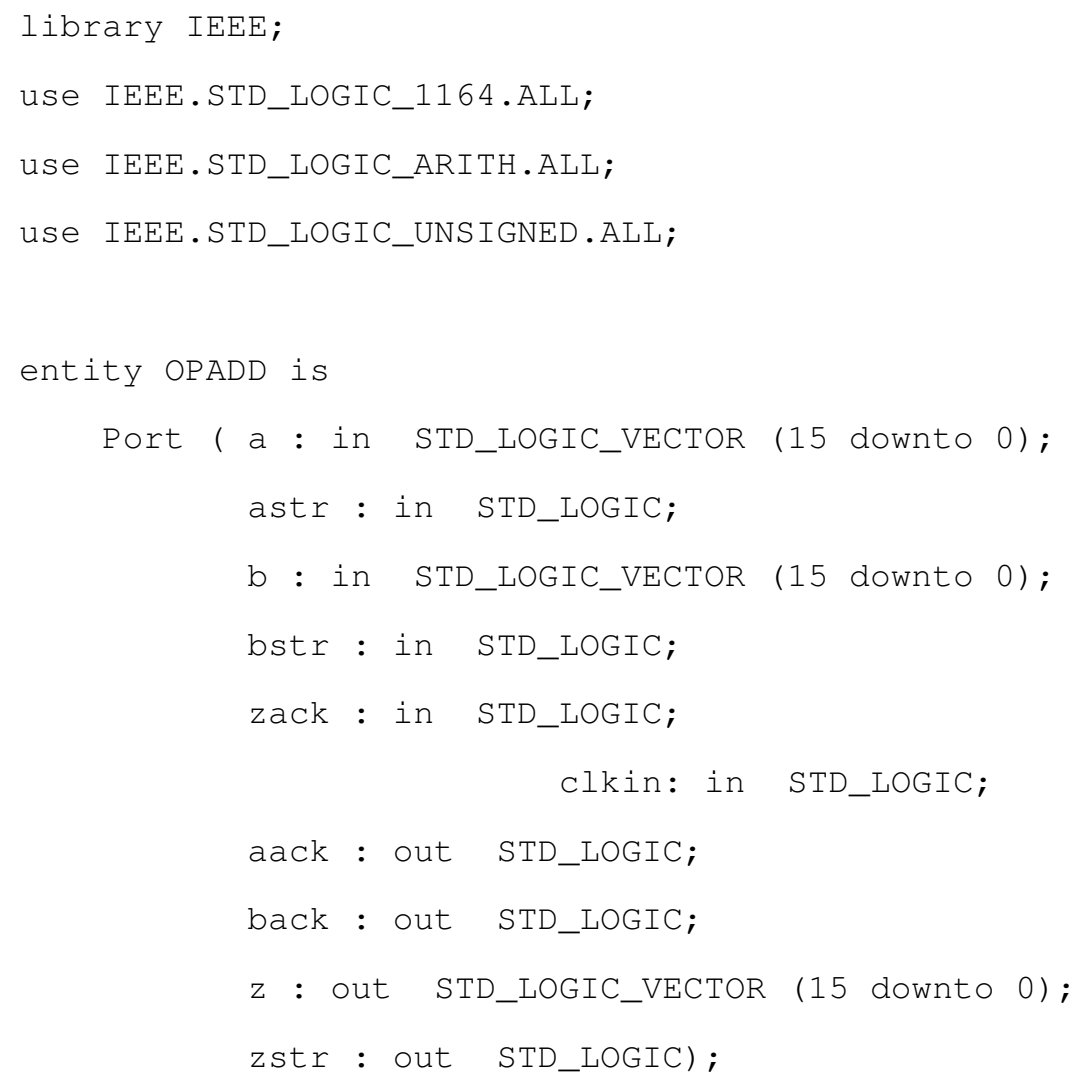


begin

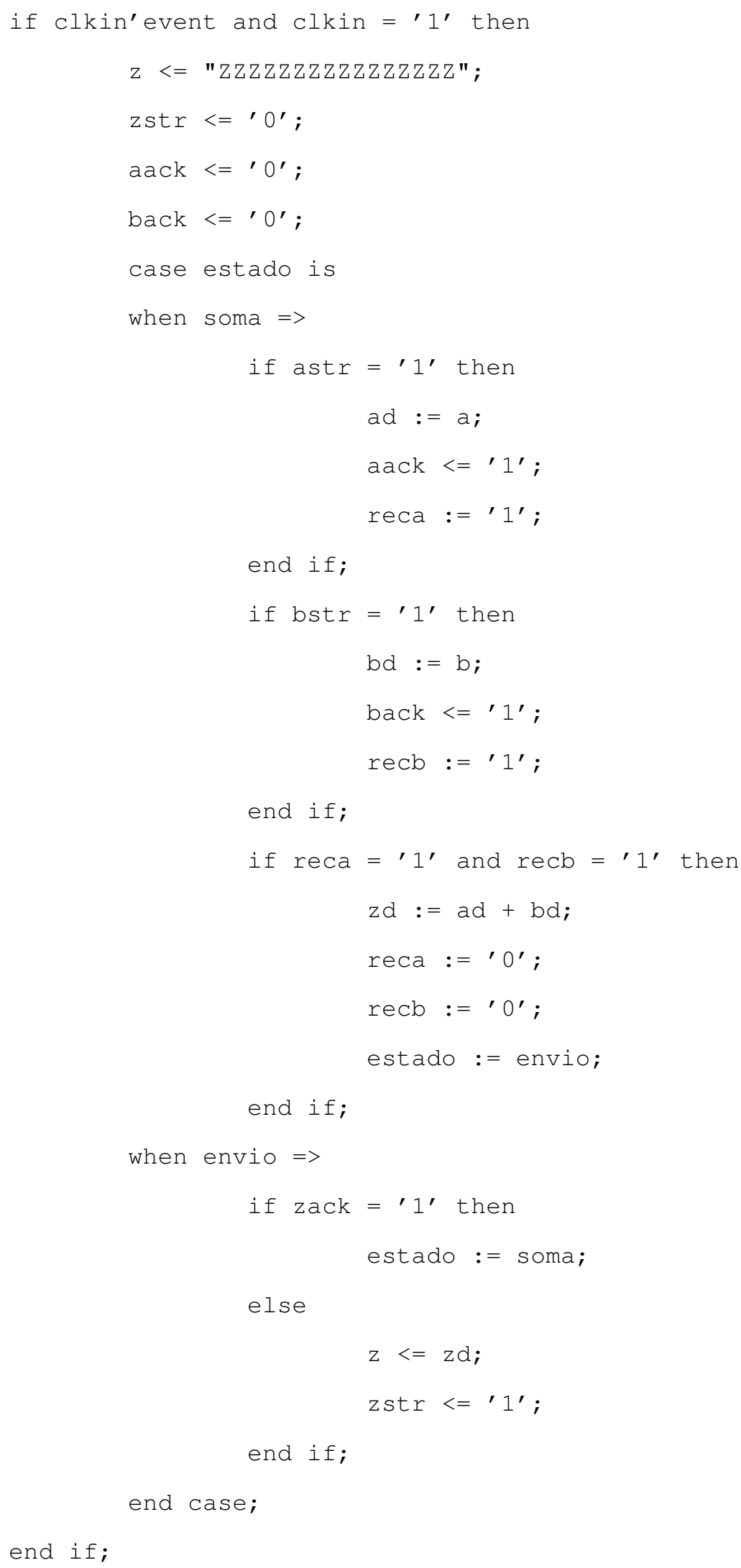




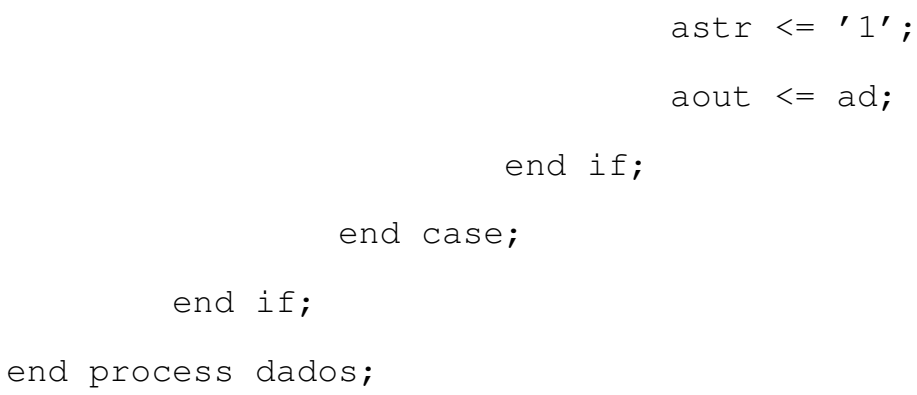

end Behavioral;

Listing A.7: Código VHDL para o operador AOUT.

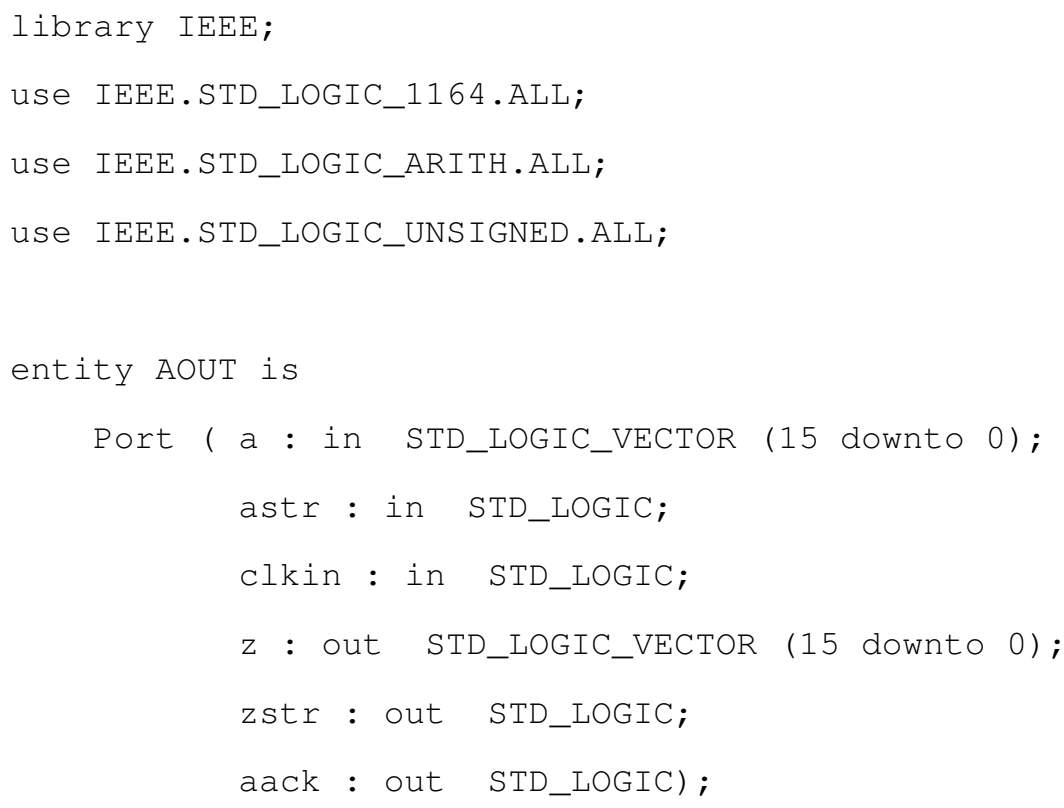


end if;

end if;

end process dados;

end Behavioral;

Listing A.8: Código VHDL para o operador ITMAN.

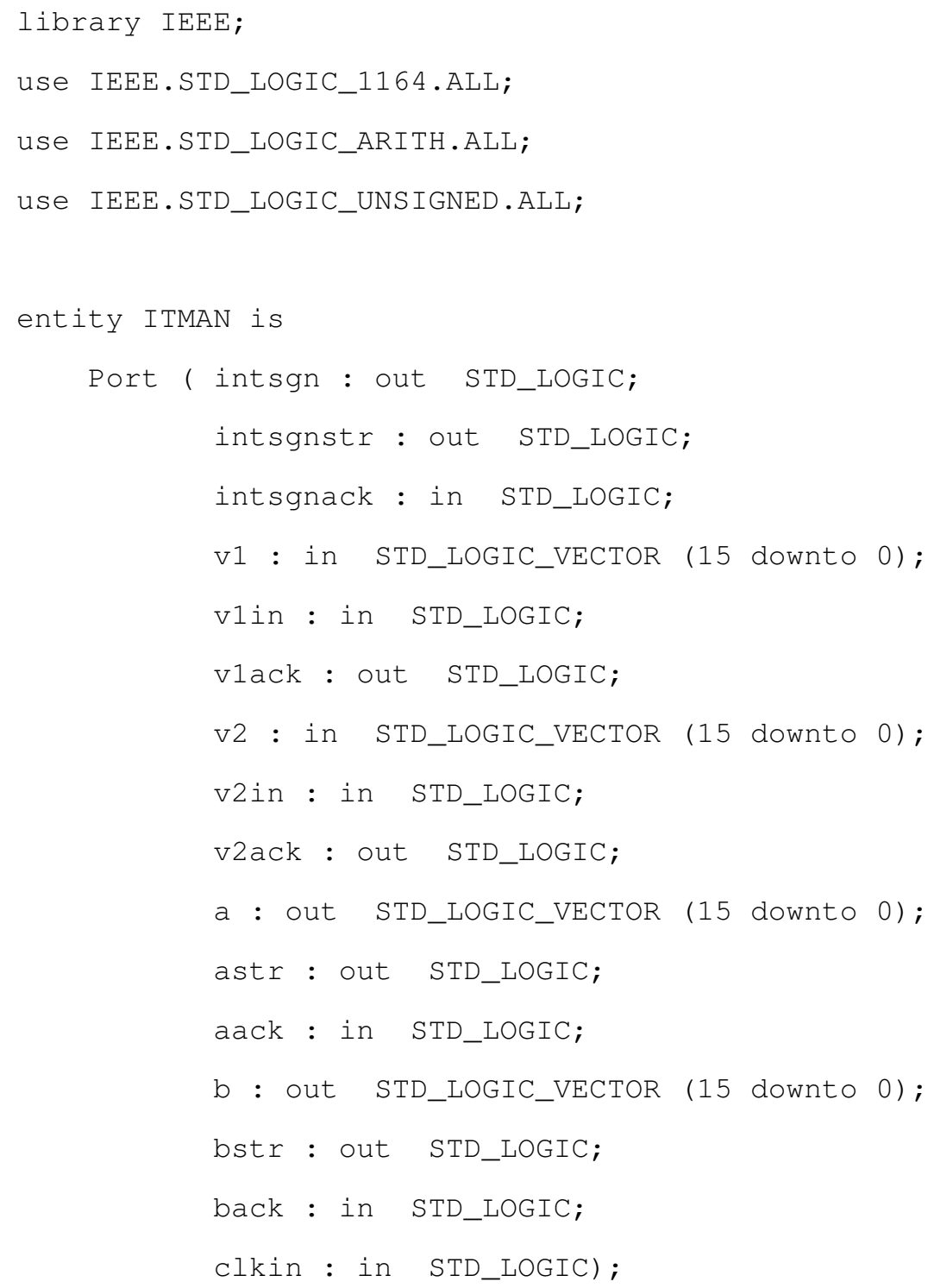

end ITMAN;

architecture Behavioral of ITMAN is

type estados is(inicio, fst_iter, wait_v2, nth_iter);

begin

dados: process(clkin, intsgnack, v1in, v2in, aack, back) variable estado: estados := inicio; 


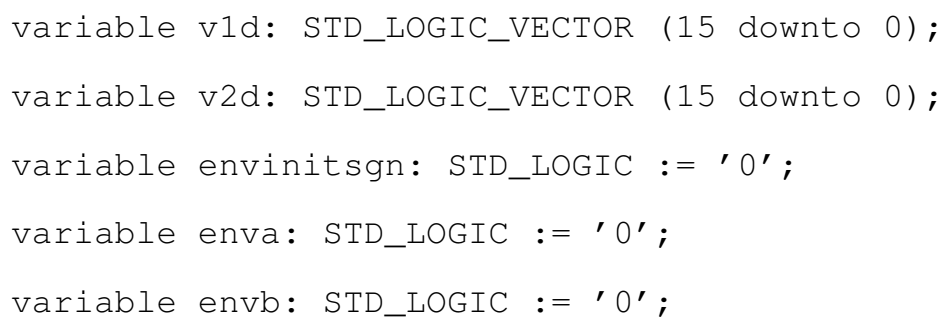




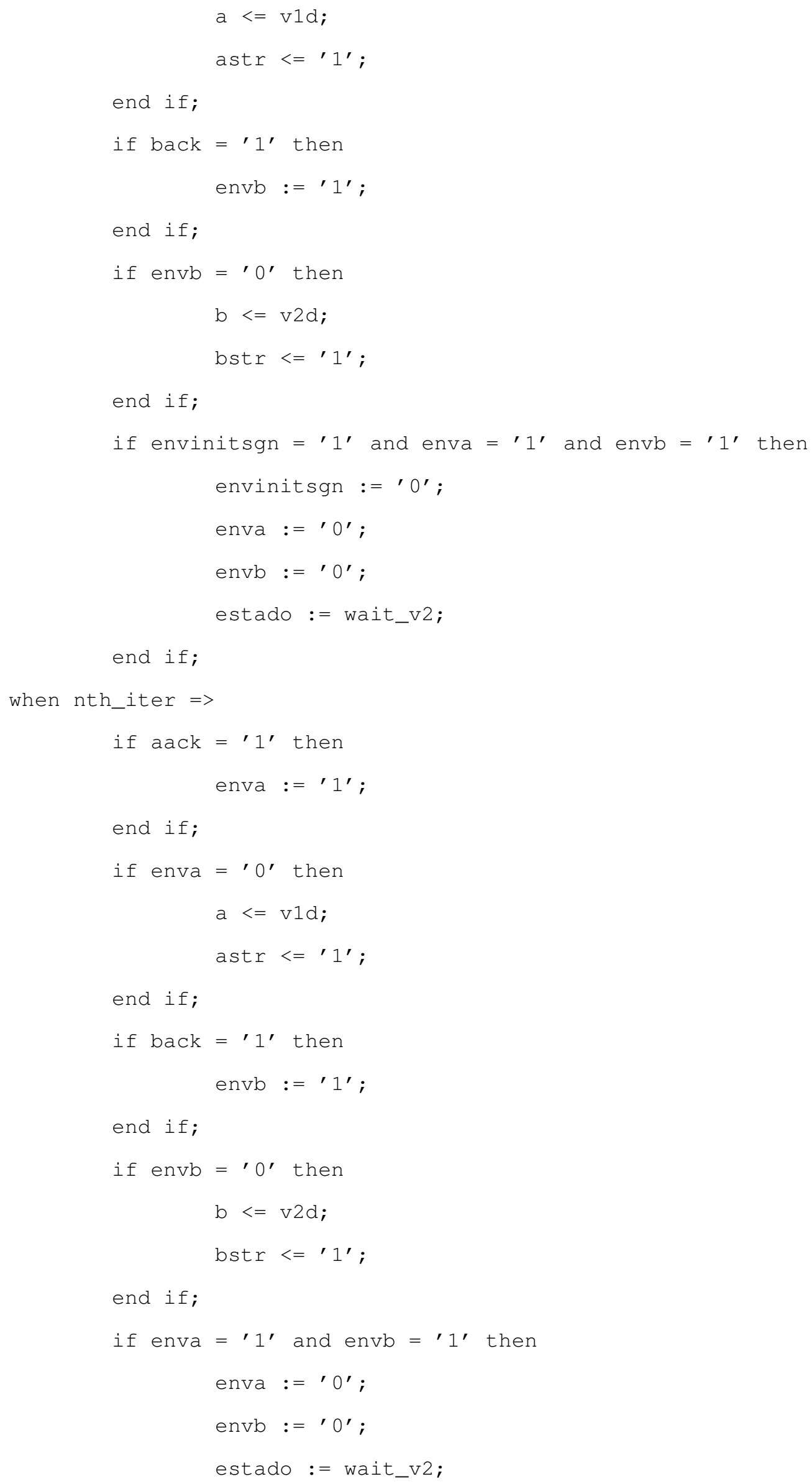




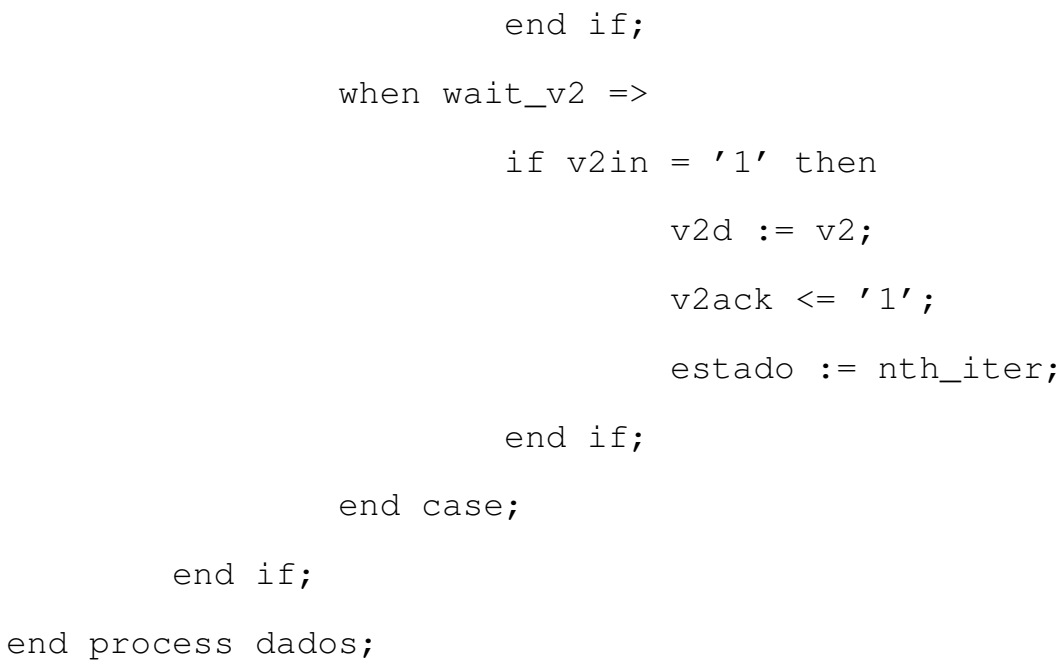

A implementação do grafo a fluxo de dados para o comando Switch pode ser observada na Figura A.1. 


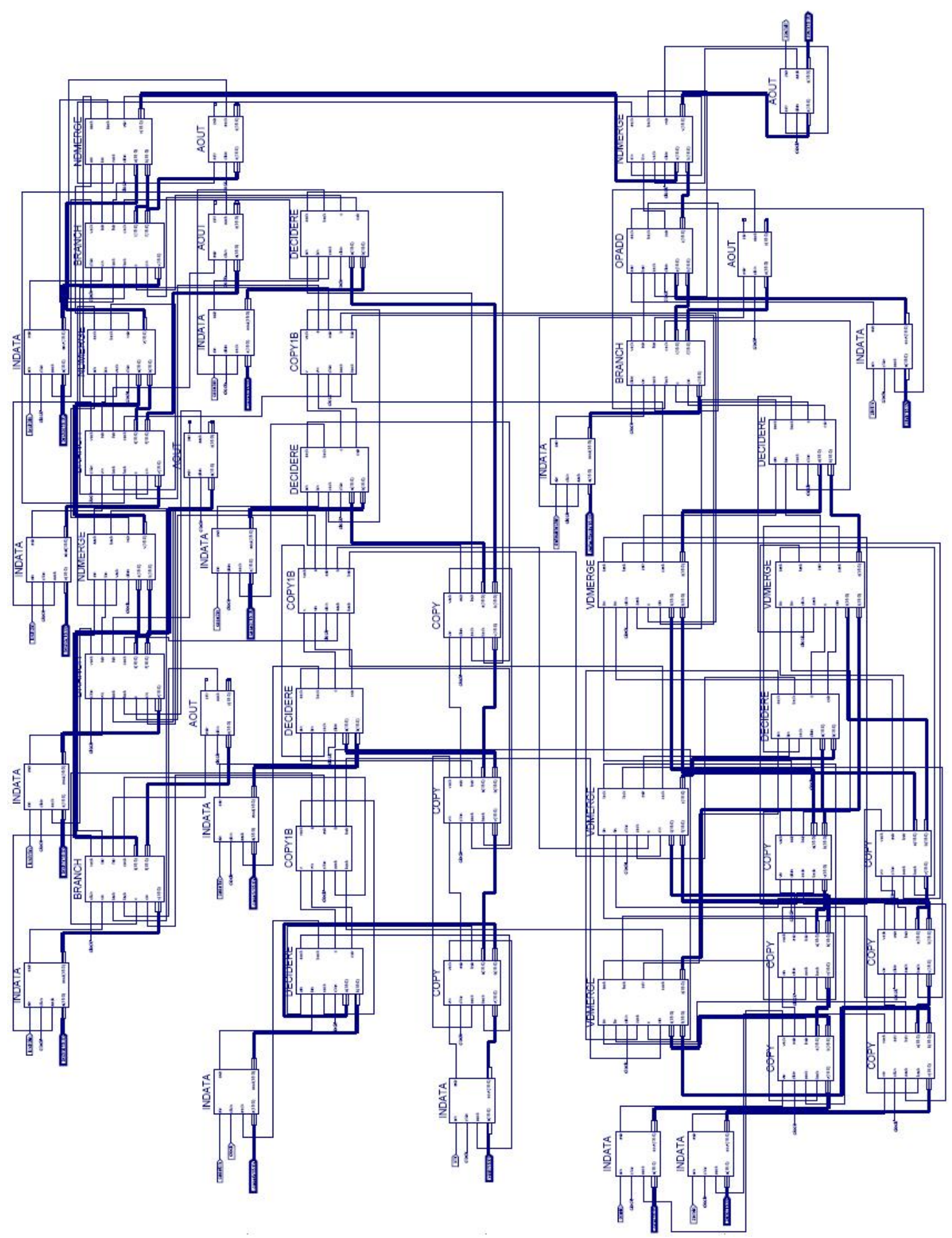

Figura A.1: Implementação do grafo a fluxo de dados para o comando Switch. 
A implementação do grafo a fluxo de dados para o comando While é apresentada na Figura A.2.

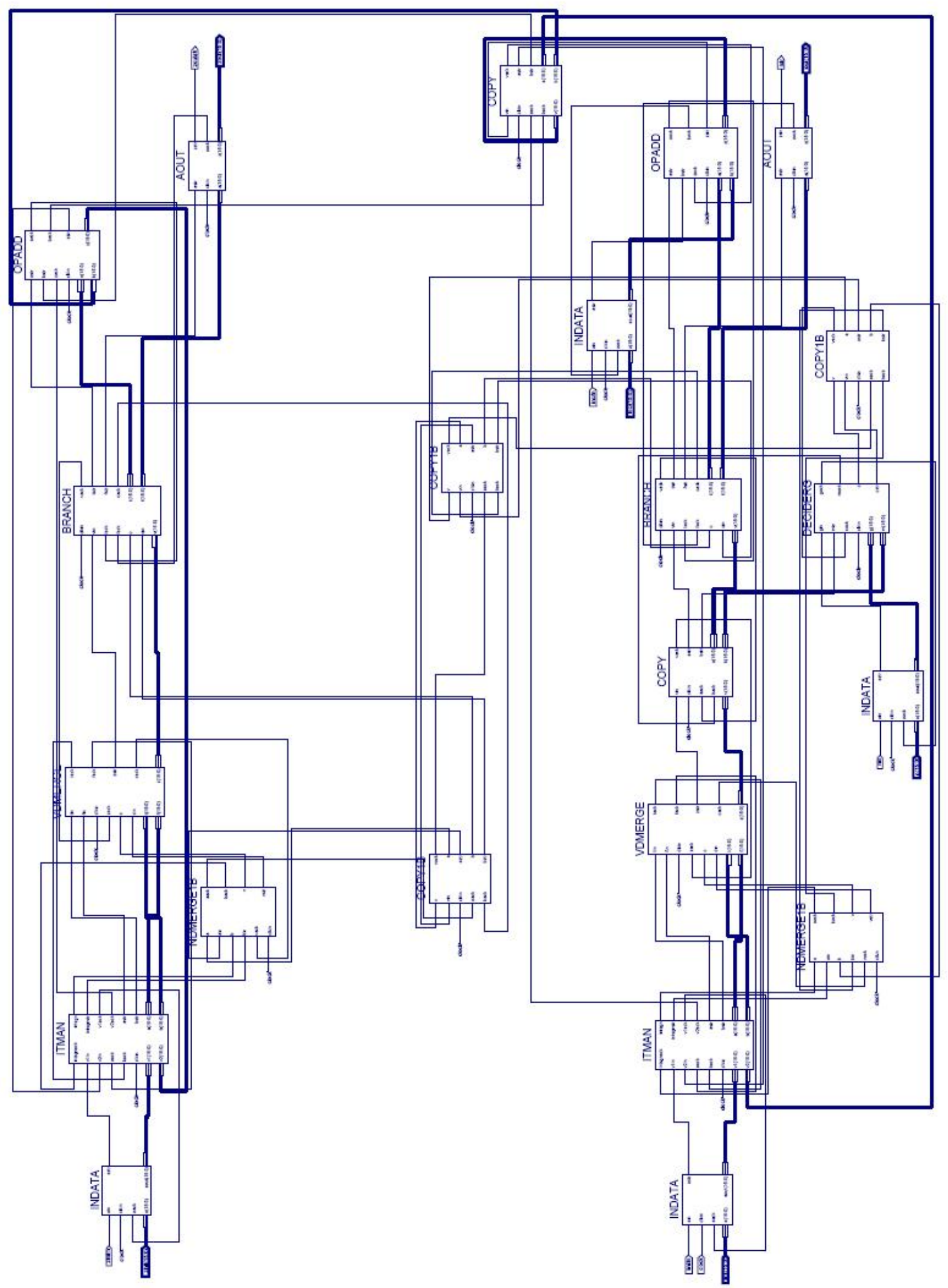

Figura A.2: Implementação do grafo a fluxo de dados para o comando While. 
A implementação do grafo a fluxo de dados para o comando For é apresentada na Figura A.3.

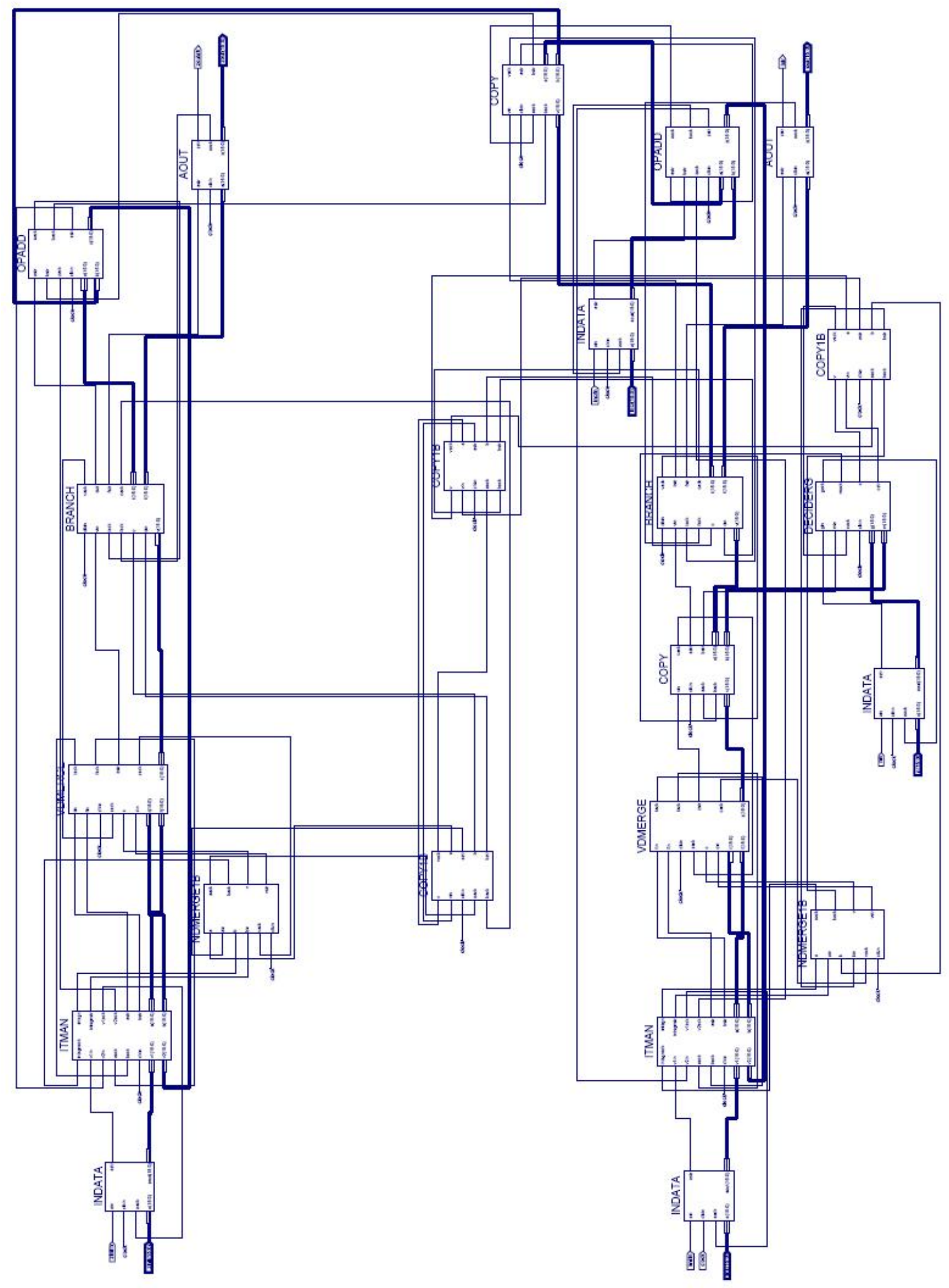

Figura A.3: Implementação do grafo a fluxo de dados do comando For. 
A implementação do grafo a fluxo de dados para o comando Do-While é apresentada na Figura A.4.

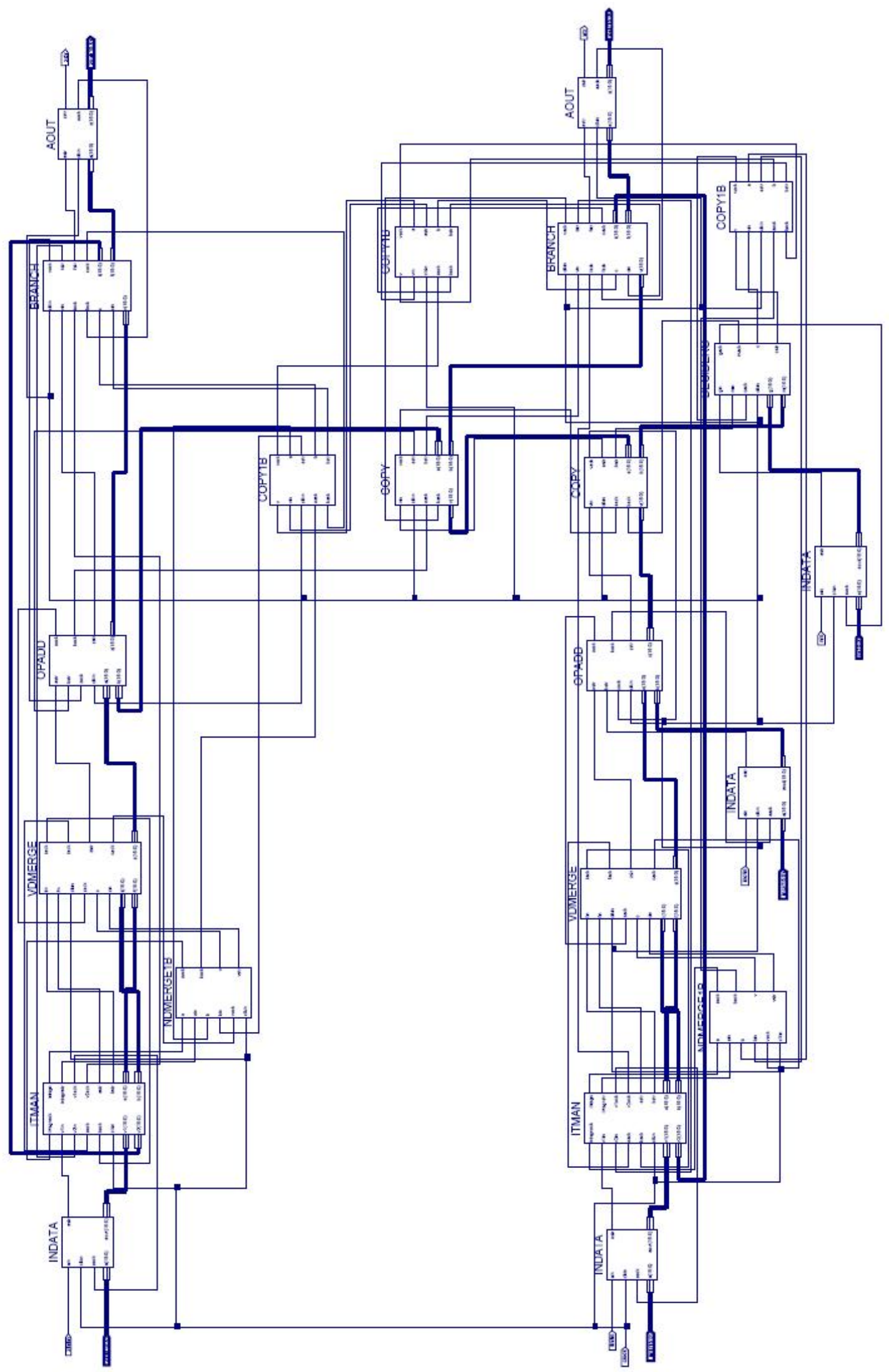

Figura A.4: Implementação do grafo a fluxo de dados para o comando Do-While. 
A implementação do grafo a fluxo de dados para a sequência de Fibonacci está disponível na Figura A.5.

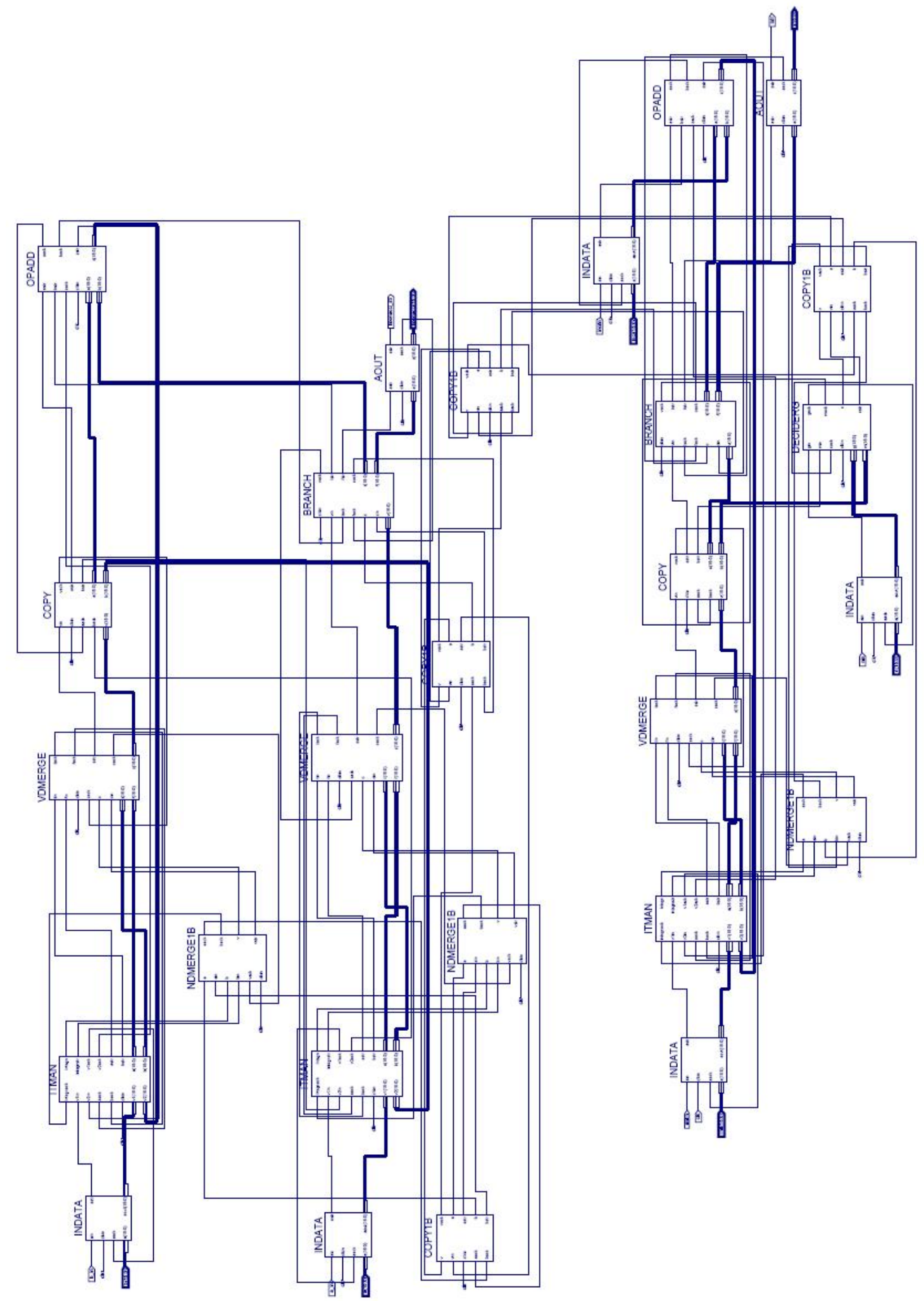

Figura A.5: Implementação do grafo a fluxo de dados para a Sequência de Fibonacci. 